MAITÊ CEVALLOS MIJAN KESSLER

AVALIAÇÃO CLÍNICA E EX VIVO DE MOLARES DECÍDUOS SUBMETIDOS A DIFERENTES PROTOCOLOS TERAPÊUTICOS NO MANEJO DA CÁRIE DENTÁRIA 


\author{
UNIVERSIDADE DE BRASÍLIA \\ FACULDADE DE CIÊNCIAS DA SAÚDE \\ PROGRAMA DE PÓS-GRADUAÇÃO EM CIÊNCIAS DA SAÚDE
}

MAITÊ CEVALLOS MIJAN KESSLER

AVALIAÇÃO CLÍNICA E EX VIVO DE MOLARES DECÍDUOS SUBMETIDOS A DIFERENTES PROTOCOLOS TERAPÊUTICOS NO MANEJO DA CÁRIE DENTÁRIA

Tese apresentada como requisito parcial para a obtenção do Título de Doutor em Ciências da Saúde pelo Programa de Pós-Graduação em Ciências da Saúde da Universidade de Brasília.

Orientadora: Soraya Coelho Leal 


\title{
AVALIAÇÃO CLÍNICA E EX VIVO DE MOLARES DECÍDUOS SUBMETIDOS A DIFERENTES PROTOCOLOS TERAPÊUTICOS NO MANEJO DA CÁRIE DENTÁRIA
}

\begin{abstract}
Tese apresentada como requisito parcial para a obtenção do Título de Doutor em Ciências da Saúde pelo Programa de Pós-Graduação em Ciências da Saúde da Universidade de Brasília.
\end{abstract}

Aprovado em Brasília, 02 de dezembro de 2015.

\section{BANCA EXAMINADORA}

\author{
Soraya Coelho Leal (presidente) \\ Universidade de Brasília \\ Vera Ligia Vieira Mendes Soviero \\ Universidade do Estado do Rio de Janeiro
}

\author{
Ana Paula Dias Ribeiro \\ Universidade de Brasília \\ João Paulo Figueiró Longo \\ Universidade de Brasília \\ Gustavo Adolfo Gonçalves Rivera Moreira Santos \\ Universidade Católica de Brasília \\ Leandro Augusto Hilgert (suplente) \\ Universidade de Brasília
}


Ao meu marido e à minha família, por darem sentido à minha existência:

Se nós não tivéssemos nos conhecido, acho que eu teria compreendido que minha vida não estava completa. E teria perambulado pelo mundo à sua procura, mesmo se não soubesse o que estava buscando (Nicholas Sparks) 


\section{AGRADECIMENTOS}

À Universidade de Brasília, e ao Programa de Pós-graduação em Ciências da Saúde, pela infraestrutura disponibilizada ao longo desses anos e por ter sido responsável pela minha formação. Sinto-me orgulhosa por fazer parte da história dessa Instituição.

À Secretaria de Educação do Distrito Federal - SES-DF, pela parceria realizada ao longo dos últimos anos, sem a qual esse trabalho não poderia ter sido conduzido.

À querida Prof. Dra. Soraya Coelho Leal, pelos ensinamentos durante a graduação, pelo caráter e pela conduta profissional que inevitalmente são um espelho e, principalmente, pela oportunidade e pela confiança em mim depositadas para a continuidade desse estudo. Sinto-me honrada em fazer parte de seu grupo e continuo não me considerando à altura disso; contudo, foi uma das responsáveis por me encorajar e fazer com que esse trabalho se transformasse em uma realidade. Admiro-a profundamente e serei eternamente grata.

Ao querido Prof. Dr. Jo Frencken, pela confiança e por trazer ao meu mundo uma dimensão de pesquisa científica que antes eu desconhecia. Seu entusiasmo e dedicação à Odontologia me fazem admirá-lo e querer tê-lo sempre por perto, para que eu possa ouvir as belas histórias e os ensinamentos ditos com uma paciência e dedicação incomuns; talvez observada apenas em uma relação entre pai e filho. Obrigada.

Ao Prof. Dr. Ricardo Bentes de Azevedo, por ter sido o grande precursor da minha carreira acadêmica, pelos aprendizados e parcerias ao longo dos últimos dez anos e principalmente pela amizade e carinho. Muito obrigada por ter mantido as instalações de seu laboratório à minha disposição nos últimos anos, mesmo não fazendo mais parte de seu grupo de pesquisa.

Aos professores Dr. Sacha Braun Chaves, Dr. Leandro Augusto Hilgert e Dra. Ana Paula Dias Ribeiro, pelas discussões e colaborações indispensáveis para que as metodologias desse estudo fossem realizadas com sucesso. Ao Leandro, ainda, obrigada pela parceria e amizade desde os tempos de graduação. 
À Radboud University Medical Centre, pelo suporte acadêmico e financeiro, pela possibilidade de realizar pesquisa em outro continente e, ainda, por ter conhecido pessoas tão dedicadas ao meu trabalho como Ewald, Jan Jos e Janny.

Aos membros que compõem a banca examinadora, Vera Ligia Vieira Mendes Soviero, Ana Paula Dias Ribeiro, João Paulo Figueiró Longo, Gustavo Adolfo Gonçalves Rivera Moreira Santos e Leandro Augusto Hilgert, por terem aceitado prontamente o convite para a apreciação desse trabalho.

Ao Rodrigo Ferreira Silva Guedes de Amorim, por ter confiado a mim a continuidade de seu trabalho, pelos inúmeros auxílios, discussões e principalmente pelos incentivos para que este dia chegasse. Na dedicatória de sua tese da Holanda entregue a mim você escreveu: "O Paranoá vai deixar saudades". Sim, Rodrigo, já posso senti-las.

À querida Renata Nunes Cabral, pela amizade e pela contribuição, de pronto, em parte das análises realizadas nesse estudo.

À querida amiga Ana Luiza de Souza Hilgert pela linda amizade que construímos ao longo desses anos, por ter sido um espelho de dedicação, uma grande colaboradora e incentivadora desse projeto e por compartilhar momentos de angústia e outros de incríveis sentimentos. Liverpool deixará saudades... que venha a Grécia.

Aos meus colegas envolvidos nessa pesquisa: Simone Otero, Luciana Pistili, Gabriela Lopes, Danielle Abreu, Maria José Figueiredo e Rafael Gomide, pela amizade, parceria e contribuição no decorrer dos últimos anos.

Aos participantes desta pesquisa, por terem deixado marcas eternas em minha memória e pela colaboração ao longo de tanto tempo. Certos gestos e sorrisos são indescritíveis. Sem vocês essa tese não aconteceria. Muito obrigada!

Às auxiliares de saúde bucal pela dedicação, disponibilidade e seriedade na condução de tudo que foi proposto. Sem vocês isso não seria possível.

A todos que, direta ou indiretamente, contribuíram para a resolução dessa tese. 


\section{Gostaria de realizar agradecimentos especiais...}

A Deus, pela minha vida e minha saúde, e pela dos meus familiares e amigos; por iluminar meus caminhos e me fortalecer a cada momento de angústia e inquietação; e por me proporcionar uma vida plena e, agora, ainda mais feliz.

Aos meus pais, Francisco e Lucimar, pela minha vida, meu caráter, por me ensinarem a ser uma pessoa melhor, pela abnegação e pelo amor incondicional dedicados a mim. Por me fazerem sentir saudades, inúmeras vezes ao dia, dos momentos que tínhamos e que já não voltam mais; mas, principalmente, por terem sido dois dos grandes incentivadores para que eu conseguisse finalizar esse projeto. Obrigada pela insistência e pelo suporte ao me ouvir falar "vou desistir" incansáveis vezes. Esse título é por vocês e, para vocês.

Ao amor da minha vida, Marcelo, pela amizade, amor, parceria, cumplicidade, compreensão e tanta dedicação. Os últimos anos também não foram fáceis para você, tenho certeza, mas o último ano certamente foi especial. Sem você eu tenho certeza que hoje não estaria aqui e é por você que realizo essa conquista; poder despertar em você orgulho, admiração e felicidade movem os meus dias. Como disse há pouco tempo, sua felicidade é minha eterna busca; espero estar cumprindo esse dever.

Aos meus irmãos, Natalie e Pedro Henrique, pelo amor, pela amizade, pela parceria. Não consigo pensar nossa família sem algum de nós. Somos assim... diferentes, incomuns e complementares; eu diria, indispensáveis um ao outro. Amo vocês.

À Regina, Laureno, Paulo, Lígia, Schneider e Cássia e aos demais familiares, por me receberem tão bem em seus leitos familiares, pelo amor, carinho e por completarem, cada um a seu modo, a minha família e os meus dias.

Ao meu sobrinho Heitor, por despertar em mim um novo modo de amar... não achei que fosse tão profundo e intenso, pequenino.

Às minhas queridas amigas e madrinhas Ana Júlia e Larissa, por vivenciarem de uma forma tão próxima e participativa esse projeto e por me incentivarem a conquistar esse título. Nos últimos anos, a dedicação de vocês a mim 
tem feito uma diferença enorme em meus dias e a amizade de vocês me inspira e me fortalece. Obrigada, sempre.

Às minhas queridas amigas Andréa e Samanta, pela amizade e por tornar meus dias muito mais alegres, leves e suaves em suas companhias. Esse sentimento dá sentido à minha vida. Obrigada!

Às minhas queridas amigas Carolina Valente, Carolina Romero, Ingrid, Kamila, July, Lílian, Lorenna, Thais, Paula e Patty pela eterna amizade e cumplicidade.

À família MKN, por ter entrado em minha vida e na do Marcelo de uma forma tão intensa e modificadora. Nossos dias são mais alegres e motivadores e nossas vidas mais felizes com vocês.

Às queridas amigas do Instituto de Criminalística, Ana Carolina Bertollo, Ana Carolina Humanes, Beatriz, Dani, Karina, Kéllen, Mari e Raquel pela parceria, amizade e incentivo e, também aos demais colegas da SCPe, por "segurarem as pontas" para que esse sonho pudesse ser realizado. 
Talvez não tenha conseguido fazer o melhor, mas lutei para que o melhor fosse feito. Não sou o que deveria ser, mas Graças a Deus, não sou o que era antes 


\section{RESUMO}

De acordo com a Organização Mundial de Saúde, $72 \%$ e $95 \%$ das lesões de cárie cavitadas em dentina de dentes decíduos não são tratadas em países de alta e de baixa renda, respectivamente, comprovando a falta de acesso à saúde bucal e a ineficiência dos tratamentos restauradores convencionais. A busca por novas alternativas de manejo da cárie dentária introduziu abordagens como o ART e o UCT. Em 2009 um estudo clínico controlado quasi-randomizado foi iniciado no Paranoá, DF-Brazil, comparando três protocolos no manejo de cárie dentária cavitadas em dentina em molares decíduos: CRT - remoção de cárie por instrumentos rotatórios e restauração com amálgama; ART - remoção de cárie por instrumentos manuais e restauração com cimento de ionômero de vidro e; UCT combinação de ART para cavidades pequenas e controle de biofilme para cavidades médias e grandes. Este estudo avaliou clinicamente ao longo de 3,5 anos a taxa de sobrevida e a taxa de esfoliação dos molares decíduos submetidos aos três protocolos terapêuticos e avaliou, em um estudo ex vivo, as microfraturas marginais de dentes restaurados com amálgama (CRT) e restaurados com CIV (ART e UCT). O método Kaplan-Meier estimou as curvas de sobrevida e o de PHERG estimou as curvas de esfoliação. A análise de microfraturas marginais em dentes com restaurações classificadas como bem-sucedidas foi realizada pela quantificação de microfendas por microscopia eletrônica de varredura e por microinfiltração com solução aquosa de nitrato de prata a $50 \%$. Neste experimento, a diferença entre grupos e a relação com variáveis independentes foram aferidas pelos Teste de Fischer, teste t e ANOVA. Após 3,5 anos, a taxa de sobrevida cumulativa e erro padrão para todos os molares tratados foi de $90,9 \pm 2,0 \%$ para CRT, $90,4 \pm 2,4 \%$ para ART e $88,6 \pm 1,9 \%$ para UCT $(p=0,13)$. Apenas um efeito do tipo de superfície foi observado - a taxa de sobrevida para dentes com cavidade envolvendo única superfície foi maior que aquela observada para dentes com múltiplas superfícies. Por sua vez, após o mesmo período, não houve diferença na taxa de esfoliação dos molares decíduos: $51 \%$ (CRT), 48,7\% (ART) e 48,1\% (UCT) ( $p=0,37$ ). Dentes com envolvimento de múltiplas superfícies esfoliaram em maior proporção que os com única superfície para todos os grupos de tratamento $(p=0,04)$. Não houve diferença nas taxas de microinfiltração $(p=0.20)$ e no tamanho das microfendas $(p=0,83)$ observadas nos dentes restaurados por amálgama e por CIV pela técnica ART. 
Dentes com envolvimento de múltiplas superfícies apresentaram maior infiltração de nitrato de prata que os dentes com única superfície $(p=0,02)$. Os resultados demonstram que a restauração de cavidades pela técnica ART associada à manutenção das cavidades de molares decíduos sob controle de biofilme dental, como empregado no protocolo UCT, pode se tornar uma alternativa adequada para o manejo de cárie na dentição decídua frente aos tratamentos restauradores convencionais, uma vez que introduz componentes de prevenção da doença e promoção de saúde bucal.

Palavras-chave: cárie dentária; dentição decídua; amálgama; cimento de ionômero de vidro; ART; UCT; controle de biofilme e; microfratura marginal. 


\begin{abstract}
According to World Health Organization, $72 \%$ and $95 \%$ of dentin cavitated carious lesions in primary teeth are untreated in high- and low-income countries, respectively, proving the lack of access to oral health and the inefficiency of the conventional restorative treatment options. The search for new approaches in the management of dental caries introduced ART and UCT in recent years. In 2009, a controlled, quasi-randomized, clinical trial was carried out in Paranoá, DF-Brazil with the aim to compare three treatment protocols for dentin cavitated dental caries in primary molars: CRT - caries removal with rotary instruments and amalgam restoration; ART - caries removal with hand instruments and glass-ionomer cement restoration and; UCT - combination of ART for small cavities and biofilm control for medium and large cavities. The present study evaluated clinically the survival and the exfoliation rates of the deciduous molars submitted to the three therapeutic protocols over a period of 3.5-years, and assessed in an ex vivo study, the marginal microleakage of the teeth restored with amalgam (CRT) and restored with GIC (ART and UCT). The Kaplan-Meier method estimated survival curves and the PHERG estimated the exfoliation curves. The marginal microleakage analysis was performed by quantification of the gap size by scanning electron microscopy and microinfiltration with a silver nitrate solution $50 \%$. In this experiment, the difference between groups and the relationship with independent variables were estimated by Fischer's test, ttest and ANOVA. After 3.5 years, the cumulative survival rate and standard error for all molars treated was $90.9 \pm 2.0 \%$ for CRT, $90.4 \pm 2.4 \%$ for ART and $88.6 \pm 1.9 \%$ for UCT ( $p=0.13$ ). Only a type of surface effect was observed: the survival rate for molars were higher for single- than for multiple-surface cavities. In turn, there was no difference in the exfoliation rate of primary molars: 51\% (CRT), 48.7\% (ART) and $48.1 \%$ (UCT) ( $p=0: 37$ ) had exfoliated after 3.5-years. Teeth with multiple surfaces cavities exfoliated in a higher proportion than those with single surface for all treatment groups $(p=0.04)$. There was no difference in microleakage rates $(p=$ $0.20)$, and gap size $(p=0.83$ ) observed in teeth restored with amalgam and GIC according to the ART technique. Teeth with multiple-surfaces cavities showed greater infiltration of silver nitrate than those with single-surface $(P=0.02)$. Taken together, the results show that restoring cavities according to the ART technique and maintaining opened cavities through biofilm control, as in the UCT protocol, can
\end{abstract}


become a suitable alternative for caries management in primary dentition, compared to the to conventional restorative treatments once disease prevention and promotion of oral health are introduced.

Keywords: dental caries; primary dentition; amalgam; glass-ionomer cement; ART; UCT; biofilm control and; marginal microleakage. 


\section{LISTA DE FIGURAS}

Figura 1 Diagrama da etiologia multifatorial da cárie dentária.

Figura 2 Mapa geográfico do Distrito Federal, Brasil.

Figura 3 Diagrama da determinação do tamanho da cavidade proximal utilizado durante o estudo epidemiológico.

Figura 4 Fotografias de dentes molares decíduos de crianças inseridas no estudo clínico do Paranoá.

Figura 5 Diagrama de fluxo com síntese dos resultados das avaliações clínicas de sobrevida dos dentes no período de 3,5 anos.

Figura 6 Diagrama de fluxo com síntese dos resultados das avaliações clínicas de esfoliação dos dentes no período de 3,5 anos.

Figura 7 Taxas de esfoliação (\%) e erro padrão de primeiros e segundos molares decíduos por grupo de protocolo terapêuticos após o período de 3,5 anos.

Figura 8 Taxas de esfoliação (\%) e erro padrão dos molares decíduos com envolvimento de múltiplas superfícies por grupo de protocolo terapêutico após o período de 3,5 anos.

Figura 9 Distribuição dos escores de microinfiltração em dentes com envolvimento de única e de múltiplas superfícies.

Figura 10 Fotomicrografias de dentes restaurados por amálgama e por CIV pela técnica ART. Análise clínica, após microinfiltração de nitrato de prata e microscopia eletrônica de varredura. 


\section{LISTA DE TABELAS}

Tabela 1 - Critério ART de avaliação clínica das restaurações.

Tabela 2 - Variáveis avaliadas no início do estudo (original) nas crianças inseridas nos diferentes protocolos terapêuticos.

Tabela 3 - Sobrevida cumulativa (\%) e erro padrão pelo método Jackknife (EP) de todos os primeiros molares submetidos aos diferentes protocolos terapêuticos, por intervalo de tempo.

Tabela 4 - Sobrevida cumulativa (\%) e erro padrão pelo método Jackknife (EP) dos primeiros molares com envolvimento de múltiplas superfícies, submetidos aos diferentes protocolos terapêuticos, por intervalo de tempo.

Tabela 5 - Distribuição de frequência das razões para extrações dos primeiros molares decíduos submetidos aos diferentes protocolos terapêuticos.

Tabela 6 - Variáveis avaliadas no início do estudo (original) nas crianças inseridas nos diferentes protocolos terapêuticos.

Tabela 7 - Taxa cumulativa de esfoliação de todos os molares decíduos (\%) e erro padrão Jackniffe (EP) por grupo de protocolo terapêutico e intervalo de tempo (IP).

Tabela 8 - Critério ART de avaliação clínica das restaurações.

Tabela 9 - Variáveis independentes relacionadas aos dentes selecionados para o estudo de selamento marginal por tratamento restaurador realizado.

Tabela 10 - Classificação quanto à presença de microfendas nas interfaces denterestaurações de amálgama e de CIV e média de extensão da microfenda em $\mu \mathrm{m}$, quando presente, obtidas por observação em MEV.

Tabela 11 - Classificações segundo escores de profundidade de penetração da solução de nitrato de prata em dentes restaurados por amálgama, pertencentes ao grupo CRT e restaurados por cimento de ionômero de vidro, pertencentes aos grupos ART e UCT.

Tabela 12 - Correlação das metodologias aplicadas para a análise se microfraturas marginais nas restaurações de amálgama e CIV pela técnica ART. 


\title{
LISTA DE ABREVIATURAS E SIGLAS
}

\author{
ANOVA - Análise de variância \\ ART - Tratamento Restaurador Atraumático \\ CAIC - Centro de Atenção Integral à Criança e ao Adolescente \\ CIV - Cimento de ionômero de vidro \\ CIV-AV - Cimento de ionômero de vidro de alta viscosidade \\ CODEPLAN - Companhia de Planejamento do Distrito Federal \\ CRT - Tratamento Restaurador Convencional \\ FDI - Fédération Dentaire Internationale \\ MEV - Microscopia Eletrônica de Varredura \\ MI - Microinfiltração \\ OMS - Organização Mundial de Saúde \\ Ppm - partes por milhão \\ PUFA - Pulpal Involvement, Ulceration, Fistula, Abscess \\ RA - Região Administrativa \\ SAS - Statistical Analysis System \\ SB Brasil - Pesquisa Nacional de Saúde Bucal \\ UCT - Tratamento Ultraconservador \\ UnB - Unversidade de Brasília \\ USPHS - United States Public Health Service
}




\section{SUMÁRIO}

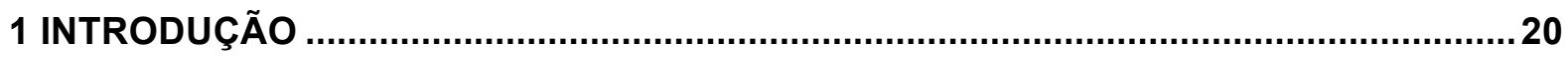

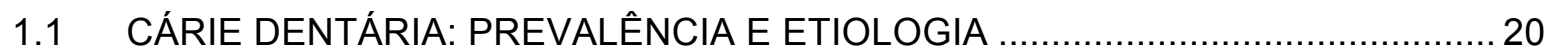

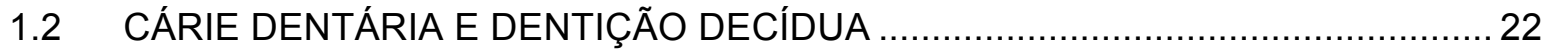

1.3 MANEJO TRADICIONAL DA CÁRIE DENTÁRIA NA DENTIÇÃO DECÍDUA ........ 24

1.4 TRATAMENTOS CONSERVADORES NO MANEJO DA CÁRIE DENTÁRIA NA

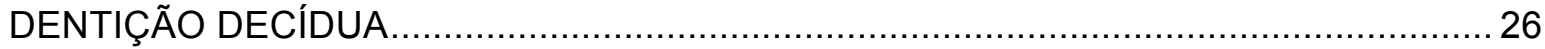

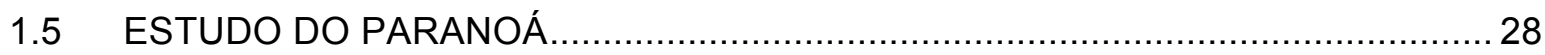

1.6 ESTUDO CLÍNICO: TRÊS PROTOCOLOS TERAPÊUTICOS DE MANEJO DA

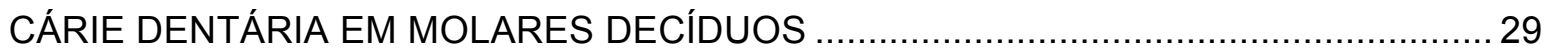

1.7 ANÁLISE CLÍNICA DE TRATAMENTOS RESTAURADORES ….............................. 35

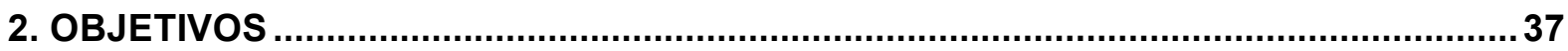

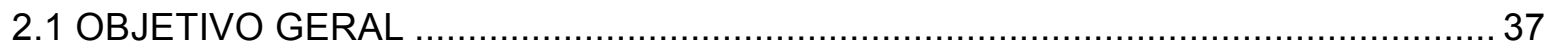

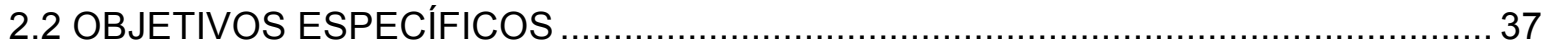

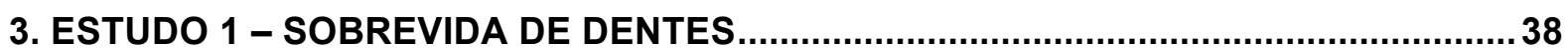

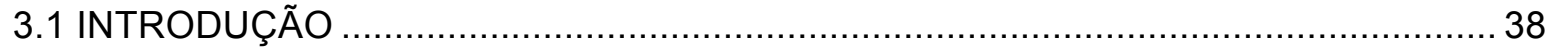

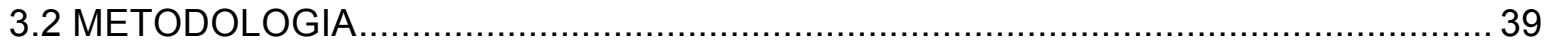

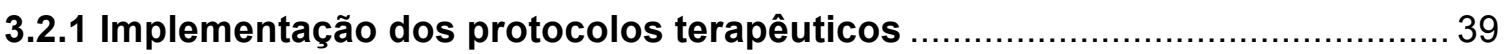

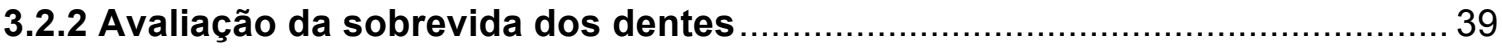

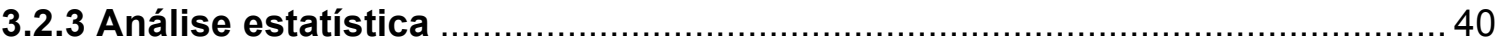

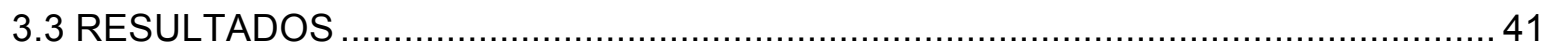

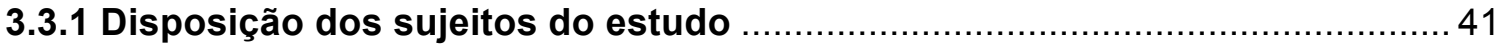

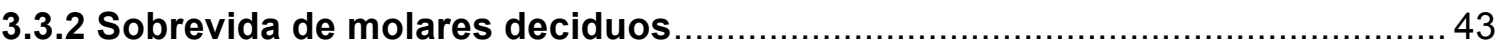

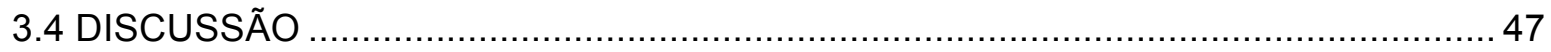

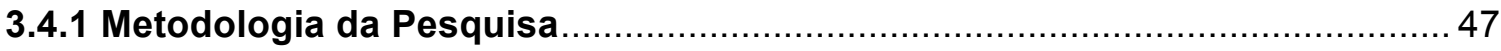

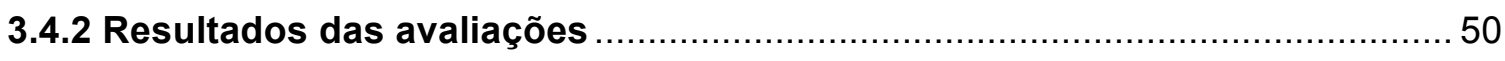

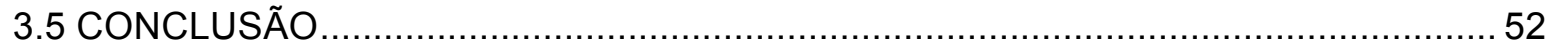

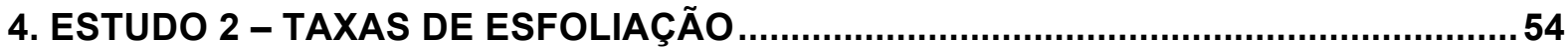


4.1 INTRODUÇÃO

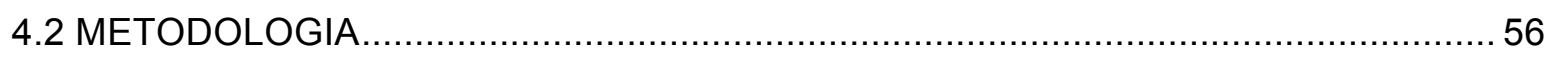

4.2.1 Implementação dos protocolos terapêuticos ............................................. 56

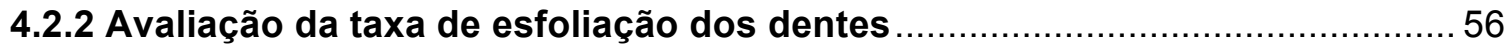

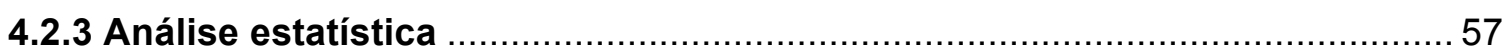

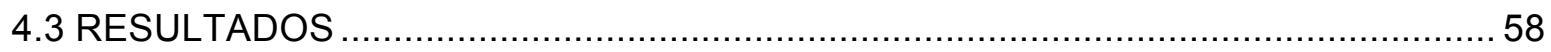

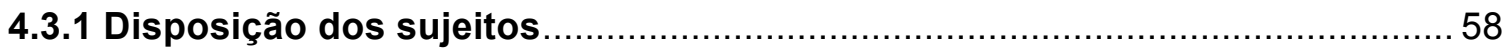

4.3.2 Padrão de esfoliação de molares decíduos por grupo de protocolo terapêutico 60

4.3.3 Análise dos efeitos das variáveis independentes nas taxas de esfoliação... 63

4.4 DISCUSSÃO . 64

4.4.1 Metodologia do estudo 64

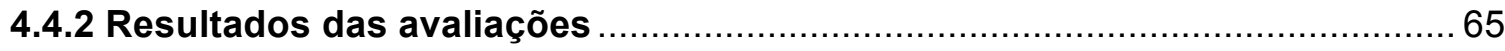

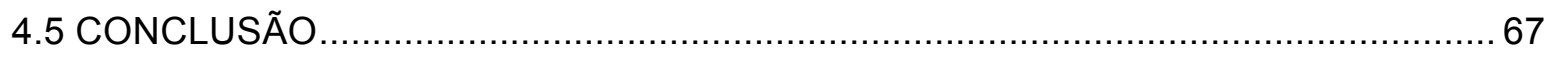

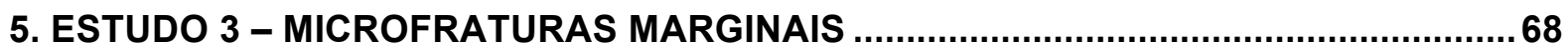

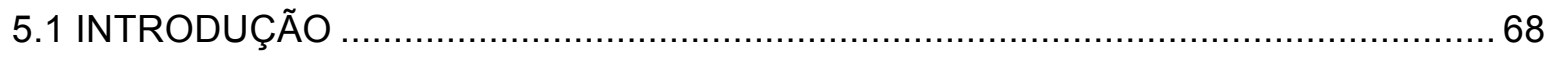

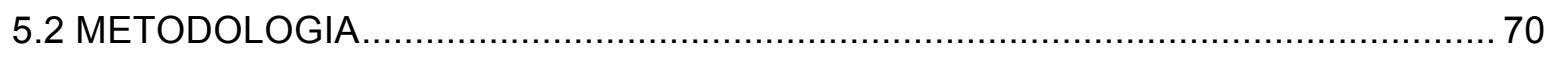

5.2.1 Implementação dos tratamentos restauradores........................................... 70

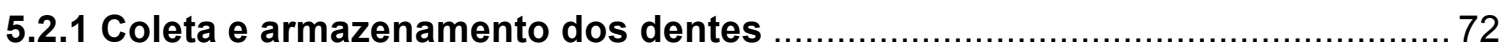

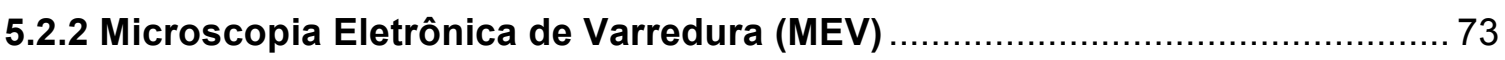

5.2.3 Infiltração com solução de nitrato de prata …............................................ 74

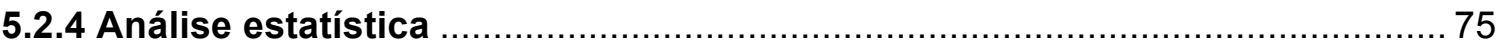

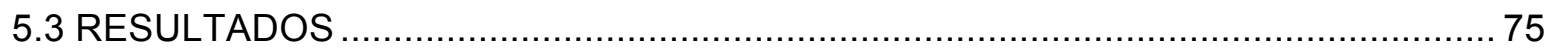

5.3.1 Dentes selecionados e variáveis independentes ….................................. 75

5.3.2 Presença de microfendas nas margens das restaurações .......................... 76

5.3.3 Profundidade de penetração da solução de nitrato de prata ........................ 77

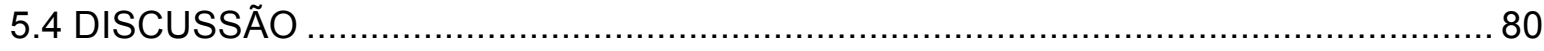

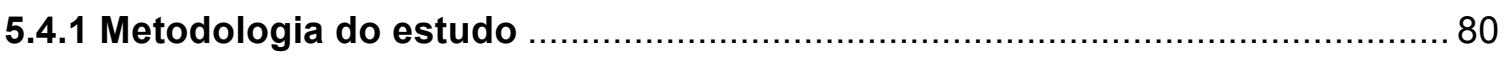

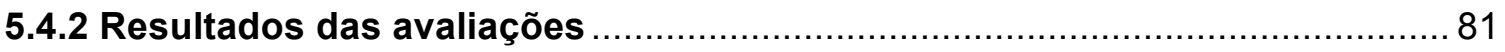


5.5 CONCLUSÃO

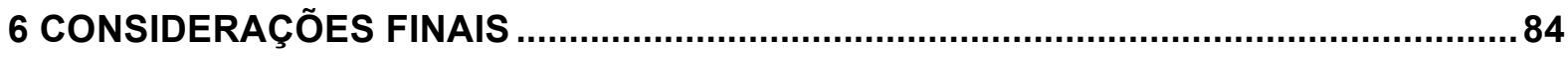

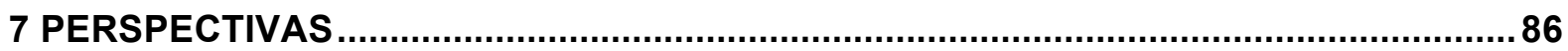

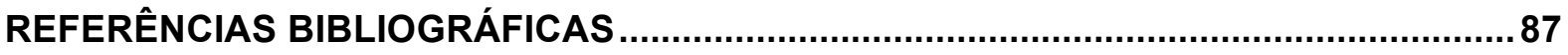

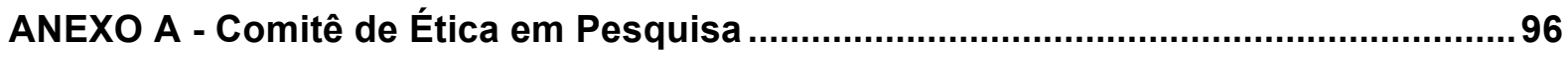

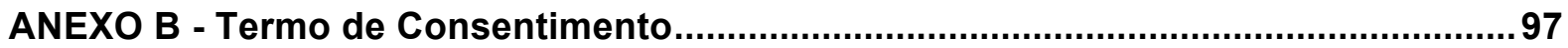

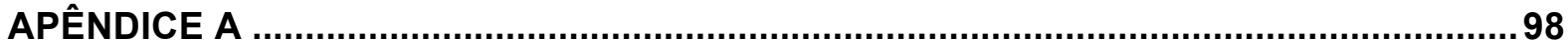

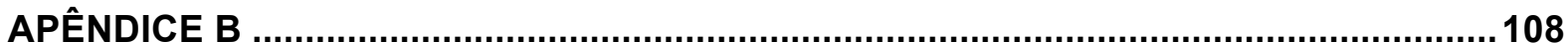




\section{INTRODUÇÃO}

\subsection{CÁRIE DENTÁRIA: PREVALÊNCIA E ETIOLOGIA}

A cárie dentária é uma das doenças crônicas mais prevalentes em todo o mundo, atingindo cerca de 60 a 90\% de crianças em idade escolar e uma vasta parcela da população adulta. Pode ocorrer ao longo da vida e perfaz, junto com as doenças periodontais, fardos globais para a saúde bucal, uma vez que sua complexidade etiológica associada à sua prevalência a elevam a um status endêmico de difícil erradicação (1).

Sua etiologia decorre da interação múltipla e complexa de fatores inerentes ao hospedeiro (dente) com fatores ambientais, como a microbiota cariogênica e a presença de carboidratos fermentáveis -, majoritariamente relacionados à dieta, conceito este consolidado pela apresentação da tríade de fatores etiológicos primários proposta no Diagrama de Keyes e incrementado por Newbrun, em 1988, ao inserir também o tempo como um fator determinante. Quanto mais prolongada a interação dos fatores acima citados, mais grave o efeito dos ácidos na dissolução mineral dos tecidos dentários (2-4).

Aliada à presença dos fatores etiológicos primários, existem aqueles tidos como secundários que, apesar de não serem essenciais para o início da doença, atuam de modo a favorecer sua progressão e gravidade, entre os quais se situam o fluxo salivar (quantidade e qualidade), a exposição ao flúor, o padrão de higiene oral e de ingestão alimentar e aspectos socioculturais e econômicos (4-6). A Figura 1 evidencia a interação entre os diversos fatores associados ao início e à progressão da cárie dentária. 


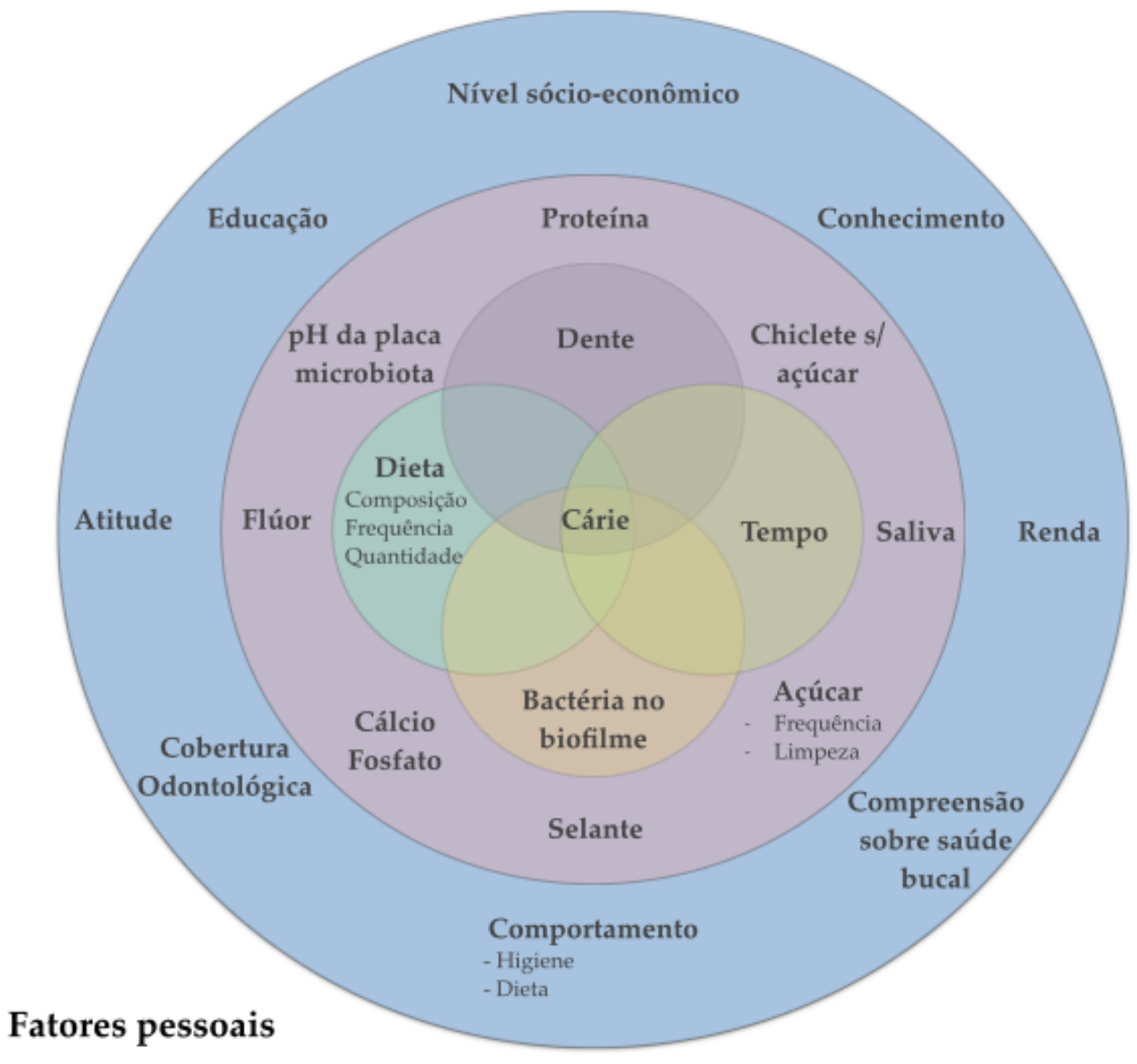

Fatores ambientais

Figura 1 Diagrama da etiologia multifatorial da cárie dentária, extraído e adaptado de Selwitz, Ismail, and Pitts, 2007.

A cárie dentária pode atingir tanto a coroa quanto a raiz e pode ser referenciada como uma perda mineral consequente à queda do $\mathrm{pH}$ do biofilme abaixo de um valor crítico necessário para a dissolução dos tecidos minerais que o compõem - inicialmente o esmalte dentário e, em seguida a dentina/cemento (4). Como afirmado por Newbrun (7), esse processo não é irreversível, visto que as lesões de cárie, entendidas aqui como a manifestação clínica da doença, são manifestações cíclicas que surgem a partir do desequilíbrio entre as fases de desmineralização e remineralização decorrentes da variação de $\mathrm{pH}$ pela fermentação dos carboidratos oriundos da dieta, em que a primeira é predominante em relação à segunda. 
Enquanto o equilíbrio dinâmico de perda e ganho do conteúdo mineral do dente encontra-se equalizado, há um processo fisiológico instalado no qual a doença se manifesta apenas de forma sub-clínica. Contudo, se a perturbação da homeostasia é intensa e de longa duração, há a predominância da desmineralização, levando assim a um desequilíbrio no qual a perda mineral modifica estruturalmente os tecidos dentais - momento em que há a evidência clínica da doença, introduzindo assim um caráter não mais fisiológico, e sim patológico à cárie dentária $(8,9)$.

Como correspondência clínica dos primeiros sinais da doença, verificam-se manchas brancas na superfície do esmalte dentário, assintomáticas, enquanto que sua evolução para um estado mais severo corresponderia clinicamente ao surgimento de lesões em dentina - cavitadas ou não, podendo inclusive apresentar envolvimento pulpar $(10,11)$.

\subsection{CÁRIE DENTÁRIA E DENTIÇÃO DECÍDUA}

A detecção de cárie dentária em estudos epidemiológicos é geralmente conduzida segundo o critério recomendado pela Organização Mundial de Saúde (OMS), em que a prevalência da doença é calculada a partir da quantidade de superfícies ou dentes cariados $(C)$, perdidos $(P)$ e obturados (O). Para dentes permanentes, usa-se a denominação CPO, enquanto para dentes decíduos, a denominação ceo é aplicada, em que "e" faz referência aos dentes com extração indicada (12).

Em 2010 foi publicada uma pesquisa nacional de saúde bucal, denominada SB Brasil, na qual um dos aspectos observados foi a prevalência de lesões de cárie em dentes decíduos e permanentes, tendo sido constatado que aos 5 anos de idade, aproximadamente $54 \%$ das crianças apresentavam lesões de cárie e que, aos 12 anos de idade, este índice alcançou o valor de 57\% (13). Essa prevalência não se restringe apenas ao Brasil ou a países em desenvolvimento, sendo diversos os relatos da alta prevalência da cárie dentária em dentes decíduos em países desenvolvidos $(14,15)$. 
Mesmo com essa elevada prevalência de cárie na dentição decídua, dados da OMS indicam que, em média, $72 \%$ e 95\% das lesões de cárie cavitadas em dentina de dentes decíduos não são tratadas em países de alta e de baixa renda, respectivamente (16). Esse dado está em acordo com o publicado pela SB Brasil, onde cerca de $80 \%$ dos dentes decíduos afetados por lesões de cárie encontravamse sem tratamento no momento dos exames (13).

Ainda, conforme relatado por Kassebaum, 2015 (14), entre 1990 e 2010, as lesões de cárie sem tratamento em dentes decíduos afetaram cerca de 621 milhões de crianças até 14 anos de idade em todo o mundo, sendo a décima condição patológica mais prevalente nessa faixa etária; além disso, os resultados descritos indicaram uma perspectiva em que, a cada 100 pessoas acompanhadas, 15 novos casos de lesão de cárie em dentes decíduos se desenvolverão anualmente.

Tomados em conjunto, tais achados indicam e reforçam que grande parte das crianças em todo o mundo não tem acesso a programas destinados à saúde bucal por baixa cobertura ou inacessibilidade a tratamentos restauradores - e revelam o fracasso tanto dos cuidados preventivos no manejo da cárie dentária, quanto dos tratamentos restauradores convencionais empregados. Ademais, de acordo com relatório da OMS, em países pobres, na possibilidade de o tratamento bucal para cárie dentária em crianças estar disponível - o que já não ocorre com frequência -, o seu custo excederia todo orçamento destinado à saúde infantil, uma vez que a cárie dentária é o $4^{\circ}$ distúrbio mais caro de se tratar, inviabilizando, assim, uma política de saúde bucal efetiva para toda a população (1).

Outro aspecto a ser considerado é a vasta comprovação de que a presença de lesões de cárie dentárias sem tratamento impacta negativamente na saúde geral das crianças, no seu desenvolvimento, no rendimento escolar e em sua qualidade de vida, devendo, portanto, ser considerada como uma prioridade no âmbito das políticas públicas de promoção de saúde (17-19). Parte desses estudos fez uso do índice PUFA ${ }^{1}$ (Pulpal involvement, Ulceration, Fístila, Abscess), proposto em 2010, com o objetivo de acessar as consequências clínicas de lesões cariosas sem tratamento por meio da detecção de estágios avançados desse processo. Tal ferramenta fornece informações sobre exposição pulpar - componente $P / p$-, ulceração da mucosa em função de fragmentos radiculares associados à cárie

\footnotetext{
${ }^{1}$ Índe "PUFA" se refere à dentição permanente e "pufa" à dentição decídua.
} 
dentária - componente $\mathrm{U} / \mathrm{u}$-, fístula - componente F/f - e abcesso - componente A/a -, atuando de forma complementar aos instrumentos epidemiológicos já existentes (20).

\subsection{MANEJO TRADICIONAL DA CÁRIE DENTÁRIA NA DENTIÇÃO DECÍDUA}

A intervenção restauradora em dentes decíduos, principalmente aqueles afetados por lesões de cárie cavitadas em dentina, ainda é uma decisão subjetiva e envolve uma análise multifatorial do paciente e do contexto sócio-econômico-cultural em que este se encontra inserido.

Recentemente, uma revisão sistemática foi atualizada com o objetivo de verificar qual o melhor material restaurador para o manejo da cárie dentária em dentes decíduos (21). Como metodologia da análise, apenas três estudos clínicos foram considerados, tendo sido comparadas as seguintes abordagens: coroas estéticas versus coroas não estéticas (22); restaurações de ionômero de vidro modificado por resina versus restaurações de amálgama (23) e; restaurações de compômeros versus restaurações de amálgama (24). Os resultados mostraram não haver diferença na performance clínica entre os materiais testados, impossibilitando a recomendação de um material restaurador ideal. Adicionalmente, o pequeno número de ensaios clínicos incluídos inviabiliza uma conclusão, indicando a necessidade de mais estudos que objetivem testar protocolos restauradores em dentes decíduos.

No Brasil, os manejos usualmente aplicados são: tratamentos convencionais, em que a remoção da cárie se faz pelo uso de instrumentos rotatórios e pelo emprego de amálgama ou resina composta como materiais restauradores e; o tratamento restaurador atraumático - ART, no qual a remoção da cárie se faz pelo uso de instrumentos manuais e pelo emprego de cimento de ionômero de vidro como material restaurador. Ressalte-se que coroas metálicas têm sido relatadas mundialmente como uma modalidade terapêutica comumente aplicada no manejo de cárie dentária na dentição decídua. Tal abordagem, entretanto, não é convencional 
no Brasil e seu emprego é muitas vezes restrito, não sendo, portanto, objeto de revisão no presente estudo.

A respeito do tratamento convencional com emprego de amálgama, sabe-se que este ainda é o mais utilizado em algumas localidades do Brasil, devendo-se, principalmente, ao fato de o sistema público de saúde elegê-lo em grande parte dos postos de atendimento $(25,26)$. Apesar de apresentar características vantajosas como a durabilidade e o bom custo-benefício, sua inserção, principalmente em odontologia pediátrica, requer abordagens mais invasivas com o emprego de instrumentos rotatórios, além de apresentar um resultado estético pobre e, frequentemente, requerer o uso de anestesia local (27). Mais recentemente, em função da presença do mercúrio em sua composição, o que pode trazer toxicidade, surgiu um movimento de abrangência mundial que pleiteia o seu banimento como material restaurador (28). Desta forma, embora o amálgama tenha sido usado em larga escala no passado e ainda o seja no presente, faz-se necessário investigar novos materiais e protocolos de manejo da cárie dentária que o substituam.

Por sua vez, o tratamento convencional com emprego de resina composta é amplamente disseminado na prática clínica, sendo, em muitos casos, considerado um componente integral da odontologia restauradora contemporânea. Seu uso é indicado tanto para dentes anteriores quanto para dentes posteriores, não sendo, entretanto, o tratamento de eleição nos serviços públicos de saúde, razão pela qual não foi considerado nesta pesquisa (29-31). Não obstante, os tratamentos convencionais estão centrados na manifestação clínica da doença cárie e no reparo de suas sequelas, mostrando-se insuficiente no controle da doença ao longo do tempo (32).

Sob outra perspectiva, de mínima intervenção, o ART surgiu há cerca de três décadas, em um contexto social no qual equipamentos com acionamento elétrico aplicados nos tratamentos restauradores convencionais não poderiam ser utilizados, como em muitas localidades de países de média e baixa renda (33). Frencken e Holmgren, em 1999, (34) o definiram como uma abordagem preventiva e minimamente invasiva, de modo a retardar a progressão da cárie dentária por meio da remoção de esmalte sem suporte e de dentina necrótica com o uso de instrumentos manuais, seguida da restauração da cavidade por um material adesivo 
que sela também as fóssulas e fissuras adjacentes, sendo o cimento de ionômoro de vidro de alta viscosidade (CIV-AV) o mais comumente aplicado (35).

Ensaios clínicos sobre o ART foram capazes de demonstrar a efetividade da técnica no tocante à durabilidade e à resistência das restaurações - especialmente nos casos com envolvimento de única superfície -, no efeito preventivo do

selamento das fóssulas e fissuras, bem como na minimização de traumas e ansiedades durante o tratamento, sendo atualmente empregado em diversos países, inclusive naqueles considerados desenvolvidos $(36,37)$, e atuando como um catalisador para uma nova forma de se pensar sobre os cuidados de saúde bucal (33).

\subsection{TRATAMENTOS CONSERVADORES NO MANEJO DA CÁRIE DENTÁRIA NA DENTIÇÃO DECÍDUA}

Notadamente, a maior razão para restaurar dentes com lesões cavitadas em dentina, sob um ponto de vista de cariologia e de odontologia preventiva, é selar esta cavidade e facilitar, assim, a remoção do biofilme dental das superfícies restauradas, bem como promover alívio de dor e reestabelecer parâmetros funcionais e estéticos da dentição (38). Contudo, apesar do sucesso técnico e das orientações sobre a necessidade de realização de tratamentos restauradores para lesões de cárie, a viabilidade de sua implementação na prática clínica para todos os dentes decíduos que estejam nessa condição tem sido questionada (39).

Tal questionamento surge principalmente no âmbito de políticas públicas de promoção de saúde bucal, ao se considerar, como exposto anteriormente, a alta prevalência de lesões cavitadas sem tratamento, a falta de acesso de boa parte da população e também o alto custo para sua operacionalização. Outro fator que deve ser considerado no que se refere aos tratamentos restauradores na dentição decídua é a sua substituição progressiva pela dentição permanente, sendo o tempo de vida dos dentes decíduos de cerca de 6 a 8 anos, momento em que se observa sua esfoliação natural (40). 
Atualmente, há evidências crescentes de que as abordagens minimamente invasivas podem deter a progressão da cárie de tal forma que o dente decíduo envolvido permaneça na boca sem dor e infecção até a sua esfoliação, resultando em uma abordagem com custo acessível e simplicidade de implementação $(41,42)$.

Como respaldo teórico para a implementação de tratamentos conservadores, em 2012, Edwina Kidd, uma expert em cariologia (43), argumentou que o tratamento mais importante para prevenir o desenvolvimento de lesões de cárie e/ou paralisação de uma lesão já existente é o controle do biofilme. Como o controle do biofilme dental é tão essencial na progressão e/ou paralisação de lesões incipientes de cárie, poderia o seu controle em dentes com cavidades em dentina ser obtido pela sua remoção regular, capaz de paralisar esses tipos de lesões? Esta sugestão não é nova: GV Black, em 1908, já recomendava a escovação para remover a "placa dentária" em cavidades abertas em superfícies vestibulares (44). Diante disso, a sugestão de que as cavidades devem ser mantidas livres de biofilme por meio de limpeza dos dentes tem sido considerada alvo de investigações científicas.

Isto posto, alguns protocolos terapêuticos conservadores têm sido propostos nos últimos anos, entre os quais: a detenção da progressão de lesões de cárie cavitadas em dentina pela aplicação de diamino fluoreto de prata (45), vernizes de flúor $(46,47)$ e solução de fluoreto de sódio $(48)$, bem como pela escovação diária com creme dental fluoretado (1000 ppm) (49). Apesar disso, é importante considerar que nem todas as lesões cavitadas são adequadas para uma limpeza interna por meio de escovação com creme dental fluoretado, ainda mais considerando a rapidez de progressão da cárie em dentes decíduos em comparação com os permanentes, especialmente em lesões proximais, sendo facilitada a limpeza de cavidades maiores $(39,50)$.

Nesse sentido, um protocolo terapêutico denominado ultraconservador (UCT) tornou-se objeto de análise do presente estudo, no qual a abordagem das lesões de cárie cavitadas em dentina na dentição decídua baseia-se na restauração de pequenas cavidades com ART e limpeza diária, por meio de escovação com creme dental fluoretado, de cavidades médias e grandes. Para a avaliação de seus efeitos clínicos, um estudo foi conduzido pela Universidade de Brasília em parceria com a Rabdoud University Nijmegen Medical Centre, sendo a seguir pormenorizado. 


\subsection{ESTUDO DO PARANOÁ}

A Região Administrativa do Paranoá - RA VII, de acordo com dados publicados pela CODEPLAN em 2007, está situada a $25 \mathrm{~km}$ do Centro de Brasília, possuindo extensão de aproximadamente $850 \mathrm{~km}^{2}$, dos quais $2,8 \mathrm{~km}^{2}$ considerados urbanos (Figura 2). Em 2011, apresentou um contingente populacional estimado em 46.527 habitantes, dos quais $23 \%$ com idade de até 14 anos. A renda domiciliar média apurada na pesquisa é da ordem de $R \$ 1.955,00$, correspondente, à época, a 3,6 salários mínimos (SM) e a renda per capita é de $\mathrm{R} \$ 487,00$ (0,9 SM). Da totalidade das residências, 99,7\% possuem abastecimento de água regularizado (51).

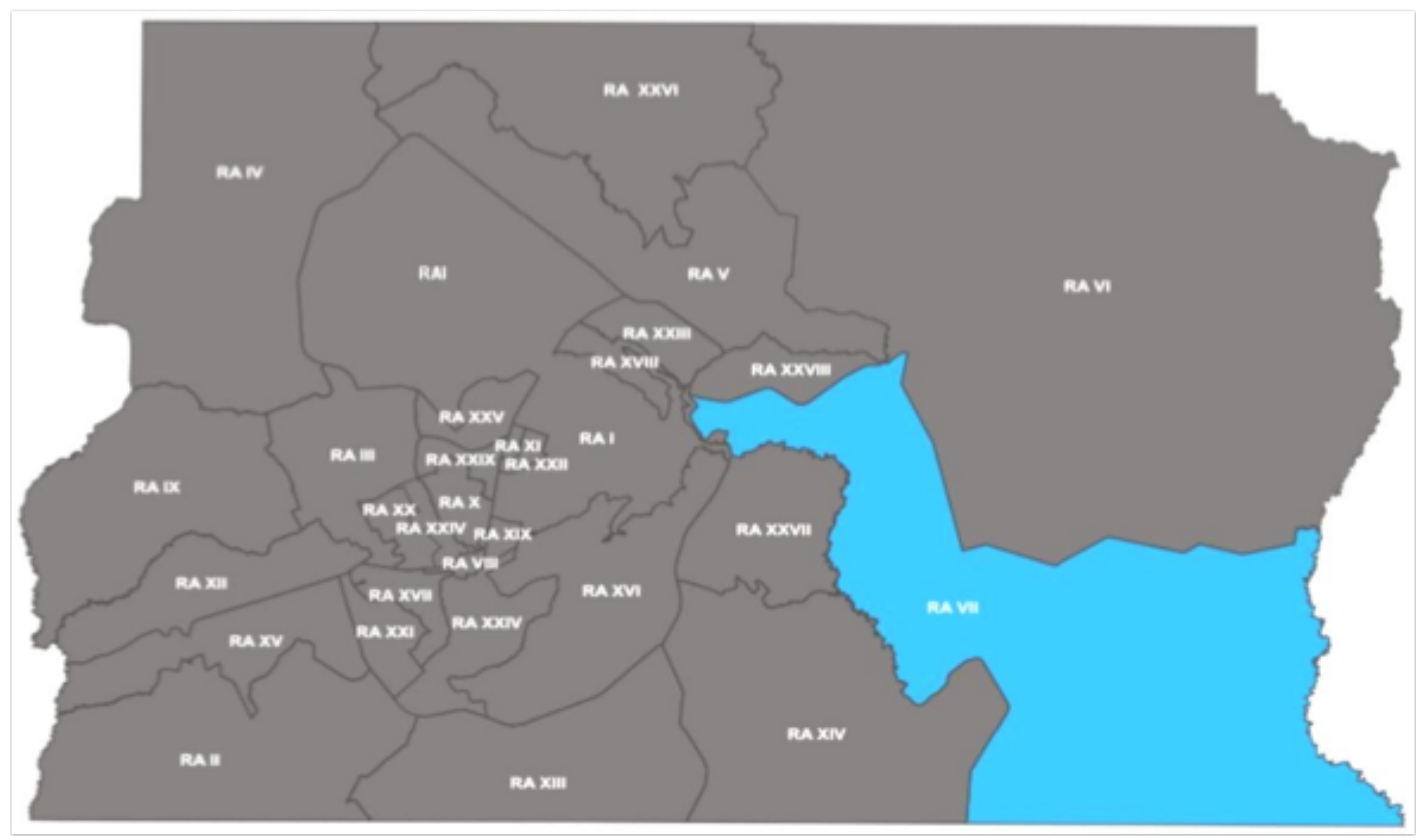

Figura 2 Mapa geográfico do Distrito federal, Brasil. Observa-se a divisão política em Regiões Administrativas. Em destaque (azul), a Região Administrativa do Paranoá, DF- Brasil (Imagem extraída de CODEPLAN, 2007). 
Em 2009, a Universidade de Brasília - UnB, com o apoio da Secretaria de Educação do Distrito Federal iniciou um projeto destinado ao estudo epidemiológico de cárie dentária em crianças em idade escolar, entre 6 e 7 anos, estudantes das seis escolas públicas do Paranoá que possuíam crianças matriculadas nesta faixa etária - Escolas Classe 01, 02, 03, 04, 05 e CAIC (Centro de Atenção Integral à Criança e ao Adolescente).

A partir dos dados epidemiológicos obtidos (52), que resultaram também nas publicações da avaliação da gravidade da cárie e da presença de lesões cavitadas em dentina sem tratamento (53) e da qualidade de vida relacionada ao seu estado de saúde bucal (17), um estudo clínico foi delineado para a avaliação de três diferentes protocolos terapêuticos de manejo da cárie dentária cavitada em dentina em molares decíduos:

- Tratamento Conservador - CRT;

- Tratamento Restaurador Atraumático - ART e;

- Tratamento Ultraconservador - UCT.

O objetivo foi determinar e comparar o desempenho clínico e ex vitro das diferentes abordagens, bem como, a partir dos resultados obtidos, propor uma política intervencionista alternativa à saúde pública do Distrito Federal.

\subsection{ESTUDO CLÍNICO: TRÊS PROTOCOLOS TERAPÊUTICOS DE MANEJO DA CÁRIE DENTÁRIA EM MOLARES DECÍDUOS}

No período de março a julho de 2009, três operadores realizaram a implementação dos protocolos terapêuticos nas crianças previamente selecionadas a partir do estudo epidemiológico de prevalência de cárie dentária em escolas do Paranoá (53). Ainda durante a avaliação epidemiológica, foram determinados, também, o tamanho da cavidade, classificando-as em pequenas, médias e grandes, considerando-se como superfícies referência:

para cavidades proximais: a dimensão da metade da superfície oclusal, ilustrado na Figura 3 e;

para as cavidades oclusais: a dimensão de toda a superfície oclusal. 


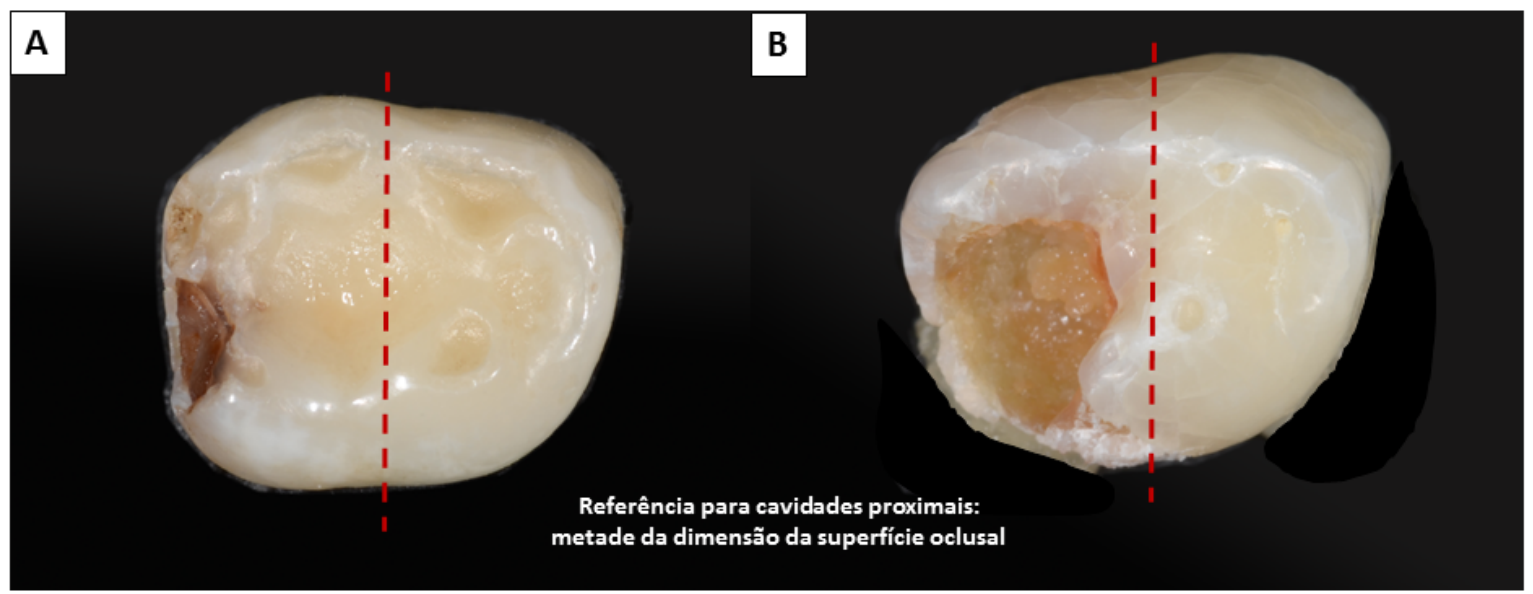

Figura 3. Diagrama ilustrativo da determinação do tamanho da cavidade realizado durante o estudo epidemiológico para lesões de cárie cavitadas em dentina envolvendo a face proximal. Considerou-se nesses casos, a metada da dimensão da superfície oclusal, indicada pela linha tracejada em vermelho, como a superficie referência. Em A, dente com cavidade proximal classificada como pequena. Em B, dente com cavidade proximal classificada como grande.

As cavidades pequenas abrangiam menos de $1 / 3$ da superfície referência, as cavidades médias abrangiam entre 1/3 e 2/3 da superfície referência e as cavidades grandes abrangiam mais que $2 / 3$ da superfície referência. Tal classificação foi baseada em um estudo piloto publicado em 2009 por Topaloglu et al (54).

Os critérios de inclusão para participar do estudo clínico foram: i) o pleno gozo de saúde geral; e ii) a existência de ao menos duas lesões de cárie cavitadas em dentina em ao menos dois dentes molares decíduos sem envolvimento pulpar, determinado clinicamente. Ao todo, 302 crianças com idade entre 6 e 7 anos foram distribuídas em três grupos de protocolos terapêuticos: CRT, ART e UCT, totalizando um número de 835 dentes.

A distribuição das crianças nos diferentes grupos de protocolos terapêuticos seguiu uma alocação quasi-randomizada, na qual a escola foi o sítio de alocação do indivíduo. Pelo fato de o protocolo CRT exigir instalações odontológicas equipadas, instalações estas pré-existentes em duas das escolas inseridas no estudo - Escola Classe 1 e CAIC -, sua alocação não foi aleatória. A distribuição dos grupos ART e UCT, por sua vez, seguiu uma distribuição randomizada nas quatro escolas restantes, obtendo-se como sítios de implementação do protocolo ART as Escolas 
Classe 2 e Classe 4 e, como sítios de implementação do protocolo UCT as Escolas Classe 3 e Classe 5.

Antes do início da implementação dos protocolos, todas as crianças receberam um kit de higiene bucal contendo uma escova de dente, creme dental fluoretado e fio dental. Elas foram ensinadas, coletivamente, a utilizar o kit e também foram informadas sobre bons hábitos alimentares. Um folheto demonstrando como limpar os dentes de forma eficaz foi encaminhado aos pais/cuidadores.

Após a conclusão da implementação dos protocolos terapêuticos, os pais/cuidadores das crianças foram aconselhados a contatar os operadores ou o diretor da escola em caso de dor de dente ou da ocorrência de inchaço ao lado do dente. Em ambas as situações o dente afetado foi extraído por um dos operadores e a razão para a extração foi registrada. Durante o período experimental, um auxiliar odontológico visitou as escolas dos grupos CRT, ART e UCT com regularidade, com o intuito de avaliar se alguma queixa havia sido recebida.

As crianças foram tratadas nas instalações das escolas em que estudavam por três dentistas especialistas em Odontopediatria, treinados para a aplicação dos diferentes protocolos terapêuticos. Os procedimentos clínicos nos três grupos, descritos abaixo e ilustrados na Figura 4, seguiu um protocolo padronizado desenvolvido após um estudo piloto utilizado para treinamento e calibragem dos operadores:

\section{Protocolo de tratamento restaurador convencional (CRT):}

O isolamento do dente foi realizado por roletes de algodão e um dispositivo de sucção. As cavidades de cárie em dentina foram preparadas com instrumentos rotatórios e restauradas com amálgama (Kit Permite Regularß, SDI, Melbourne, Austrália). Esta é a prática comum na maioria dos centros de saúde bucal das instituições públicas brasileiras.

O preparo cavitário seguiu os princípios de GV Black, sem, entretanto, a "extensão para prevenção". Em cavidades profundas, foi aplicada uma camada de cimento de hidróxido de cálcio $\mathrm{Ca}(\mathrm{OH})_{2}$. Foram utilizadas cunha de madeira e uma banda matriz de aço (Injecta $\AA$, Diadema, São Paulo, Brasil) em um retentor de matriz Tofflemire (Golgran ${ }^{\circledR}$, São Paulo, Brasil). 


\section{Protocolo de tratamento restaurador atraumático (ART):}

$\mathrm{O}$ isolamento do dente foi realizado por roletes de algodão. As cavidades de cárie em dentina foram acessadas e preparadas somente com instrumentos manuais (ART Kit ${ }^{\circ}$; Henry Schein, Chicago, EUA) e restauradas utilizando cimento de ionômero de vidro de alta viscosidade (Ketac Molar EasyMix $\AA$, 3M ESPE, Seefeld, Alemanha). Em cavidades profundas, foi aplicada uma camada de cimento de hidróxido de cálcio $\mathrm{Ca}(\mathrm{OH})_{2}$. Foram utilizadas cunha de madeira e uma banda matriz de aço (Injecta ${ }^{\circledR}$, Diadema, São Paulo, Brasil) em um retentor de matriz Tofflemire (Golgran ®, São Paulo, Brasil).

Depois de limpa, a cavidade foi condicionada durante 10 segundos com uma bolinha de algodão molhada com o líquido diluído do ionômero de vidro, lavada durante cinco segundos com uma bolinha de algodão molhada com água, e seca durante cinco segundos com uma bolinha de algodão seco. A assistente, previamente treinada, realizou a manipulação do ionômero de vidro em uma placa de vidro com uma espátula de metal, de acordo com as instruções do fabricante. A mistura foi inserida na cavidade em incrementos, utilizando-se um instrumento aplicador/entalhador (ART Kit $\AA$ ). As cavidades foram completamente preenchidas e, em seguida, o material foi pressionado para baixo por pressão digital com o dedo enluvado e vaselinado. A mordida foi verificada e o excesso de material foi removido com aplicador/escultor (ART Kit $®$ ). A restauração foi protegida com vaselina e a criança foi orientada a não ingerir alimentos por pelo menos uma hora.

\section{Protocolo do tratamento Ultraconservador (UCT):}

As cavidades pequenas de cárie em dentina foram tratadas de acordo com o protocolo ART.

As cavidades médias de cárie em dentina não foram restauradas, mas sim ampliadas com um instrumento específico (Henry Schein ${ }^{\circledR}$ ), para facilitar a remoção do biofilme com uma escova de dentes e creme dental fluoretado (1100 ppm).

As cavidades grandes de cárie em dentina também não foram restauradas, mas sim limpas, como descrito para cavidades médias.

Durante todo o período do estudo, uma assistente odontológica treinada supervisionou a escovação diária no período letivo - aproximadamente 200 dias por ano -, observando se as crianças estavam executando a técnica de escovação vestíbulo-lingual em todas as cavidades não restauradas, como foram ensinadas 
pelos dentistas durante a implementação do estudo clínico. A assistente foi treinada para a detecção de biofilme. Caso fossem verificadas escovações ineficientes, a assistente repetia a demonstração. As crianças foram aconselhadas a limpar os dentes durante as férias, bem como durante os períodos de recessos escolares, da mesma forma.
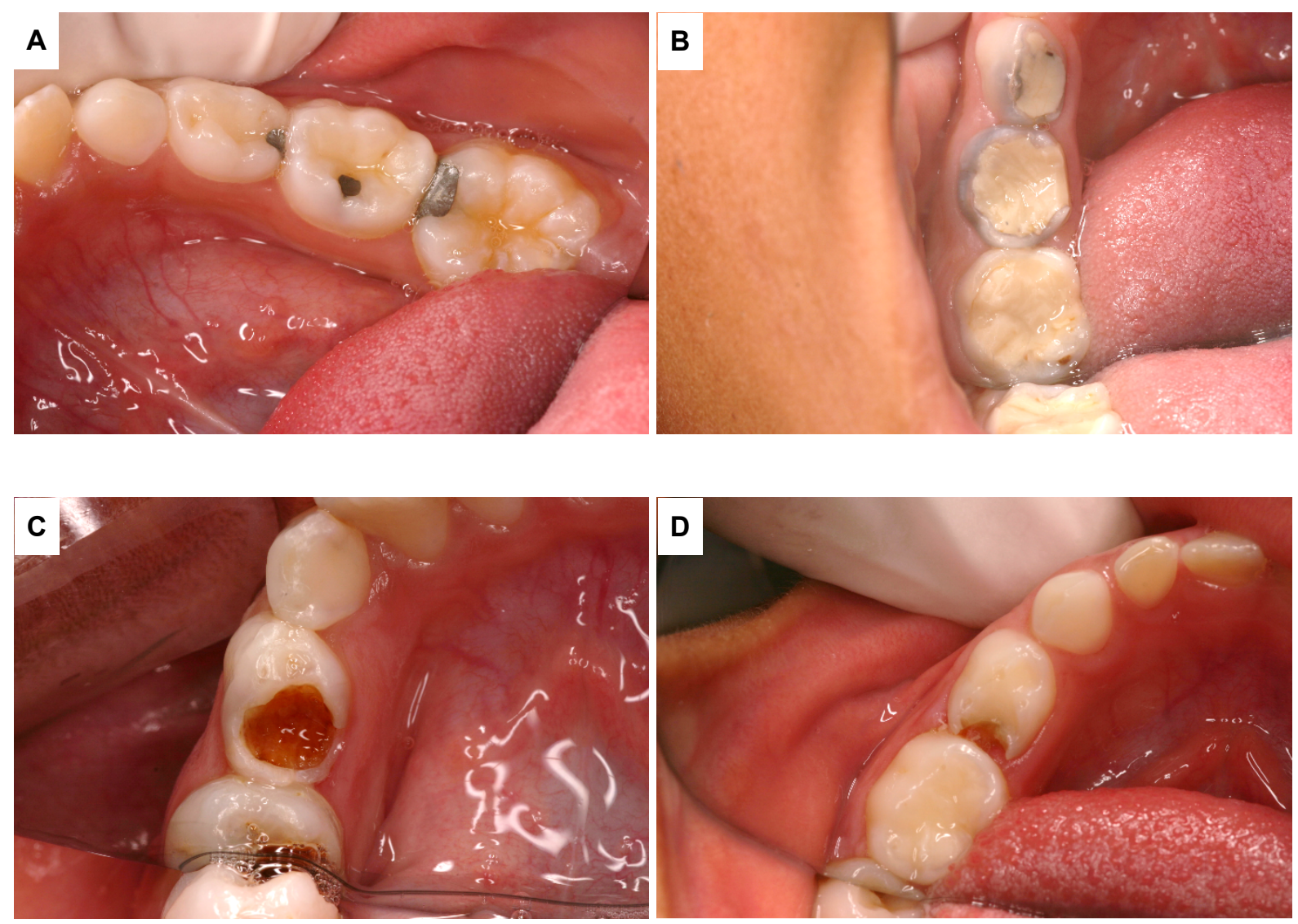

Figura 4 Fotografias de dentes molares decíduos de crianças inseridas no estudo clínico do Paranoá. Em A, observam-se restaurações em amálgama (CRT) no primeiro e segundo molares decíduos e também no primeiro molar permanente (não inserido no estudo); em $B$, observam-se restaurações em cimento de ionômero de vidro (ART) no primeiro e segundo molares decíduos e também no primeiro molar permanente (não inserido no estudo); em C e D, observam-se cavidades abertas (UCT) com envolvimento de múltiplas superfícies nos primeiros molares decíduos.

Ressalta-se que o estudo obteve aprovação no Comitê de Ética da Faculdade de Medicina da Universidade de Brasília, sob o registro CEP-FM 081/2008 (Anexo A). Foi obtida autorização junto aos responsáveis, por meio do esclarecimento e 
assinatura do termo de consentimento livre e esclarecido para a realização dos exames epidemiológicos e participação nos programas de tratamento (Anexo B). Desde o início do estudo em 2009, as crianças foram acompanhadas periodicamente por meio de avaliações semestrais e anuais das restaurações. Todas as necessidades de tratamento, como por exemplo dentes com indicação de exodontia, foram realizadas.

Desde a implementação dos protocolos terapêuticos, diversos aspectos foram avaliados, destacando-se:

- a experiência de dor e ansiedade relacionados aos diferentes protocolos terapêuticos implementados (55-58);

- a avaliação da qualidade de vida das crianças antes e após um ano da implementação dos diferentes protocolos terapêuticos $(17,59)$;

- a avaliação do sucesso clínico das restaurações de amálgama e de cimento de ionômero de vidro pelo ART após dois e três anos de sua implementação $(60,61)$ e;

- mais recentemente, o efeito preventivo da escovação supervisionada e de selantes no desenvolvimento da cárie (62).

Diante disso, a presente tese insere-se no contexto do Estudo do Paranoá ante a necessidade de continuidade de avaliações de aspectos diversos relacionados aos protocolos terapêuticos implementados, sendo, para tanto, conduzidas análises clínicas e laboratoriais, apresentadas nesta peça como:

Estudo 1 - Análise da taxa de sobrevida dos molares decíduos

- Estudo 2 - Análise da taxa de esfoliação dos molares decíduos

- Estudo 3 - Análise de microfraturas marginais

Especificamente quanto às análises laboratoriais, se faz importante salientar que estudos in vitro têm sido conduzidos com o objetivo de avaliar comportamentos biológicos/biomecânicos a partir do controle de variáveis externas e tornaram-se, nas últimas décadas, ferramentas imprescindíveis para suportar cientificamente a implementação clínica de novas tecnologias e protocolos, bem como a consolidação de metodologias comumente empregadas sem o devido respaldo acadêmico.

A grande maioria dos trabalhos que investigam a biocompatibilidade, a dureza e a resistência de materiais dentários utiliza modelos in vitro e in situ. Desta forma, a possibilidade de se avaliar dentes que foram tratados in vivo e mantidos na cavidade bucal por um período longo de tempo, estabelecendo um modelo de estudo ex vivo, 
demonstra-se importante e deve ser realizada quando possível, para que se possa entender melhor o comportamento desses materiais em situações clínicas.

\subsection{ANÁLISE CLIINICA DE TRATAMENTOS RESTAURADORES}

Alguns aspectos que se referem especificamente à avaliação clínica e à avaliação laboratorial dos tratamentos restauradores merecem ser evidenciados.

Em estudos clínicos, a avaliação de tratamentos restauradores segue critérios específicos, dentre os quais o critério USPHS (United States Public Health Service), proposto por Ryge na década de 70. Contudo, alguns artigos relatam que tal critério apresentava sensibilidade limitada para avaliação de mudanças das restaurações ao longo do tempo, pois, em alguns casos, a sua insensibilidade levou à interpretações errôneas de boas performances clínicas (63-65).

Em 2007, o critério FDI (Fédération Dentaire Internationale) foi proposto para a avaliação direta e indireta das restaurações, ante as limitações do critério USPHS e também o surgimento de materiais restauradores com melhor performance clínica. Nele, propriedades estéticas, funcionais e biológicas foram abarcadas, o que resultaria em uma análise mais detalhada, sendo utilizado principalmente para a avaliação de resinas compostas (64).

Paralelamente à criação e ao desenvolvimento da abordagem da técnica ART, em que as restaurações produzidas diferem daquelas em resina composta ou amálgama por selarem fóssulas e fissuras adjacentes à cavidade afetada, um critério de avaliação de restaurações e selantes denominado critério ART (Tabela 1) foi desenvolvido. Um dos principais objetivos de sua criação foi sua replicabilidade com o intuito de facilitar comparações de performances clínicas da nova abordagem, principalmente no tocante à sobrevida das restaurações, sendo um critério mais simplificado quando comparado aos anteriores $(36,66)$.

No critério ART, consideram-se bem-sucedidas aquelas restaurações que apresentam código 0 ou 1, ou seja, que não apresentam deficiência em alguma de suas margens ou, no segundo caso, que esta deficiência seja menor que $0,5 \mathrm{~mm}$. 
Esta classificação traz uma dificuldade quanto ao estudo de microfraturas marginais das restaurações, uma vez que o código 1 pressupõe sua existência na interface dente-restauração, visível clinicamente. Diante disso, um questionamento surge acerca da real interferência da presença de microfraturas marginais e do sucesso clínico de tratamentos restauradores.

Tabela 1 - Critério ART de avaliação clínica das restaurações

\begin{tabular}{ll}
\hline Código & Critério \\
\hline $\mathbf{0}$ & Restauração presente, satisfatória \\
$\mathbf{1}$ & Restauração presente, pequena deficiência na margem da cavidade, menor que 0,5 mm* \\
$\mathbf{3}$ & Restauração presente, deficiência na margem da cavidade, com 0,5 mm ou mais* \\
$\mathbf{4}$ & Restauração presente, fratura na restauração \\
$\mathbf{5}$ & Restauração presente, margem extendida 0,5 mm além da margem proximal \\
$\mathbf{6}$ & Restauração ausente, maior parte ou toda a restauração ausente \\
$\mathbf{7}$ & Restauração ausente, outro tratamento restaurador inserido \\
$\mathbf{8}$ & Restauração ausente, dente ausente \\
& Diagnóstico prejudicado
\end{tabular}

* Acessada pela sonda da OMS. (Tabela extraída e adaptada de Frencken et al, 1996 (66))

A presença de microfraturas nas margens de uma restauração permite a passagem de bactérias, moléculas e íons na interface dente-material restaurador, o que pode causar descoloração dentária, hipersensibilidade, quebra do material restaurador e, principalmente, ocorrência de danos pulpares e cárie secundária (6769). Contudo, a relação precisa entre o desempenho clínico dos procedimentos restauradores e a ocorrência de microfraturas nas margens das restaurações ainda é controversa (70), sendo necessária a realização de mais estudos sobre o tema, especialmente daqueles que relatem tal correspondência clínico-laboratorial. 


\section{OBJETIVOS}

\subsection{OBJETIVO GERAL}

Avaliar aspectos clínicos e ex vivo relacionados a três diferentes protocolos terapêuticos no manejo da cárie dentária em molares decíduos inseridos no Estudo do Paranoá - Distrito Federal, Brasil.

\subsection{OBJETIVOS ESPECÍFICOS}

Avaliar clinicamente a sobrevida de molares decíduos submetidos a três diferentes protocolos terapêuticos no manejo da cárie dentária após o período de 3,5 anos de sua implementação.

Avaliar clinicamente o padrão de esfoliação de molares decíduos submetidos aos três diferentes protocolos terapêuticos no manejo da cárie dentária após o período de 3,5 anos de sua implementação.

Avaliar o selamento marginal de restaurações de amálgama e de cimento de ionômero de vidro de alta viscosidade de dentes inseridos no estudo clínico de manejo da cárie dentária. 


\section{ESTUDO 1 - SOBREVIDA DE DENTES}

\section{Avaliação clínica da sobrevida de molares decíduos submetidos a três diferentes protocolos terapêuticos no manejo da cárie dentária após o período} de 3,5 anos

Tal análise encontra-se publicada sob a seguinte referência (Apêndice A):

Mijan M, de Amorim RG, Leal SC, Mulder J, Oliveira L, Creugers NH, Frencken JE: The 3.5-year survival rates of primary molars treated according to three treatment protocols: a controlled clinical trial. Clin Oral Invest 2014, May, 18(4):1061-9.

\subsection{INTRODUÇÃO}

A inacessibilidade aos sistemas de saúde bucal, bem como a tentativa na prática clínica em realizar o controle da doença cárie por meio de modelos restauradores conservadores (CRT), têm se mostrado ineficiente, tanto em países desenvolvidos quanto naqueles em desenvolvimento, e contribuem para a manutenção da referida doença em um status endêmico, principalmente na população infantil (16).

As restaurações realizadas por meio do ART apresentam-se como alternativa aos tratamentos conservadores, uma vez que adicionam à abordagem da doença um aspecto preventivo, além do fato de poderem ser aplicadas em locais desprovidos de energia elétrica e água corrente (33). Em termos de sobrevida, as restaurações ART funcionam tão bem quanto o CRT utilizando amálgama (71) ou resinas compostas (72). Outrossim, apresentam relação custo-benefício melhor que aqueles tratamentos realizados com CRT após um período de avaliação de dois anos (73).

Contudo, considerando a alta prevalência de lesões de cárie não tratadas em dentina, especialmente na população infantil, e a dificuldade em se estabelecer 
cuidados preventivos adequados para o seu controle, é sabido que tais problemas não podem ser resolvidos unicamente pela introdução do ART, sendo necessário, para tanto, o desenvolvimento de outras abordagens. Nesse sentido, a introdução de um protocolo terapêutico denominado ultraconservador (UCT), utilizando restaurações ART em dentes com pequenas cavidades em dentina e remoção do biofilme por meio de escovação com creme dental fluoretado em dentes com cavidades médias e grandes em dentina, pode apresentar-se como alternativa para o manejo da cárie dentária na dentição decídua.

Neste estudo, a hipótese testada foi a de que não há nenhuma diferença nas taxas acumuladas de sobrevivência dos molares decíduos tratados de acordo com os protocolos CRT, ART e UCT em um período de avaliação de 3,5 anos.

\subsection{METODOLOGIA}

\subsubsection{Implementação dos protocolos terapêuticos}

A amostra de sujeitos foi obtida por meio de um levantamento epidemiológico de saúde bucal de crianças de 6 e 7 anos de idade que frequentavam as 6 escolas públicas do Paranoá-DF: Escola Classe 1, 2, 3, 4, 5 e CAIC, consideradas aqui os sítios de alocação.

Tratou-se de um ensaio clínico controlado, quasi-randomizado, que teve como critério de inclusão: i) crianças apresentarem o pleno gozo de saúde geral; e ii) ao menos duas lesões de cárie cavitadas em dentina em ao menos dois dentes molares decíduos sem envolvimento pulpar. Dos 835 dentes das 302 crianças inseridas originalmente no estudo epidemiológico, 391 dentes foram submetidos ao protocolo CRT, 277 dentes foram submetidos ao protocolo ART e 315 dentes foram submetidos ao protocolo UCT.

Os protocolos terapêuticos CRT, ART e UCT foram implementados conforme descrito previamente nesta tese e também relatado por de Amorim, 2014 (61).

\subsubsection{Avaliação da sobrevida dos dentes}

A sobrevida dos dentes foi aferida por dois avaliadores independentes do estudo e calibrados entre si, especialistas em odontopediatria, que foram treinados 
previamente. Foram realizadas cinco avaliações nos tempos de 6 meses, 1 ano, 2 anos, 3 anos e 3,5 anos após a implementação dos protocolos terapêuticos.

Os critérios de avaliação incluíram a presença ou a ausência de cada elemento dentário durante todo o período de avaliação. Se ausente, o motivo foi questionado: se por esfoliação natural ou se foi extraído. Adicionalmente, os dentes foram avaliados de acordo com o código PUFA (20), que inclui as seguintes alterações clínicas: envolvimento pulpar $(P)$; ulceração $(U)$; fístula $(F)$; ou abscesso (A) em função de cárie e/ou de tratamentos implementados e também se havia presença de dor. Em caso de um resultado positivo, o avaliador indicava o dente para a extração, que foi realizada posteriormente por um dos operadores.

\subsubsection{Análise estatística}

A análise estatística foi conduzida em colaboração com a Rabdoud University, Nijmegen Centre, Holanda, por um bioestatístico experiente.

Inicialmente, um cálculo de poder utilizando um coeficiente a de 0,05 e um coeficiente 1- $\beta$ de 0,8 precedeu o processo de amostragem. Com base no aumento esperado de $10 \%$ na taxa de sobrevivência de dentes não-restaurados, de $82 \%$ (50) para $92 \%$, o tamanho da amostra seria de 173 dentes por grupo. O critério de inclusão no estudo determinou a quantidade de pelo menos 2,5 dentes com necessidade de tratamento por criança, sendo que o número de crianças necessárias foi de 70 por grupo experimental. Considerando uma correção de 10\% para dependência de tratamentos dentro de uma criança e uma estimativa de $8 \%$ de perda anual de crianças, o tamanho da amostra foi de 97 crianças e 239 dentes por protocolo de tratamento após 3,5 anos.

Todos os dados coletados foram inseridos em um programa de inserção de dados especialmente concebido para o julgamento. As análises foram realizadas seguindo a abordagem por protocolo terapêutico, utilizando o software SAS versão 9.2. A variável dependente foi a taxa de sobrevida de molares decíduos tratados de acordo com os três protocolos terapêuticos (CRT, ART, UCT). As variáveis independentes foram: idade (6 e 7 anos), sexo, valor médio do ceo-d no início do estudo (estudo epidemiológico), o tipo de superfície (única ou múltipla) e o operador.

A sobrevida do dente foi considerada falha quando este foi extraído por dor, sepsia (fístula/abscesso) ou exposição pulpar. Dentes naturalmente esfoliados e dentes extraídos por outros dentistas foram consideradas observações censuradas. 
O modelo de regressão proporcional de Hazard (74) com correção de fragilidade (75) foi usado para calcular as taxas cumulativas de sobrevida de dentes e para analisar o efeito das variáveis independentes sobre a variável dependente ao longo do período de 3,5 anos.

O teste de Wald foi utilizado para aferir as diferenças entre as taxas de sobrevida acumuladas de 3,5 anos e para os efeitos das variáveis independentes sobre as curvas de sobrevida. O método Jackknife foi utilizado para a correção de dependência de dentes tratados dentro de cada criança. Em seguida, o teste-t foi utilizado para aferir as diferenças entre as taxas de sobrevida no intervalo pretendido (76). A significância estatística foi estabelecida em $\alpha=0,05$.

\subsection{RESULTADOS}

\subsubsection{Disposição dos sujeitos do estudo}

O número de crianças inseridas originalmente no estudo foi de 302 . O grupo UCT foi subdividido em 109 dentes tratados unicamente com restaurações de ionômero de vidro pela técnica ART, por apresentarem cavidades pequenas em dentina e 166 dentes que tiveram suas cavidades limpas por escovação com creme dental fluoretado, por apresentarem cavidades médias e grandes em dentina e 6 dentes que combinaram restauração com ionômero de vidro e cavidades limpas.

Não houve nenhum efeito das variáveis de gênero $(p=0,71)$ e escore médio do ceo-d $(p=0,75)$ entre as crianças nos diferentes grupos de protocolos terapêuticos no início do estudo (baseline). Entretanto, um efeito de tipo de superfície $(p=0,03)$ e de idade foi constatado $(p<0,0001)$. As crianças do grupo CRT eram, em média, 0,2 anos mais novas que as crianças alocadas nos demais grupos experimentais, e havia, proporcionalmente, menos molares com múltiplas

superfícies envolvidas no grupo CRT comparado aos demais (Tabela 2). 
Tabela 2 - Váriáveis avaliadas no início do estudo (original) nas crianças inseridas nos diferentes protocolos terapêuticos.

\begin{tabular}{lccc}
\hline & CRT & ART & UCT \\
\hline Idade média \pm SD & $6,7 \pm 0,4$ & $6,9 \pm 0,4$ & $6,9 \pm 0,4$ \\
Gênero & & & \\
N meninos & 67 & 49 & 47 \\
N meninas & 59 & 36 & 44 \\
Média do escore ceo-d \pm DP & $5,8 \pm 3,2$ & $5,8 \pm 2,7$ & $5,5 \pm 2,6$ \\
Tipo de superfície & & & 62 \\
N superfícies únicas & 103 & 56 & 219 \\
N superfícies múltiplas & 238 & 188 & \\
\hline
\end{tabular}

$\mathrm{CRT}=$ Tratamento Restaurador Conservador; ART = Tratamento Restaurador Atraumático; UCT = Tratamento Ultraconservador; $\mathrm{N}=$ número; $\mathrm{DP}$ = desvio padrão

Durante o período de 3,5 anos, houve uma evasão total de $52 \%$ no número de crianças avaliadas. Entretanto, o percentual de crianças que efetivamente evadiram-se do estudo (evasão real) foi de $12 \%$. Tal valor considerou o percentual de crianças que estavam presentes, mas que possuíam a totalidade de dentes ausentes por esfoliação ou extração - 39,7\%, não havendo efeito da idade ( $p=$ $0,28)$, gênero $(p=0,29)$ e escore médio do ceo-d $(p=0,70)$ tomando-se como base o estudo epidemiológico original.

Um diagrama com a síntese dos resultados das avaliações clínicas da sobrevida dos dentes, de acordo com cada protocolo terapêutico, no período de 3,5 anos é apresentado na Figura 5. Vale ressaltar que durante a implementação dos protocolos, os operadores excluíram mais dentes cavitados por envolvimento pulpar nos grupos CRT (34\%) e ART (27,3\%) que no grupo UCT (17,6\%). Tal fato ocorreu em função de, em alguns casos, a implementação do tratamento ter se dado até 3 meses após a seleção do dente para o estudo. Assim, considerando a rápida 
progressão da lesão cariosa em dentes decíduos, uma lesão que foi anteriormente considerada sem envolvimento pulpar já apresentava esta condição no momento do tratamento, sendo, portanto, excluído do estudo.

\subsubsection{Sobrevida de molares deciduos}

A Tabela 3 apresenta a sobrevida cumulativa de todos os primeiros molares submetidos aos diferentes protocolos terapêuticos pelo intervalo de tempo. O teste de Wald demonstrou não haver diferença estatisticamente significativa entre os três grupos de protocolos terapêuticos estudados $(p=0,13)$. Durante o período de 3,5 anos, não houve efeito de idade $(p=0,41)$, gênero $(p=0,93)$, operador $(p=0,30)$ e escore médio do ceo-d $(p=0,94)$. Apenas um efeito do tipo de superfície foi observado ( $p=0,009)$, demonstrando que molares com única superfície envolvida sobreviveram por um período maior que os molares que possuíam múltiplas superfícies envolvidas. 


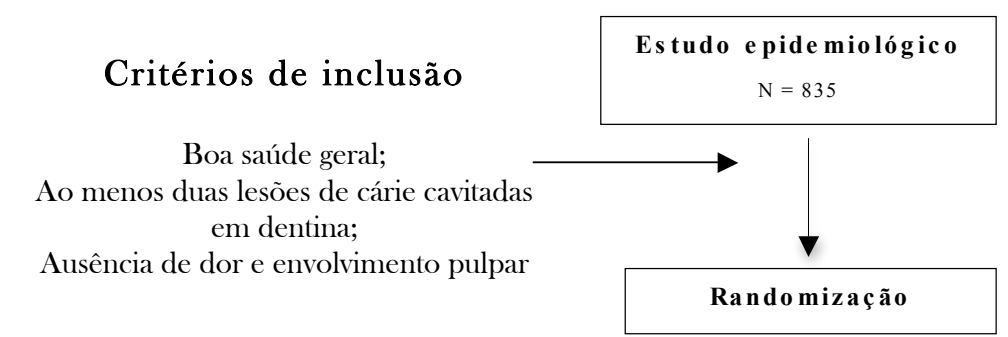

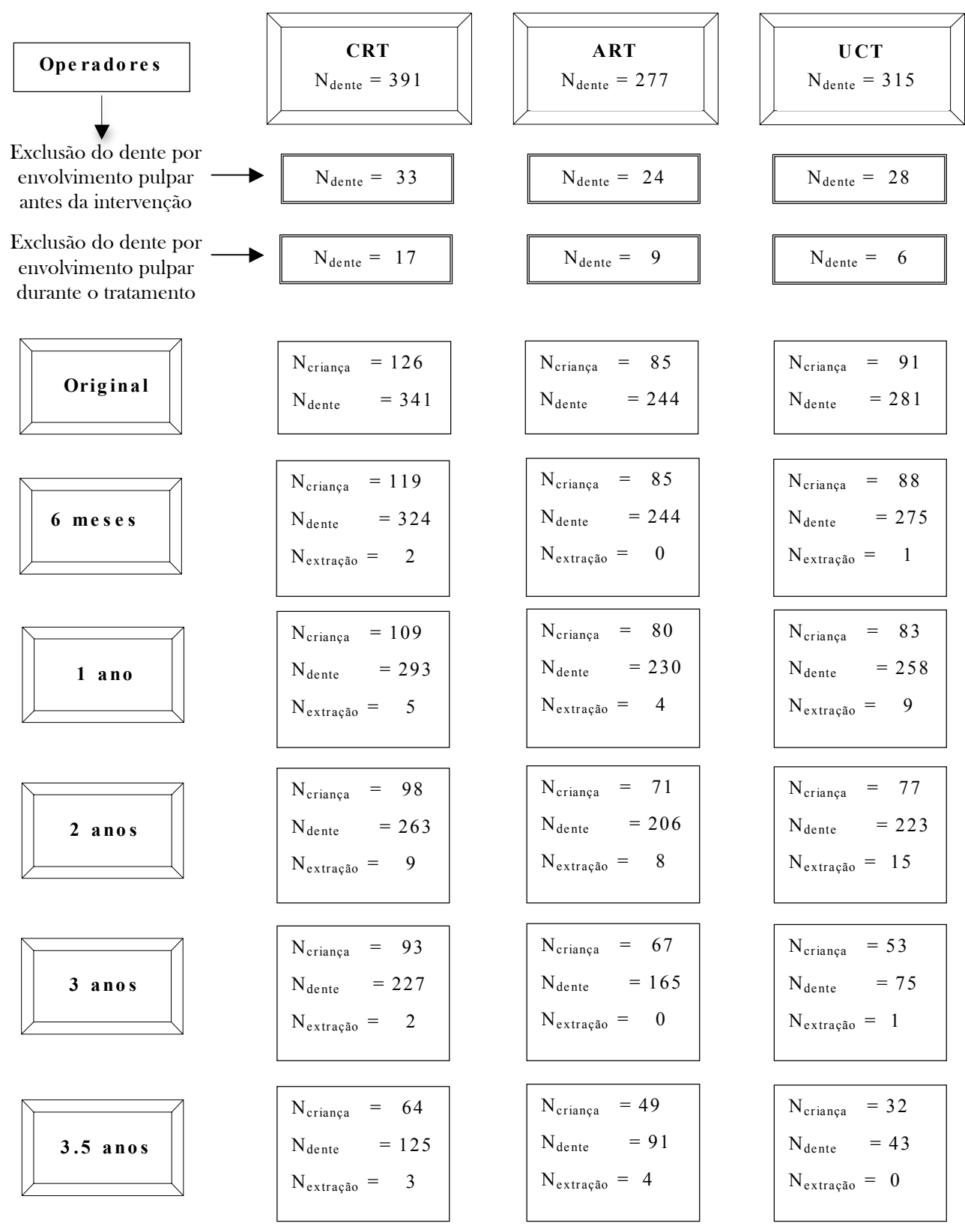

Figura 5 Diagrama de fluxo com a síntese dos resultados das avaliações clínicas de sobrevida dos dentes no período de 3,5 anos. CRT $=$ Tratamento Restaurador Conservador; ART $=$ Tratamento Restaurador Atraumático; UCT = Tratamento Ultraconservador; $\mathrm{N}$ = número; 
Tabela 3 - Sobrevida cumulativa (\%) e erro padrão pelo método Jackknife (EP) de todos os primeiros molares submetidos aos diferentes protocolos terapêuticos, por intervalo de tempo.

\begin{tabular}{|c|c|c|c|c|c|c|c|c|c|c|c|c|}
\hline & & & CRT & & & & ART & & & & JCT & \\
\hline $\begin{array}{l}\text { Intervalo } \\
\text { de tempo } \\
\text { (anos) }\end{array}$ & $\mathrm{N}$ & $\mathrm{N}_{\mathrm{X}}$ & $\%$ & EP & $\mathrm{N}$ & $\mathrm{N}_{\mathrm{X}}$ & $\%$ & $\mathrm{EP}$ & $\mathrm{N}$ & $\mathrm{N}_{\mathrm{X}}$ & $\%$ & EP \\
\hline $0,0-0,5$ & 324 & 02 & 99,4 & 0,4 & 244 & 00 & 100,0 & 0,0 & 275 & 01 & 99,6 & 0,0 \\
\hline $0,5-1,0$ & 293 & 07 & 97,7 & 0,9 & 230 & 04 & 98,3 & 0,8 & 258 & 10 & 96,2 & 1,3 \\
\hline $1,0-2,0$ & 263 & 16 & 94,4 & 1,4 & 206 & 12 & 94,5 & 1,6 & 223 & 25 & 89,7 & 1,9 \\
\hline $2,0-3,0$ & 227 & 19 & 93,1 & 1,5 & 165 & 12 & 94,5 & 1,6 & 75 & 26 & 88,6 & 1,9 \\
\hline $3,0-3,5$ & 125 & 22 & 90,9 & 2,0 & 91 & 16 & 90,4 & 2,4 & 43 & 26 & 88,6 & 1,9 \\
\hline
\end{tabular}

$\mathrm{N}=$ número de dentes; $\mathrm{N}_{\mathrm{X}}=$ número cumulativo de extrações

Uma análise adicional foi conduzida uma vez que a maioria dos dentes extraídos possuíam cavidades com múltiplas superfícies envolvidas. A Tabela 4 mostra a sobrevida cumulativa dos primeiros molares com cavidades com envolvimento de múltiplas superfícies tratadas de acordo com cada grupo de protocolo terapêutico e com o período de intervalo de avaliação. Não foi observada nenhuma diferença estatisticamente significativa entre os três grupos após as avaliações cumulativas no período de 3,5 anos $(p=0,29)$. Ademais, não foi observada influência estatisticamente significativa das variáveis estudadas ( $p>0,05)$. 
Tabela 4 - Sobrevida cumulativa (\%) e erro padrão pelo método Jackknife (EP) dos primeiros molares com envolvimento de múltiplas superfícies, submetidos aos diferentes protocolos terapêuticos, por intervalo de tempo.

\begin{tabular}{|c|c|c|c|c|c|c|c|c|c|c|c|c|}
\hline & \multicolumn{4}{|c|}{ CRT } & \multicolumn{4}{|c|}{ ART } & \multicolumn{4}{|c|}{ UCT } \\
\hline $\begin{array}{l}\text { Intervalo } \\
\text { de tempo } \\
\text { (anos) }\end{array}$ & $\mathrm{N}$ & $\mathrm{N}_{\mathrm{X}}$ & $\%$ & EP & $\mathrm{N}$ & $\mathrm{N}_{\mathrm{X}}$ & $\%$ & EP & $\mathrm{N}$ & $\mathrm{N}_{\mathrm{X}}$ & $\%$ & EP \\
\hline $0,0-0,5$ & & 2380 & 99 & $2 \quad 0,6$ & 188 & 00 & 100,0 & 0,0 & 219 & 01 & 100,0 & 0,0 \\
\hline $0,5-1,0$ & 215 & 07 & 96,9 & 1,2 & 176 & 04 & 97,7 & 1,1 & 207 & 09 & 95,7 & 1,3 \\
\hline $1,0-2,0$ & 193 & 16 & 92,4 & 2,1 & 156 & 11 & 93,4 & 2,0 & 174 & 23 & 88,0 & 2,1 \\
\hline $2,0-3,0$ & 161 & 18 & 91,2 & 2,1 & 120 & 11 & 93,4 & 2,0 & 38 & 23 & 88,0 & 2,1 \\
\hline $3,0-3,5$ & 80 & 20 & 89,0 & 2,1 & 68 & 15 & 88,0 & 2,7 & 22 & 23 & 88,0 & 2,1 \\
\hline
\end{tabular}

$\mathrm{N}=$ número de dentes; $\mathrm{N}_{\mathrm{X}}=$ número cumulativo de extrações

Em todo o período de 3,5 anos, um total de 22 dentes do grupo CRT, 16 dentes do grupo ART e 26 dentes do grupo UCT foram extraídos. Deste total, apenas 6 dentes possuíam cavidade em dentina com envolvimento de única superfície, dos quais: 2 dentes do grupo CRT, 1 dente do grupo ART e 3 dentes do grupo UCT. Todos os outros dentes extraídos ao longo do estudo possuíam cavidades em dentina envolvendo múltiplas superfícies.

A Tabela 5 mostra a frequência de distribuição das razões para a extração de todos os molares decíduos, agrupadas por grupo de protocolo terapêutico adotado. Como é possível constatar, a presença de fístula foi a principal razão para a extração dentária. 
Tabela 5 - Distribuição de frequência das razões para extrações dos primeiros molares decíduos submetidos aos diferentes protocolos terapêuticos.

\begin{tabular}{lccc}
\hline & CRT & ART & UCT \\
\hline Razões para extração & $\mathrm{N}_{\mathrm{X}}$ & $\mathrm{N}_{\mathrm{X}}$ & $\mathrm{N}_{\mathrm{X}}$ \\
Exposição pulpar & 08 & 01 & 09 \\
Fístula & 02 & 11 & 11 \\
Abscesso & 04 & 02 & 04 \\
& & & \\
Dor & 08 & 02 & 01 \\
Outras razões & 00 & 00 & 01 \\
\hline
\end{tabular}

$N_{X}=$ número de extrações

\subsection{DISCUSSÃO}

\subsubsection{Metodologia da Pesquisa}

Uma randomização em sítio contendo a escola como a unidade foi utilizada. Tal fato decorreu da pré-existência, em duas das escolas, de equipamentos odontológicos destinados à realização de tratamentos restauradores convencionais. A hipótese desta quasi-randomização ter criado um viés de seleção depende da análise dos resultados obtidos sob a ótica do efeito das variáveis analisadas, tais como status sócioeconômico, prevalência de cárie, idade e tipos de superfície envolvidas.

O estudo epidemiológico realizado no Paranoá, previamente à inserção das crianças no estudo clínico, mostrou não haver diferença estatisticamente significativa entre as crianças inseridas nos três grupos de protocolos terapêuticos no tocante ao seu status sócioeconômico, prevalência de cárie e tipo de superfície envolvida (53). A única diferença observada foi que as crianças inseridas no grupo CRT eram, em 
média, 0,2 anos mais jovens que as dos outros dois grupos de protocolos terapêuticos.

Como a diferença nos escores médios de ceo-d não foi significativa entre as crianças dos três grupos de protocolos terapêuticos, admite-se que essa diferença de idade não foi capaz de influenciar no resultado do estudo. Apesar do processo de randomização padrão não ter sido aplicado, o desenho experimental do estudo apresenta características que tornam improvável a tendência na seleção na alocação dos sujeitos.

Outro aspecto que deve ser discutido atine ao cegamento dos sujeitos do estudo. Dada a natureza dos procedimentos restauradores, dos materiais dentários aplicados, bem como da presença de cavidades abertas, o cegamento dos participantes, operadores e avaliadores do estudo não foi possível, uma vez que os protocolos eram facilmente distinguíveis. O cegamento dos pacientes, por sua vez, foi provavelmente obtido, já que a grande maioria das crianças, mesmo aquelas que estavam alocadas nas escolas com equipamento dental, não apresentava, no momento da implementação dos protocolos terapêuticos, experiência prévia em atendimento odontológico. Por fim, a análise estatística também não atingiu o total cegamento, já que seis crianças do grupo UCT receberam tratamento tanto por restauração quanto por controle do biofilme com escovação supervisionada com creme dental fluoretado. Apesar da recomendação em se atingir o cegamento em todos o quatro aspectos, a natureza do estudo clínico não permitiu alcançá-lo, sendo presumida a necessidade de um teste de consistência inter-examinador, operador, avaliador e estatístico. Levando tais aspectos em consideração, o melhor nível de cegamento dos sujeitos foi alcançado.

Ademais, afim de garantir a alta qualidade na coleta de dados, os avaliadores foram os mesmos durante todo o período de estudo e foram calibrados antes de cada um dos intervalos de tempo de avaliação. Como a ausência de um dente é facilmente identificável por um odontopediatra e a sintomatologia do dente, quando presente, foi relatada para o dentista responsável pelo estudo durante os períodos de avaliação, a totalidade absoluta da determinação do número de dentes extraídos e aqueles naturalmente esfoliados pode ser considerada altamente confiável (77).

Quanto à implementação dos protocolos terapêuticos, a não utilização de raios-X e de isolamento absoluto merecem ser discutidas. Em muitos países, o uso do lençol de borracha para realização de restaurações de amálgama é obrigatório, 
enquanto em outros, não. Estudos demonstram que o seu uso frente ao de roletes de algodão (isolamento relativo) para a restauração de dentes decíduos e permanentes não produziu resultados estatisticamente diferentes para o comportamento clínico e para a longevidade das restaurações $(78,79)$. Além disso, já foi levantada a hipótese de que a ausência do isolamento absoluto poderia levar a uma maior inflamação pulpar, criando um viés técnico, à medida que um maior número de extrações poderia ser realizado nos dentes isolados relativamente. Contudo, não foram verificadas diferenças estatisticamente significativas na inflamação pulpar entre restaurações realizadas sob isolamento relativo ou absoluto (80).

Outro aspecto que merece atenção refere-se à ausência de raios- $X$ como ferramenta complementar de diagnóstico de cárie. Tal como descrito no diagrama de fluxo, a exclusão de dentes devido ao envolvimento pulpar baseou-se tanto na avaliação clínica como no procedimento clínico do protocolo terapêutico, uma vez que, por se tratar de um ambiente escolar, tal equipamento não se encontrava disponível e seu uso seria questionável ante as especificidades técnicas exigidas para tal. Associado a isso, no Brasil, a maioria dos centros de saúde pública é desprovida dos referidos equipamentos, o que pode se repetir em outros países em desenvolvimento nos quais o protocolo UCT serviria como opção terapêutica. Ao considerar toda esta argumentação, infere-se que nenhum viés técnico tenha influenciado a taxa de sobrevida dos dentes no presente estudo.

Comparativamente a outros estudos de longo prazo com crianças, após o período de 3,5 anos, a percentagem de perda de acompanhamento foi baixa $12,2 \%$ - e cumpre os critérios de qualidade elegíveis para inclusão em publicações do tipo revisão sistemática - 30\% (81). Os valores ausentes foram contabilizados por meio de um método de imputação aplicado, na maioria dos casos, de forma direta. Estes dois aspectos permitiram uma estimativa mais precisa das taxas de sobrevida dos dentes inseridos no estudo.

A extração de molares decíduos por um dentista externo ao estudo foi considerada uma observação censurada, uma vez que a razão para tanto não pôde ser determinada, e poderia ser diversa aos critérios utilizados para extração no presente estudo. Esta situação foi particularmente aplicável aos molares decíduos com cavidades abertas pertencentes ao grupo UCT e àqueles com falhas (quebras 
ou perdas do material restaurador) nas restaurações pertencentes aos grupos CRT e ART (63).

Uma vez ter tido agrupamento de duas escolas, um modelo de efeitos mistos, que é geralmente utilizado em estudos randomizados por agrupamentos em sítios, não é adequado. Por isso, a análise estatística conduzida considerou a dependência de dados dentro de uma mesma criança e somente o modelo de riscos proporcionais com fragilidade foi usado para correções para crianças.

\subsubsection{Resultados das avaliações}

O estudo mostrou que o manejo de lesões de cárie cavitadas em dentina em molares decíduos de acordo com o protocolo UCT (restaurando-se cavidades pequenas com ART e promovendo a limpeza regular de cavidades médias e grandes) é tão eficaz na manutenção destes dentes quanto à restauração destas cavidades de acordo com os protocolos CRT e ART. O estudo também mostrou que não houve diferença na sobrevida cumulativa dos dentes tratados de acordo com os protocolos CRT e ART.

Neste estudo, a extração dos dentes foi a variável avaliada. O número de extrações obtido por grupo de protocolo terapêutico foi influenciado pela exclusão dos dentes cavitados durante a implementação do tratamento, em particular, durante a escavação da dentina. Nos grupos de protocolos CRT e ART essa exclusão foi facilitada, uma vez que os operadores realizavam ativamente a remoção do tecido cariado. No grupo UCT, a avaliação de um possível envolvimento pulpar da cavidade foi mais difícil, já que nenhum tipo de remoção de tecido cariado ocorreu. Esse fato pode ser uma razão para o maior número de dentes extraídos no grupo UCT, sendo inclusive suportado pela proporção de dentes excluídos do estudo durante a sessão de tratamento, que foi muito mais elevada nos grupos CRT e ART. Os motivos para as extrações também variaram conforme o grupo de tratamento. $A$ presença de fístula foi a principal causa nos grupos ART e UCT, enquanto a exposição pulpar e a dor de dente foram as mais prevalentes nos dentes tratados de acordo com o protocolo CRT.

Este, até onde se tem conhecimento, é o primeiro estudo a investigar a eficácia de um protocolo terapêutico que consiste em uma combinação de restauração e limpeza de molares decíduos cavitados em dentina em uma análise 
longitudinal, o que torna a comparação com outros estudos difícil. Entretanto, uma investigação relacionada ao escopo do presente estudo foi feita em uma floresta no Suriname, em uma população de crianças com idade média de 6,1 nos, com grupos de protocolos: CRT, ART, extração e ausência de tratamento (82). Esse estudo utilizou variáveis diferentes das utilizadas neste estudo, sendo que os resultados obtidos diferem no seguinte aspecto: no estudo do Suriname, uma maior proporção de dentes com envolvimento pulpar foi observada no grupo sem tratamento do que no grupo CRT, sendo a ausência de controle do biofilme dental um possível responsável por isso. Os autores concluíram que o protocolo CRT deveria ser a estratégia escolhida para aplicação em um programa de saúde bucal para estas crianças, com extração de dentes com envolvimento pulpar como a segunda melhor estratégia (82).

Apenas alguns estudos retrospectivos sobre este tema estão disponíveis. No presente estudo, a taxa de sobrevida dos molares decíduos tratados com 0 protocolo UCT foi de $89,7 \%$ após 2 anos da implementação; taxa esta maior que os $82 \%$ relatados por Levine et al (50) no mesmo intervalo de avaliação, em que os dentes não restaurados foram manejados apenas pelo aconselhamento dietético e reforço de escovação dental em um ambiente de prática odontológica privada. Em outro relato, uma taxa de esfoliação de $82 \%$ foi descrita para molares decíduos atendidos no serviço público de saúde, não sendo abordado o período de sobrevida (39). As diferenças nos resultados entre tais pesquisas e o presente estudo podem ser atribuídas, muito provavelmente, à restauração das pequenas cavidades do grupo UCT e à escovação supervisionada durante o período letivo das cavidades abertas.

Os resultados desses estudos corroboram as reflexões expressas por Kidd, 2012 (43), segundo as quais a progressão das lesões de cárie pode ser controlada pela limpeza cuidadosa de cavidades abertas até a esfoliação natural dos dentes. As vantagens desta abordagem incluem o baixo nível de dor e ansiedade experimentados durante a intervenção clínica, bem como a oportunidade para se aumentar o acesso à saúde bucal em áreas carentes, a um baixo custo (57).

O protocolo UCT foi conduzido em crianças com idade entre 6 e 7 anos que tinham, em média, 4 a 5 anos a percorrer antes que todos os dentes decíduos fossem substituídos. Pode-se argumentar que se o tratamento tivesse sido implementado anteriormente, o número de extrações poderia ser mais baixo, já que 
a cárie dentária é uma doença diretamente relacionada à idade. Contudo, a intervenção por meio do UCT em uma idade menor, inclusive a limpeza das cavidades abertas, poderia revelar-se uma tarefa de difícil implementação.

O desempenho do protocolo UCT foi, em grande parte, atribuído à supervisão da escovação por um assistente treinado durante o período letivo, de aproximadamente 220 dias por ano. Diante disso, um questionamento surge: será este regime de supervisão realista? Para isso, novos estudos devem ser conduzidos a fim de avaliar a eficácia do protocolo UCT em crianças com menos de 6 anos de idade e também a de um regime de supervisão com base, por exemplo, na diminuição das visitas escolares, associado a um incremento em atendimento odontológico domiciliar (83). Isso poderia ser acompanhado pela aplicação de verniz de flúor ou, ainda, de uma fina camada de cimento de ionômero de vidro sobre as cavidades profundas (84).

Demonstra-se difícil supor quanto os resultados do presente estudo podem ser generalizados para outras populações de crianças, uma vez que a validação externa requer uma análise mais detalhada, na qual o conhecimento prévio, as considerações estatísticas, a plausibilidade biológica e os critérios de elegibilidade são todos relevantes (85). Considerando ser este o primeiro estudo de avaliação da eficácia do protocolo UCT, esta questão só pode ser respondida a partir de resultados obtidos em populações similares submetidas à aplicação de uma metodologia semelhante.

\subsection{CONCLUSÃO}

Não houve diferença nas taxas de sobrevida de molares decíduos tratados de acordo com os protocolos CRT, ART e UCT após o período de 3,5 anos. Considerando que o tratamento restaurador convencional nem sempre é possível de ser implementado em áreas carentes, abordagens alternativas adequadas devem ser utilizadas com o objetivo de diminuir o fardo que as lesões de cárie cavitadas em dentina na dentição decídua representam para a saúde pública.

O protocolo de tratamento ultraconservador testado no presente estudo pode tornar-se uma nova opção, adicionalmente à abordagem ART, a manter dentes decíduos cavitados de maneira assintomática até o momento da esfoliação. Para 
tanto, mais pesquisas sobre a aplicação do UCT e seus impactos clínicos e biológicos se fazem necessárias. 


\section{ESTUDO 2 - TAXAS DE ESFOLIAÇÃO}

\section{Taxas de esfoliação de molares decíduos submetidos a três diferentes protocolos terapêuticos no manejo da cárie dentária após o período de 3,5 anos}

Tal análise encontra-se publicada sob a seguinte referência (Apêndice B):

Mijan MC, de Amorim RG, Mulder J, Frencken JE, Leal SC: Exfoliation rates of primary molars submitted to three treatment protocols after 3.5 years. Community Dent Oral Epidemiol. 2015, Jun;43(3):232-9.

\subsection{INTRODUÇÃO}

Dados coletados pela Organização Mundial da Saúde (OMS) mostraram que a grande maioria das lesões de cárie cavitadas em dentina na dentição decídua de crianças com 5 anos de idade não foram restauradas (1). Este estado reflete, em parte, a incapacidade do tratamento convencional - por meio de instrumentos rotatórios e restaurações de cavidades - de controlar a doença cárie.

Há cerca de uma década, dois estudos retrospectivos relataram o caminho de dentes decíduos com lesões de cárie cavitadas em dentina até esfoliação, em que cerca de $82 \%$ esfoliavam sem sintomas $(39,50)$. Tais achados são apoiados por outro estudo prospectivo, recentemente publicado, que relatou o curso natural da dentição decídua com cavitação em dentina em crianças com média de 8 anos de idade (86). Após 3,5 anos, apenas 7\% desses dentes foram restaurados, e dos 93\% dos dentes com cavidades abertas, $81,5 \%$ deles esfoliaram sem sintomas.

Tendo em vista os bilhões de dentes decíduos com lesões de cárie cavitadas em dentina presentes na população infantil em todo o mundo, os estudos acima mencionados alimentam a corrente de pensamento de que nem todas as lesões de cárie cavitadas precisam ser restauradas e, caso isso seja necessário, tal tratamento 
não necessariamente deva ser realizado seguindo uma abordagem restauradora tradicional (43).

Protocolos restauradores alternativos têm sido sugeridos. Um deles é o tratamento restaurador atraumático (ART) (66), que tem sido associado a uma abordagem de maior aceitação entre crianças (33) e produz resultados restauradores similares ao longo do tempo, se comparado aos tratamentos convencionais com utilização de amálgama $(71,87)$ nas dentições decídua e permanente, bem como com a utilização de resina composta na dentição decídua (72). Contudo, mesmo com o emprego dessa alternativa, a grande maioria dos dentes decíduos com lesões de cárie cavitadas em dentina pode não ser plenamente atendida. Outros estudos sugeriram alternativas como o selamento de lesões de cárie com coroas de aço inoxidável pré-fabricadas (88) ou, ainda, o alargamento das cavidades para permitir a sua limpeza em conjunto com aplicação de verniz de flúor ou de um forramento com cimento de ionômero de vidro (84); entretanto, as evidências de tais alternativas ainda são fracas.

A última alternativa para garantir a esfoliação assintomática de dentes decíduos com lesões de cárie cavitadas em dentina refere-se a uma abordagem que combina tratamentos restauradores de pequenas cavidades, por meio da técnica ART e da remoção diária do biofilme dental por escovação supervisionada com creme dental fluoretado de cavidades médias e grandes. Este protocolo é chamado tratamento ultraconservador (UCT) $(59,89)$ e, comparado ao tratamento restaurador convencional com emprego de amálgama (CRT) e ao ART, mostrou-se um protocolo efetivo no tratamento de molares decíduos, sem causar sintomas ao longo de um período de 3,5 anos (89).

No entanto, ainda não se sabe se os dentes decíduos tratados pelo protocolo UCT esfoliam mais cedo que aqueles tratados de acordo com o CRT e o ART, justificando-se, assim, uma análise secundária ao estudo citado (89).

No presente estudo, a hipótese testada foi de que as taxas de esfoliação de molares decíduos tratados de acordo com o protocolo UCT não são diferentes daqueles dentes tratados de acordo com os protocolos CRT e ART ao longo de um período de 3,5 anos. 


\subsection{METODOLOGIA}

\subsubsection{Implementação dos protocolos terapêuticos}

A amostra de sujeitos foi obtida por meio de um levantamento epidemiológico de saúde bucal de crianças de 6 e 7 anos de idade que frequentavam escolas públicas de ensino fundamental no Paranoá-DF, onde foram avaliadas 302 crianças.

Em 2009, iniciou-se o ensaio clínico controlado, quasi-randomizado, nas Escolas Classe 1, 2, 3, 4, 5 e CAIC, as quais foram consideradas sítios de alocação dos indivíduos. Para a inserção no estudo, a criança deveria satisfazer critérios de: i) bom estado de saúde geral; e ii) ao menos duas lesões de cárie cavitadas em dentina em ao menos dois molares decíduos.

Dos dentes originalmente avaliados no estudo epidemiológico, 391 foram tratados conforme o protocolo terapêutico CRT, 277 dentes conforme o protocolo terapêutico ART e 315 de acordo com o protocolo terapêutico UCT. Tais protocolos foram implementados conforme descrito previamente nesta tese e também relatado por de Amorim, 2012 e 2014 (61).

Em síntese, no grupo CRT, as cavidades de cárie cavitadas em dentina foram preparadas com instrumentos rotatórios e restauradas com amálgama; no grupo ART, as cavidades de cárie em dentina foram acessadas e preparadas somente com instrumentos manuais, sendo restauradas com cimento de ionômero de vidro de alta viscosidade (CIV-AV) e; no grupo UCT, as cavidades classificadas como pequenas foram tratadas de acordo com o protocolo ART, enquanto as cavidades médias e grandes não foram restauradas, mas sim ampliadas com um instrumento específico para facilitar a remoção do biofilme, que foi realizada de forma diária - em dias letivos - e supervisionada, com uso de escova de dentes e creme dental fluoretado (1100 ppm).

\subsubsection{Avaliação da taxa de esfoliação dos dentes}

A avaliação da esfoliação dos dentes inseridos no estudo foi conduzida por dois avaliadores independentes e calibrados, nos tempos de 6 meses, 1, 2, 3 e 3,5 anos após a implementação dos protocolos terapêuticos. Os dentes foram avaliados de acordo com o código PUFA, que inclui as seguintes alterações clínicas: envolvimento pulpar $(P)$; ulceração $(U)$; fístula $(F)$ ou abscesso $(A)$ em função de 
cárie e/ou de tratamentos implementados (20). As crianças também foram questionadas sobre ter ou ter tido dor de dente e o porquê de um dente não estar mais presente - se foi extraído ou esfoliou.

\subsubsection{Análise estatística}

Um cálculo de representatividade do estudo de sobrevida dos dentes indicou a necessidade de uma amostra de 97 crianças ou 239 dentes por grupo de protocolo de tratamento após um período de 3,5 anos (53). Todos os dados coletados foram inseridos em um programa especialmente concebido para o estudo. Dados referentes a sete elementos dentários encontravam-se ausentes, dentre os quais cinco foram imputados por não haver nenhum erro ou presença de um momento distinto da falha, ou por ser uma observação censurada. Para os outros dois dados remanescentes, o momento da falha não pôde ser determinado e foi tomada uma decisão para alocar essas duas observações alternadamente para "ter sobrevivido" e "ter falhado".

As análises foram realizadas seguindo uma abordagem por protocolo, por um bioestatístico experiente, usando o software SAS, versão 9.2 (SAS, Cary, NC, EUA). A variável dependente foi a taxa de esfoliação dos molares decíduos tratados pelos três protocolos de tratamento (CRT, ART e UCT) até sua esfoliação. As variáveis independentes foram a idade no início do estudo (6-7 anos), o sexo, o escore médio do ceo-d obtido no início do estudo (baseline), o tipo de superfície (única ou múltipla), o operador, e o tipo de molar (primeiro ou segundo).

As razões para extração dos dentes inseridos no estudo foram: presença de dor, sepsemia (fístula ou abscesso) ou exposição pulpar. Foram consideradas observações censuradas os casos em que os dentes foram extraídos pela presença de uma das razões mencionadas, os dentes que foram extraídos por outros dentistas e, ainda, aqueles dentes ainda presentes (não esfoliados).

Um modelo de regressão da taxa de risco proporcional (74) com correção de fragilidade (75) foi utilizado para calcular as taxas de sobrevida cumulativa dos dentes esfoliados e também para analisar o efeito das variáveis independentes sobre a variável dependente ao longo do período de 3,5 anos. Um mesmo dente que apresentava cavidade em dentina com envolvimento de única e de múltipla superfície foi considerado como tendo uma cavidade de múltipla superfície; por sua 
vez, um dente que apresentava mais de uma cavidade com envolvimento de única superfície foi considerado como de única superfície.

O teste de Wald foi usado para as diferenças nas taxas de sobrevida cumulativas dos dentes esfoliados no período de 3,5 anos e também para os efeitos das variáveis independentes. O método Jackknife foi utilizado para a correção de dependência de dentes tratados na mesma criança. Em seguida, o teste-t foi usado para se calcular as diferenças nas taxas de sobrevida nos intervalos de avaliações (76). Considerou-se estatisticamente significativo um valor de coeficiente $\alpha=0,05$.

\subsection{RESULTADOS}

\subsubsection{Disposição dos sujeitos}

Um diagrama de fluxo do estudo é apresentado na Figura 6. A amostra consistiu em 302 crianças. As variáveis independentes por grupos de protocolos de tratamento estão apresentadas na Tabela 6.

O grupo UCT consistiu de 109 dentes tratados com ART, 166 dentes em que a cavidade foi limpa por escovação com creme dental fluoretado e seis dentes que continham tanto uma restauração ART quanto uma cavidade limpa por escovação com creme dental fluoretado. No início do estudo, não houve efeito de gênero $(p=0,71)$ e do escore médio do ceo-d $(p=0,75)$. No entanto, um efeito de tipo de superfície $(p=0,03)$ e de idade $(p<0,0001)$ entre as crianças dos diferentes grupos de protocolos terapêuticos foi observado. As crianças inseridas no grupo CRT eram, em média, 0,2 anos mais jovens que aquelas inseridas nos grupos ART e UCT e, apresentavam, proporcionalmente, um menor número de molares com envolvimento de múltiplas superfícies.

A taxa de perda das crianças do estudo no período de acompanhamento de 3,5 anos foi de $52 \%$. Contudo, a ausência real foi de $12,2 \%$, uma vez $39,7 \%$ das crianças estavam presentes, mas possuíam seus dentes extraídos e/ou esfoliados. A taxa dos não respondentes não revelou efeito de idade $(p=0,28)$, gênero $(p=$ $0,29)$ ou escore médio do ceo-d no estudo inicial (original) $(p=0,70)$. 

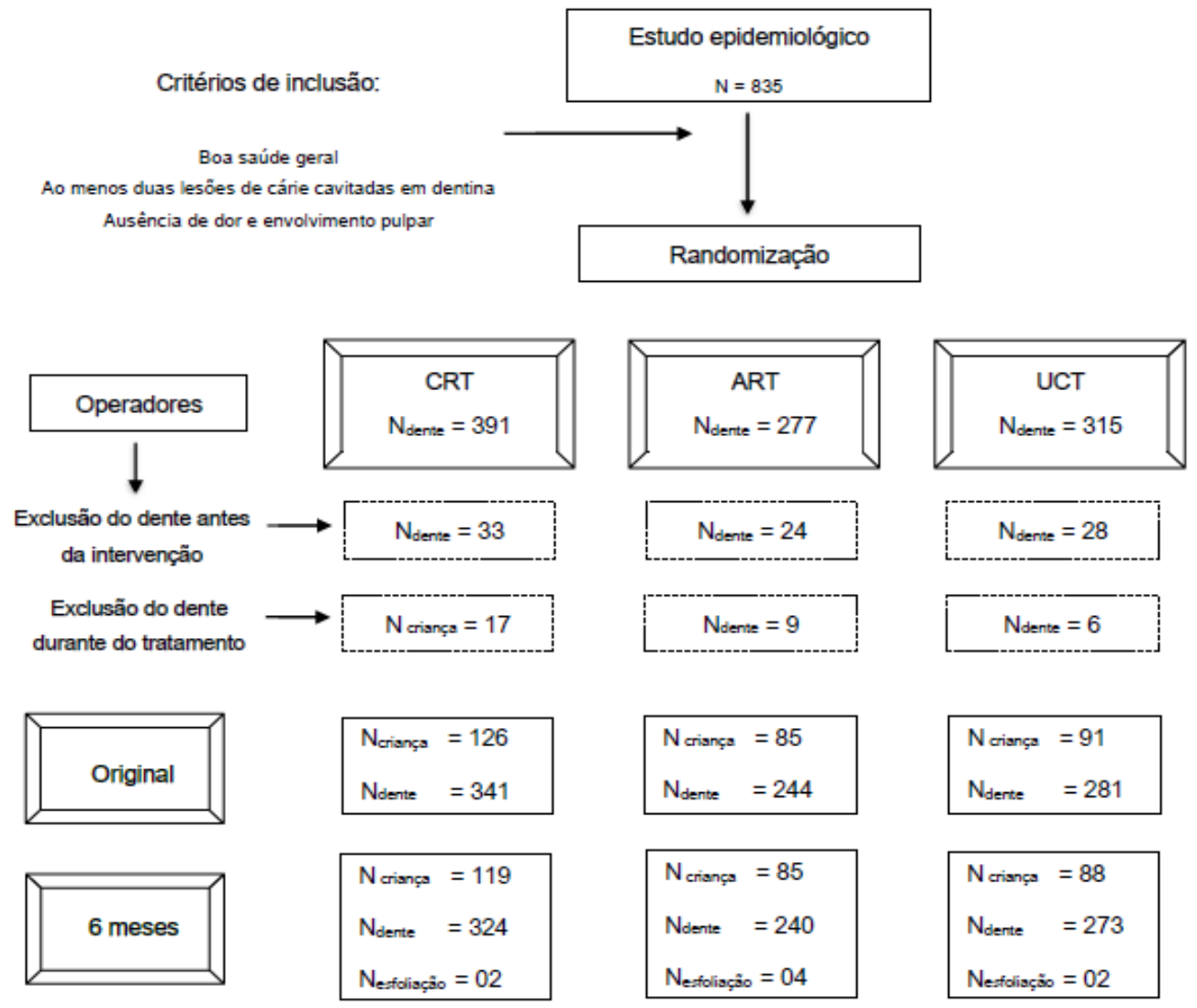

\begin{tabular}{|l}
$N_{\text {crisnça }}=88$ \\
$N_{\text {dente }}=273$ \\
$N_{\text {esfoliação }}=02$
\end{tabular}
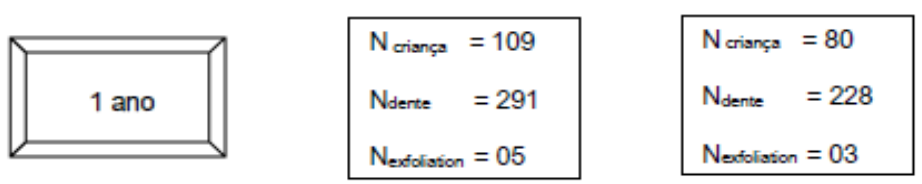

$N_{\text {criança }}=83$
$N_{\text {derte }}=251$
$N_{\text {exóliation }}=09$
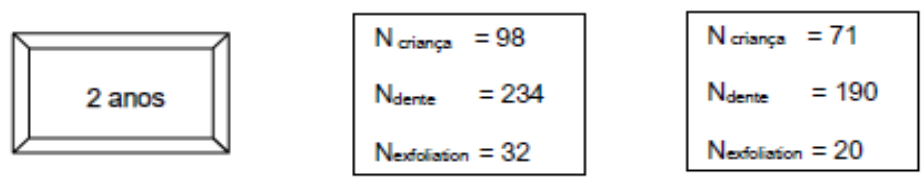

$N_{\text {criança }}=77$
$N_{\text {derte }}=197$
$N_{\text {exiolation }}=28$
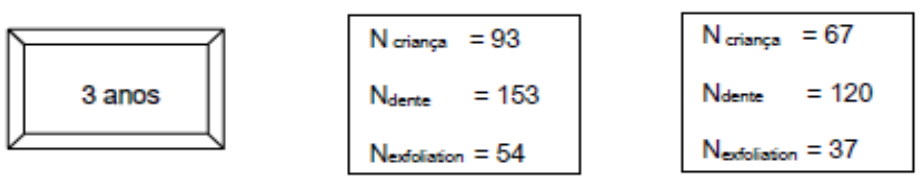

$N_{\text {driança }}=53$
$N_{\text {derte }}=48$
Nexólation $=19$

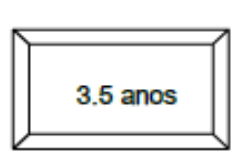

$$
\begin{aligned}
& N_{\text {criança }}=64 \\
& N_{\text {derte }}=88 \\
& \text { Nexiolation }=26
\end{aligned}
$$

$\mathrm{N}_{\text {criança }}=49$
$\mathrm{~N}_{\text {dente }}=68$
$\mathrm{~N}_{\text {exdolation }}=21$

$N_{\text {criança }}=32$
Nderte $=38$
$N_{\text {exólation }}=6$

Figura 6 Diagrama de fluxo com a síntese dos resultados das avaliações clínicas da esfoliação dos dentes no período de 3,5 anos. CRT = Tratamento Restaurador Conservador; ART = Tratamento Restaurador Atraumático; UCT = Tratamento Ultraconservador; N = número; 
Tabela 6 - Variáveis avaliadas no início do estudo (original) nas crianças inseridas nos diferentes protocolos terapêuticos do estudo clínico

$\begin{array}{lll}\text { CRT } & \text { ART } & \text { UCT }\end{array}$

Idade média \pm SD

$6,7 \pm 0,4$

$6,9 \pm 0,4$

$6,9 \pm 0,4$

Gênero

$\mathrm{N}$ meninos

$\mathrm{N}$ meninas

Média do escore ceo \pm SD

Tipo de superfície

$\mathrm{N}$ superfície única

$\mathrm{N}$ superfícies múltiplas
67

59

$5,8 \pm 3,2$

103

238
49

36

$5,8 \pm 2,7$

$5,5 \pm 2,6$
47

44

62

219

CRT = Tratamento Restaurador Conservador; ART = Tratamento Restaurador Atraumático; UCT = Tratamento Ultraconservador; $\mathrm{N}=$ número; $\mathrm{SD}$ = desvio padrão

\subsubsection{Padrão de esfoliação de molares decíduos por grupo de protocolo terapêutico}

A Tabela 7 mostra as taxas de esfoliação dos molares decíduos, por grupo de protocolo terapêutico, por intervalo de avaliação e seus respectivos erros padrão. 0 teste de Wald revelou não haver diferença estatisticamente significativa nas taxas de esfoliação para todos os molares decíduos por grupo de protocolo terapêutico no período de 3,5 anos $(p=0,37)$. Neste período, $51,6 \%$ de todos os dentes do grupo CRT havia esfoliado, enquanto esfoliaram, no mesmo período, $49,6 \%$ dos dentes do grupo ART e $48 \%$ dos dentes do grupo UCT. Apesar de não haver diferença no período total do estudo, de 3,5 anos, foram observadas diferenças nas taxas de esfoliação entre os grupos de tratamento nos intervalos de avaliações. 
Tabela 7 - Taxa cumulativa de esfoliação de todos os molares decíduos (\%) e erro padrão Jackniffe (EP) por grupo de protocolo terapêutico e intervalo de tempo (IP)

\begin{tabular}{|c|c|c|c|c|c|c|c|c|c|c|c|c|}
\hline & \multicolumn{4}{|c|}{ CRT } & \multicolumn{4}{|c|}{ ART } & \multicolumn{4}{|c|}{ UCT } \\
\hline IP (anos) & $\mathrm{N}$ & $\mathrm{N}_{\mathrm{X}}$ & $\%$ & $\mathrm{EP}$ & $\mathrm{N}$ & $\mathrm{N}_{\mathrm{X}}$ & $\%$ & EP & $\mathrm{N}$ & $\mathrm{N}_{\mathrm{X}}$ & $\%$ & $\mathrm{EP}$ \\
\hline $0,0-0,5$ & 324 & 02 & 0,0 & 0,0 & 240 & 04 & 1,6 & 1,0 & 273 & 02 & 0,7 & 0,5 \\
\hline $0,5-1,0$ & 291 & 07 & 2,4 & 1,1 & 228 & 07 & 2,9 & 1,5 & 251 & 11 & 4,3 & 1,7 \\
\hline $1,0-2,0$ & 234 & 39 & 14,5 & 2,9 & 190 & 27 & 12,6 & 2,7 & 197 & 39 & 17,5 & 3,5 \\
\hline $2,0-3,0$ & 153 & 93 & 36,8 & 4,1 & 120 & 64 & 33,6 & 4,8 & 48 & 58 & 40,2 & 6,3 \\
\hline $3,0-3,5$ & 88 & 119 & $51,6^{*}$ & $* 4,1$ & 68 & 85 & 49,6 & 6,0 & 38 & 64 & $48,0^{*}$ & 6,6 \\
\hline
\end{tabular}

$\mathrm{N}=$ número de dentes; $\mathrm{N}_{\mathrm{X}}=$ número cumulativa de esfoliações; $\mathrm{CRT}=$ tratamento restaurador convencional; $\mathrm{ART}=$ tratamento restaurador atraumático; UCT $=$ tratamento ultraconservador. * grupos CRT e UCT ( $P=0,04)$.

Para primeiros molares decíduos, observou-se que aqueles pertencentes ao grupo UCT esfoliaram em maior taxa no período de avaliação de 1 ano, com diferença estatisticamente significativa comparativamente aos dentes pertencentes do grupo CRT $(p=0,03)$ (Figura 7A). Por sua vez, para segundos molares decíduos, observou-se que aqueles pertencentes ao grupo UCT apresentavam taxa de esfoliação estatisticamente maior que aqueles pertencentes ao grupo ART no período de 2 anos ( $p=0,009)$ e 3 anos $(p=0,04)$. No período de 3 anos (Figura 7B), também apresentavam taxa de esfoliação estatisticamente maior quando comparados àqueles pertencentes ao grupo CRT $(p=0,04)$. 

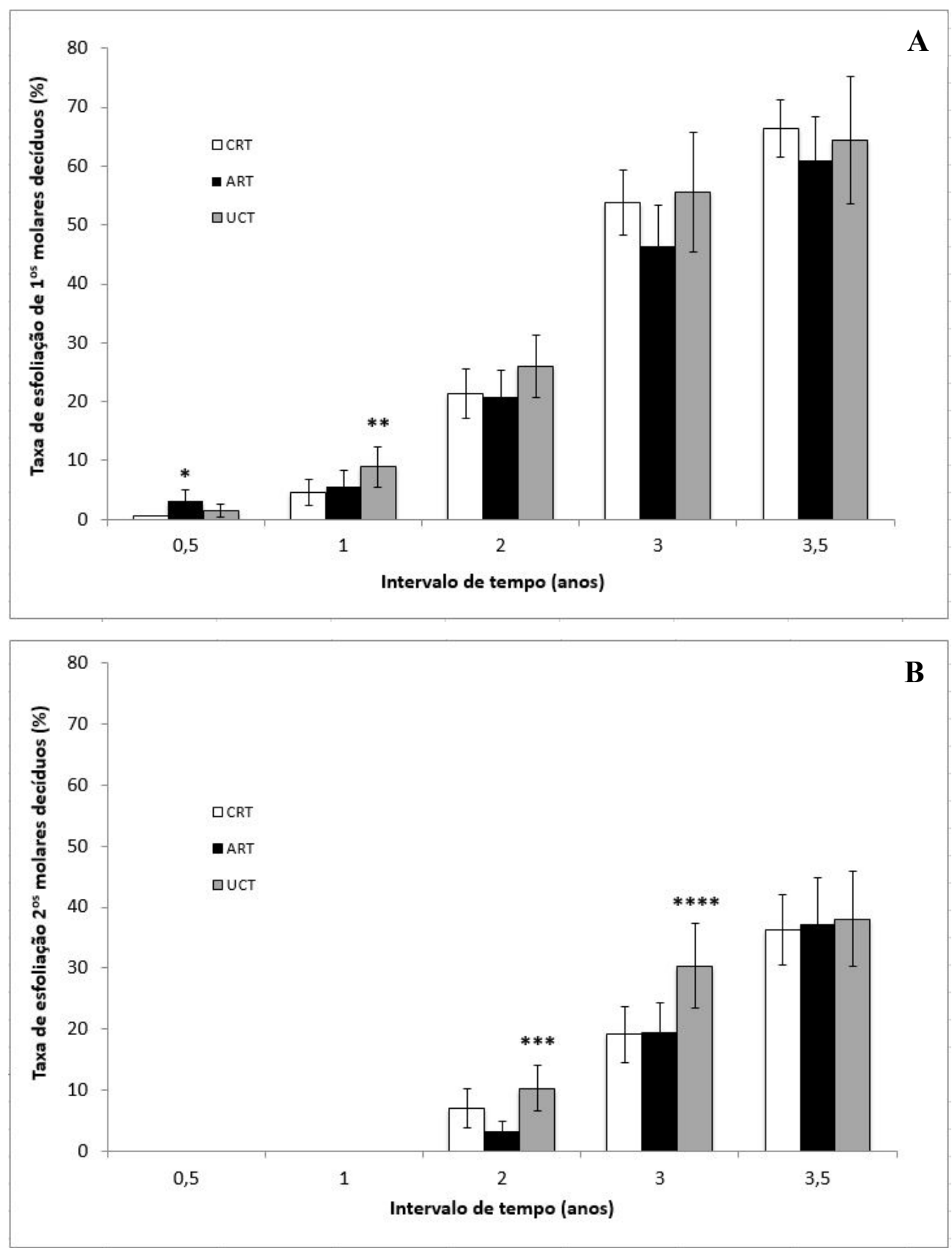

Figura 7 Taxas de esfoliação (\%) e erro padrão Jackknife de (A) primeiros molares decíduos e (B) segundos molares decíduos tratados por grupo de protocolo terapêutico após o período de avaliação de 3,5 anos. " grupos ART e CRT $(P=0,02)$. ${ }^{* *}$ grupos UCT e CRT $(P=0,03) .{ }^{* * *}$ grupo ART e os grupos UCT $(P=0,009)$ e CRT $(P=0,04)$. ${ }^{* * *}$ grupo UCT e os grupos ART $(P=0,04)$ e CRT $(P=$ $0,04)$. 


\subsubsection{Análise dos efeitos das variáveis independentes nas taxas de esfoliação}

Foram observados efeitos da idade $(p<0,0001)$, do sexo $(p=0,02)$, do tipo de molar $(p<0,0001)$ e do tipo de superfície envolvida $(p=0,03$ ) nas taxas de esfoliação dos molares decíduos dos diferentes grupos de protocolos terapêuticos ao longo do período de 3,5 anos.

A idade das crianças do grupo CRT foi, em média, 0,2 anos mais jovem em comparação idade das crianças pertencentes aos grupos ART e UCT. Ademais, constatou-se que os primeiros molares decíduos esfoliaram mais cedo que os segundos molares decíduos e, ainda, de todos os primeiros molares, aqueles com cavidades com envolvimentos de múltiplas superfícies esfoliaram em uma taxa maior que aqueles com envolvimento de uma única superfície. Este achado levou a uma análise adicional sobre o efeito do tipo de superfície sobre as taxas de esfoliação dos molares decíduos entre os três grupos de tratamento.

A Figura 8 mostra as taxas de esfoliação de todos os molares com envolvimento de múltiplas superfícies e seu erro padrão por grupo de protocolo terapêutico e intervalo de avaliação.

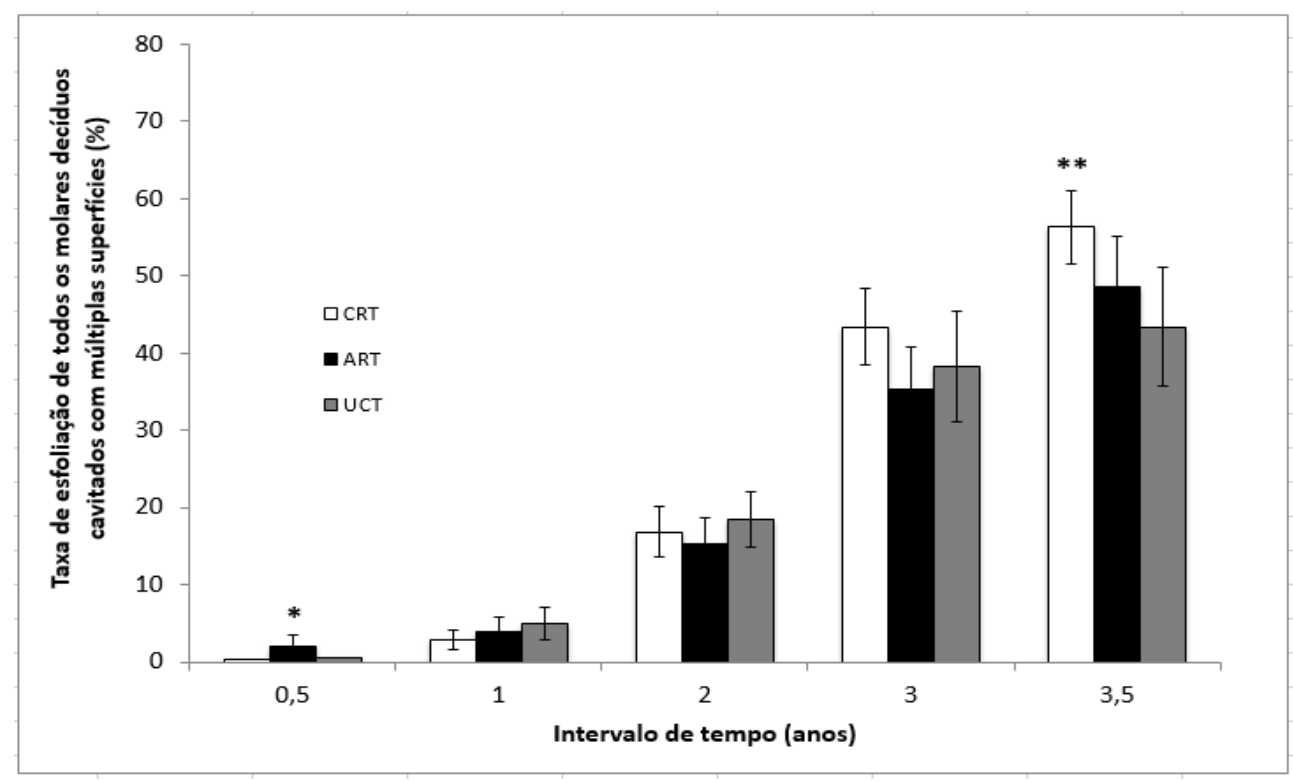

Figura 8 Taxas de esfoliação (\%) e erro padrão Jackknife de molares decíduos cavitados com envolvimento de múltiplas superfícies por grupo de protocolo terapêutico após o período de avaliação de 3,5 anos. *grupo ART e CRT $(p=0,04) e^{* *}$ grupo CRT e UCT $(p=0,04)$.

O teste de Wald não mostrou diferença estatisticamente significativa nas taxas de esfoliação no período total de 3,5 anos ( $p=0,63$ ). Após 3,5 anos, 56,3\% 
dos dentes com envolvimento de múltiplas superfícies haviam esfoliado no grupo CRT, enquanto as taxas observadas nos grupos ART e UCT foram de $48,5 \%$ e de $43,5 \%$, respectivamente. Apesar de não haver diferença no tempo total de acompanhamento, as diferenças na taxa de esfoliação entre os grupos de protocolos terapêuticos foram notadas quando considerados separadamente os intervalos de avaliação. Aqueles dentes pertencentes ao grupo ART esfoliaram em uma taxa significativamente maior do que aqueles do grupo CRT $(p=0,04)$ no intervalo de 0,5 anos, enquanto aqueles do grupo CRT esfoliaram em uma taxa significativamente maior do que aqueles do grupo UCT $(p=0,04)$ no intervalo de 3,5 anos.

\subsection{DISCUSSÃO}

\subsubsection{Metodologia do estudo}

Esta é uma análise secundária, que se baseia no desenho experimental e no processo de randomização que foram utilizados na investigação dos efeitos do protocolo UCT sobre a sobrevida dos molares decíduos em comparação com os dentes dos protocolos CRT e ART, na qual se concluiu sobre o improvável efeito de um viés de seleção sobre os resultados obtidos (89).

O cegamento dos operadores e dos avaliadores não pôde ser obtido, dada a fácil distinção dos materiais dentários usados e da presença de cavidades abertas. Tampouco houve o cegamento do estatístico, que havia realizado a análise primária. Por sua vez, o cegamento dos pacientes foi, muito provavelmente, obtido (89). Portanto, considerando a natureza do estudo e da análise secundária aqui relatada, o melhor nível de cegamento foi alcançado (77).

O percentual de perda de acompanhamento das crianças ao longo do período de 3,5 anos foi baixo e os valores faltantes foram contabilizados pela utilização de um processo de imputação aplicado de forma direta. Estes dois aspectos forneceram a estimativa mais precisa da taxa de esfoliação dos dentes inseridos no estudo. A análise estatística também teve o cuidado de observar a dependência de dados numa mesma criança - uma vez que um modelo de efeitos mistos, que é geralmente utilizado em estudos randomizados por agrupamentos em sítios, não foi considerado adequado. Portanto, somente o modelo de riscos proporcionais com fragilidade foi usado para correções. 
Considerando a natureza do presente estudo, considera-se baixa a existência de qualquer erro sistemático que tenham influenciado os seus resultados. Por conseguinte, a validade interna deste ensaio clínico controlado é considerada alta.

\subsubsection{Resultados das avaliações}

A hipótese testada de que as taxas de esfoliação de molares decíduos tratados de acordo com o protocolo UCT não são diferentes daquelas referentes aos dentes tratados de acordo com os protocolos CRT e ART, considerando o período total de 3,5 anos, não foi rejeitada. Contudo, ao interpretar separadamente o padrão de esfoliação dos molares decíduos em cada intervalo de avaliação, notou-se que os dentes do grupo UCT apresentaram uma taxa de esfoliação mais elevada que os demais. A diferença para os dentes do grupo CRT no período de 1 ano de avaliação para os primeiros molares decíduos e no período de 3 anos para segundos molares decíduos pode ter ocorrido em virtude de as crianças no grupo CRT serem 0,2 anos mais jovens que as do grupo UCT.

Esse motivo pode não ser aplicável para a diferença observada entre as taxas de esfoliação dos grupos UCT e ART. Neste caso, a diferença foi observada apenas para segundos molares decíduos nos períodos de 2 e 3 anos de avaliação. É possível que essa diferença esteja relacionada com o padrão de esfoliação natural desses dentes, levando-se em consideração a idade das crianças (9 e 10 anos de idade). Tal afirmação é suportada pela ausência de um efeito de esfoliação para os grupos de tratamento no intervalo de 3,5 anos, além do fato de, neste período, a maioria dos dentes decíduos ter esfoliado e encontrar-se em processo de substituição pelo dente permanente correspondente (90-92). Por sua vez, a possibilidade de este padrão de esfoliação precoce de dentes tratados com 0 protocolo UCT possuir um efeito no padrão de erupção dos dentes permanentes ainda está sob investigação.

Adicionalmente, o presente estudo mostrou que dentes cavitados com envolvimento de múltiplas superfícies esfoliaram em uma proporção mais elevada em comparação àqueles com envolvimento de única superfície, sendo tal efeito observado independentemente do protocolo terapêutico ao qual foi submetido. Comparando-se os molares decíduos cavitados com envolvimento de múltiplas superfícies por grupos de protocolos terapêuticos, notou-se uma diferença na taxa de esfoliação entre aqueles pertencentes ao grupo UCT quando comparados 
àqueles do grupo CRT no intervalo de 3,5 anos. Isto ocorreu, muito provavelmente, pela diferença de idade das crianças do grupo CRT - 0,2 anos mais jovens -, como mencionado anteriormente. Portanto, não houve diferença significativa no comportamento clínico de esfoliação de molares decíduos entre os dentes restaurados pelos protocolos CRT e ART comparativamente aos dentes com cavidades em dentina mantidas limpas, submetidas ao protocolo UCT.

Apenas alguns estudos têm relatado os padrões de esfoliação e de erupção dentes decíduos e permanentes, restaurados ou não. Conforme relatado por alguns deles, dentes decíduos restaurados sobreviveram significativamente mais do que dentes com cavidades, sem tratamento $(86,93)$, sugerindo que a presença de cavidades abertas na dentição decídua acelera as taxas de esfoliação desses dentes. Além disso, uma análise dos padrões de erupção dos dentes permanentes indicou que a experiência de cárie, independentemente de os dentes decíduos terem sido restaurados ou não, acelerou o processo de erupção dos sucessores (94). A perda precoce de dentes decíduos devido à cárie dentária, especialmente de primeiros molares, tem sido relacionada a problemas de espaço. Nesse sentido, restaurá-los, ao invés de extraí-los, poderia minimizar possíveis efeitos funcionais e de alinhamento da dentição permanente (95).

Estas afirmações induzem ao seguinte questionamento: será que o protocolo de limpeza aplicado nos dentes do grupo UCT poderia trazer diferenças nos efeitos biológicos que têm sido relacionados à perda precoce de dentes decíduos devido a cárie dentária? Tendo em conta os resultados obtidos no presente estudo e os acima relatados, é possível postular a seguinte hipótese: não restaurar lesões de cárie cavitadas em dentina em dentes decíduos, mas permitir que estejam livres da presença do biofilme dental, tal como aplicado pelo protocolo UCT, deve trazer efeitos biológicos semelhantes aos decorrentes da realização de tratamentos restauradores quanto ao acionamento de uma resposta fisiológica e uma consequente esfoliação assintomática desses dentes e não induziria uma perda precoce dos dentes, minimizando os possíveis prejuízos funcionais na dentição permanente. Apesar deste pressuposto, não há nenhuma evidência de tal evento na presente pesquisa e uma análise mais aprofundada sobre as diferenças nos padrões de esfoliação e erupção de dentes decíduos e permanentes deveria ser conduzida, utilizando-se como controles dentes hígidos e com lesões de cárie cavitadas em dentina sem tratamento. 
Ante o exposto, o protocolo terapêutico UCT poderia se tornar uma alternativa adequada à restaurações de dentes decíduos com lesões de cárie cavitadas em dentina, permitindo sua esfoliação assintomática em taxas semelhantes aos tratamentos restauradores. Há que se considerar, contudo, que a validade externa deste estudo, apesar de não ser alta, pode ser considerada adequada para populações que partilhem de características como inacessibilidade ao serviço de saúde bucal e com alta experiência e prevalência de cárie.

\subsection{CONCLUSÃO}

Não houve diferença nas taxas de esfoliação de molares decíduos submetidos aos protocolos de tratamento CRT, ART e UCT após o período de avaliação de 3.5 anos. No entanto, dentes cavitados com envolvimento de múltiplas superfícies esfoliaram em uma proporção mais elevada que aqueles com envolvimento de única superfície, especialmente em se tratando de segundos molares.

Outrossim, o protocolo de tratamento ultraconservador avaliado no presente estudo, associado à abordagem com ART, poderia se tornar uma opção para guiar dentes decíduos com lesões de cárie cavitadas em dentina a um processo de esfoliação assintomática. Para tanto, pesquisas adicionais ainda devem ser conduzidas para a implementação e aplicação do UCT. 


\section{ESTUDO 3 - MICROFRATURAS MARGINAIS}

\section{Avaliação ex vivo de microfraturas marginais de restaurações ART e de amálgama em molares decíduos.}

\subsection{INTRODUÇÃO}

O selamento marginal das restaurações está relacionado à manutenção da saúde pulpar e à longevidade das mesmas. A presença de microfraturas nas margens de uma restauração permite a passagem de bactérias, moléculas e íons na interface dente-material restaurador, o que pode causar descoloração dentária, hipersensibilidade, quebra do material restaurador e, principalmente, ocorrência de danos pulpares e cárie secundária (67-69). Contudo, a relação precisa entre o desempenho clínico dos procedimentos restauradores e a ocorrência de microfraturas nas margens das restaurações ainda é controversa (70).

Restaurações de amálgama convencional são conhecidas por se reter mecanicamente aos tecidos dentários, sendo a presença de infiltração marginal um fator importante para predizer a ocorrência de cárie secundária. Em contrapartida, restaurações que empregam cimentos de ionômero de vidro (CIV), como as realizadas por meio da técnica do Tratamento Restaurador Atraumático (ART), se aderem quimicamente aos tecidos dentários, sendo esta a possível razão para a baixa prevalência de cárie secundária associada a restaurações de ionômero de vidro (96). Entretanto, apesar dessa adesão físico-química e da melhora nas propriedades dos cimentos de ionômero de vidro observada nas últimas décadas, ainda é possível notar uma taxa considerável de falha de restaurações ART de múltiplas superfícies, sendo importante avaliar se o sucesso clínico dessas restaurações está associado ou não à presença de microinfiltrações marginais, comparando-as a tratamentos convencionais.

Inúmeras metodologias têm sido empregadas para avaliação do selamento marginal de restaurações, sendo a penetração de corantes e marcadores químicos uma das mais difundidas, por permitir a sua detecção em contraste aos tecidos dentários e aos materiais restauradores empregados sem a necessidade de uso de 
materiais radioativos $(67,97)$. Dentre a variedade de materiais propostos na literatura, destaca-se a solução de nitrato de prata a 50\%, cuja infiltração dos íons de prata, de aproximadamente 0,059 nm de diâmetro, mimetiza, ainda que de uma forma mais severa, a infiltração de bactérias, cujos diâmetros variam entre 0,5 a 1,0 $\mu \mathrm{m}$ (97). Adicionalmente, a microscopia eletrônica de varredura (MEV) também tem sido aplicada na análise da presença de microfendas entre as margens das restaurações e os tecidos dentários, apresentando como vantagens a alta resolução e a possibilidade de análise de composição química quando acoplada à ferramente de EDS, morfológica e topográfica tridimensional, em muitos casos de forma nãodestrutiva (98).

A maioria dos estudos in vitro que avaliam o selamento marginal de restaurações compreendem duas categorias principais: os que reproduzem, em laboratório, o ambiente oral e aqueles que meramente testam o material em si. De modo geral, os resultados obtidos por essas metodologias apontam para existência de micro-fraturas na interface dente-restauração; entretanto, ao se avaliar em estudos clínicos a performance dos materiais restauradores, nota-se bom desempenho, o que indica haver uma discrepância entre os achados de estudos laboratoriais e aqueles derivados de ensaios clínicos $(70,99)$.

Considerando a limitação na extrapolação clínica dos resultados obtidos nos estudos in vitro, ensaios clínicos realizados em dentes decíduos deveriam ser vistos como um importante instrumento de investigação, por permitirem avaliações ex vivo, o que resulta em uma análise mais fidedigna entre o desempenho clínico de uma restauração e o estado de integridade marginal da mesma.

Neste contexto, em 2009, um ensaio clínico controlado foi implementado no Paranoá, uma área do Distrito Federal, Brasil, a fim de se comparar três diferentes protocolos de tratamento no manejo de lesões de cárie cavitadas em dentina de molares decíduos em crianças entre 6 e 7 anos de idade. Os protocolos aplicados consistiram em: i) tratamento convencional (CRT), em que as cavidades foram preparadas com instrumentos rotatórios e restauradas com amálgama; ii) tratamento restaurador atraumático (ART), em que as cavidades foram limpas por meio de instrumentos manuais e restauradas com cimento de ionômero de vidro de alta viscosidade e; iii) tratamento ultraconservador (UCT), que consistiu em uma combinação da abordagem ART, para restaurar cavidades de pequeno porte, com a remoção diária do biofilme dental com uso de escova de dentes e creme dental nas 
cavidades de médio e grande portes (89). Por se tratarem de dentes decíduos, cuja esfoliação era esperada, uma análise ex vivo pôde ser conduzida, permitindo a avaliação de características químicas e mecânicas dos materiais aplicados, tal como a presença de microfraturas marginais das restaurações implementadas.

A hipótese nula testada no presente estudo foi de que a taxa de ocorrência de microfraturas marginais em molares decíduos restaurados com cimento de ionômero de vidro de alta viscosidade, inseridos nos grupos ART e UCT, não difere daquela observada em molares decíduos restaurados com amálgama pertencentes ao grupo CRT.

\subsection{METODOLOGIA}

\subsubsection{Implementação dos tratamentos restauradores}

Entre maio e junho de 2009, crianças matriculadas nas seis escolas públicas do Paranoá, Distrito Federal, Brasil, entre 6 e 7 anos de idade foram submetidas, no ambiente escolar, aos protocolos de manejo da cárie dentária, em que os critérios de inclusão foram: i) bom estado de saúde geral; ii) ao menos duas lesões de cárie cavitadas em dentina; e iii) ausência de dor e de envolvimento pulpar nos dentes a serem inseridos no estudo. Três dentistas especialistas em Odontopediatria, treinados para a aplicação dos diferentes protocolos terapêuticos, os implementaram seguindo um procedimento padronizado desenvolvido após um estudo piloto utilizado para treinamento e calibragem dos operadores.

Os procedimentos clínicos realizados foram:

Protocolo de tratamento restaurador convencional (CRT):

O isolamento do dente foi realizado por roletes de algodão e um dispositivo de sucção. As cavidades de cárie em dentina foram preparadas com instrumentos rotatórios e restauradas com amálgama (Kit Permite Regular®, SDI, Melbourne, Austrália).

O preparo cavitário seguiu os princípios de GV Black, sem, entretanto, a "extensão para prevenção". Em cavidades profundas, foi aplicada uma camada de cimento de hidróxido de cálcio $\mathrm{Ca}(\mathrm{OH})_{2}$. Foram utilizadas cunha de madeira e uma banda matriz de aço (Injecta ${ }^{\circledR}$, Diadema, São Paulo, Brasil), em um retentor de matriz Tofflemire (Golgran $®$, São Paulo, Brasil). 


\section{Protocolo de tratamento restaurador atraumático (ART):}

$\mathrm{O}$ isolamento do dente foi realizado por roletes de algodão. As cavidades de cárie em dentina foram acessadas e preparadas somente com instrumentos manuais (ART Kit ${ }^{\circ}$; Henry Schein, Chicago, EUA) e restauradas utilizando cimento de ionômero de vidro de alta viscosidade (Ketac Molar EasyMix $\AA$, 3M ESPE, Seefeld, Alemanha). Em cavidades profundas, foi aplicada uma camada de cimento de hidróxido de cálcio $\mathrm{Ca}(\mathrm{OH})_{2}$. Foram utilizadas cunha de madeira e uma banda matriz de aço (Injecta ${ }^{\circledR}$, Diadema, São Paulo, Brasil), em um retentor de matriz Tofflemire (Golgran ®, São Paulo, Brasil).

Depois de limpa, a cavidade foi condicionada durante 10 segundos com uma bolinha de algodão molhada com o líquido diluído do ionômero de vidro, lavada durante cinco segundos com uma bolinha de algodão molhada com água, e seca durante cinco segundos com uma bolinha de algodão seca. A assistente, previamente treinada, realizou a manipulação do ionômero de vidro em uma placa de vidro com uma espátula de metal, de acordo com as instruções do fabricante. A mistura foi inserida na cavidade em incrementos, utilizando-se um instrumento aplicador/entalhador (ART Kit $\AA$ ). As cavidades foram completamente preenchidas e, em seguida, o material foi pressionado para baixo por pressão digital com o dedo enluvado e vaselinado. A mordida foi verificada e o excesso de material foi removido com aplicador/escultor (ART Kit $®$ ). A restauração foi protegida com vaselina e a criança foi orientada a não ingerir alimentos por pelo menos uma hora.

\section{Protocolo do tratamento Ultraconservador (UCT):}

As cavidades pequenas de cárie em dentina foram tratadas de acordo com o protocolo ART.

As cavidades médias e grandes de cárie em dentina não foram restauradas, mas sim ampliadas, se necessário, com um instrumento manual específico (Henry Schein $\AA$ ), para facilitar a remoção do biofilme com uma escova de dentes e creme dental fluoretado (1100 ppm).

Durante todo o período do estudo, uma assistente odontológica treinada supervisionou a escovação diária no período letivo - aproximadamente 200 dias por ano. As crianças foram aconselhadas a limpar os dentes durante as férias, bem como durante os períodos de recessos escolares, da mesma forma. 


\subsubsection{Coleta e armazenamento dos dentes}

Ao longo do ensaio clínico, que perdurou por 3,5 anos, as crianças foram monitoradas no que se refere ao processo de esfoliação dos dentes tratados, com o objetivo de coletá-los com a permissão de seus pais.

Ao final do período, um total de 50 dentes foi coletado. Destes, 19 pertenciam ao grupo CRT, 18 ao grupo ART e 13 ao grupo UCT. Imediatamente após a coleta, os dentes foram armazenados em solução salina. Em seguida, foram suavemente limpos com instrumentos manuais e escovação e armazenados a $4^{\circ} \mathrm{C}$ em solução de timol a $0,1 \%$ até a realização dos experimentos.

Como critério de inclusão para a presente investigação, foram escolhidos apenas aqueles dentes com: i) restaurações classificadas clinicamente como bemsucedidas - códigos 0 e 1 do critério ART (Tabela 8) e; ii) sem cárie secundária. Assim, foram incluídos um total de 19 dentes, dos quais 10 restaurados com amálgama, pertencentes ao grupo CRT, e 9 restaurados com cimento de ionômero de vidro pela técnica ART, dos quais 6 pertenciam originalmente ao grupo ART e 3 ao grupo UCT. Como um dos objetivos do estudo era comparar a performance clínica dos diferentes materiais restauradores - amálgama e cimento de ionômero de vidro de alta viscosidade, os dentes selecionados pertencentes aos grupos ART e UCT foram agrupados em um mesmo grupo experimental, referenciado como CIV.

Quanto à ocorrência dos códigos 0 e 1 do critério ART, apenas um dente do grupo CIV apresentou código 1; todos os demais dentes selecionados apresentaram código 0.

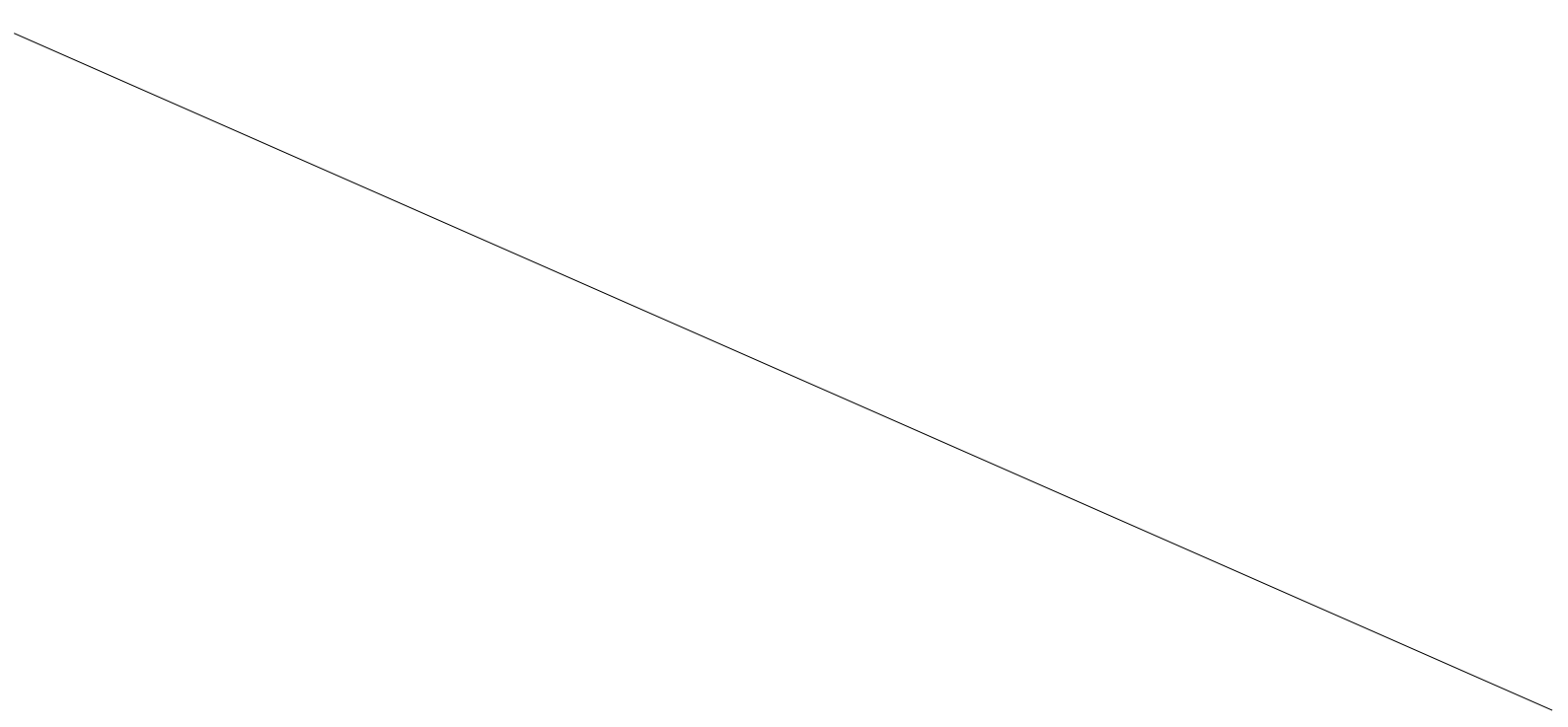


Tabela 8 - Critério ART de avaliação clínica das restaurações

\begin{tabular}{ll}
\hline Código & Critério \\
\hline $\mathbf{0}$ & Restauração presente, satisfatória \\
$\mathbf{1}$ & Restauração presente, pequena deficiência na margem da cavidade, menor que $0,5 \mathrm{~mm} *$ \\
$\mathbf{2}$ & Restauração presente, deficiência na margem da cavidade, com $0,5 \mathrm{~mm}$ ou mais* \\
$\mathbf{3}$ & Restauração presente, fratura na restauração \\
$\mathbf{4}$ & Restauração presente, fratura no dente \\
$\mathbf{5}$ & Restauração presente, margem extendida 0,5 mm além da margem proximal \\
$\mathbf{6}$ & Restauração ausente, maior parte ou toda a restauração ausente \\
$\mathbf{7}$ & Restauração ausente, outro tratamento restaurador inserido \\
$\mathbf{8}$ & Restauração ausente, dente ausente \\
$\mathbf{9}$ & Diagnóstico prejudicado \\
\hline
\end{tabular}

* Acessada pela sonda da OMS. (Tabela extraída e adaptada de Frencken et al, 1996 (66))

\subsubsection{Microscopia Eletrônica de Varredura (MEV)}

Para proceder à análise acerca da presença ou não de microfendas entre a interface dente-restauração, foram realizadas impressões dos dentes selecionados com material plástico do tipo silicone de adição e, em seguida, foram reproduzidas cópias com resina epóxica. Essas cópias foram recobertas com pulverização de platina e, sob pressão reduzida, observadas em MEV em uma voltagem de aceleração de $15 \mathrm{kV}$ em diferentes ampliações.

As margens das restaurações foram analisadas e classificadas quanto à presença de microfendas entre elas e as paredes da cavidade, sendo o código 0 atribuído à não detecção e o código 1 atribuído à presença de ao menos uma região com microfenda. No segundo caso, a extensão da microfenda foi medida por meio da utilização de um software de quantificação digital específico. Nos casos em que mais de uma região apresentou microfenda, a de maior extensão foi considerada para análise estatística. 


\subsubsection{Infiltração com solução de nitrato de prata}

Os mesmos dentes que foram replicados para a análise por MEV também foram avaliados com o objetivo de detectar a ocorrência de microinfiltração marginal. Neste caso, os dentes selecionados foram embutidos em blocos de resina acrílica, sendo sua superfície externa isolada por duas camadas de verniz, exceto a $1 \mathrm{~mm}$ da margem da restauração. Os espécimes foram imersos em uma solução aquosa de nitrato de prata $\left(\mathrm{AgNO}_{3}\right)$ a $50 \%$ de concentração de peso/volume $(\mathrm{pH}=3,88)$ e protegidos da incidência de luz por um período de $6 \mathrm{~h}$. Após a imersão, as amostras foram enxaguadas com água destilada durante 5 minutos e imersas em solução reveladora durante $12 \mathrm{~h}$, sob luz fluorescente. Uma nova lavagem em água corrente, por 5 minutos, foi realizada para remover o excesso do revelador.

Em seguida, os dentes foram seccionados longitudinalmente, em uma área mediana da extensão vestíbulo-lingual da restauração, com um disco revestido de diamante operando em baixa velocidade sob refrigeração. A secção foi feita no eixo mesiodistal, a fim de separar as superfícies linguais e bucais dos dentes.

Um membro experiente da equipe da Faculdade de Odontologia da Universidade de Brasília fotografou as secções a serem examinadas, usando uma câmera digital Nikon D70 (Nikon, Ayutthaya, Tailândia), equipado com uma lente Sigma 105 mm (Sigma, Fukushima, Japão), sob as mesmas condições de iluminação. As fotografias foram padronizadas para o tamanho, cor e contraste usando o Adobe Photoshop CS5 (San Jose, CA, EUA).

Dois avaliadores treinados classificaram, de forma independente, as fotografias de acordo com a profundidade de penetração do corante (100):

- Escore 0 - nenhuma infiltração;

- Escore 1 - infiltração até a metade da profundidade da cavidade;

- Escore 2 - infiltração além da metade da profundidade da cavidade, mas sem envolvimento da parede axial;

- Escore 3 - infiltração ao longo da parede axial.

Cabe salientar que tais escores tiveram distribuição espacial diferente entre as restaurações envolvendo única superfície e aquelas com envolvimento de múltiplas superfícies, conforme ilustrado na Figura 9.

As discordâncias entre os avaliadores foram discutidas até a obtenção de um valor de consenso. 


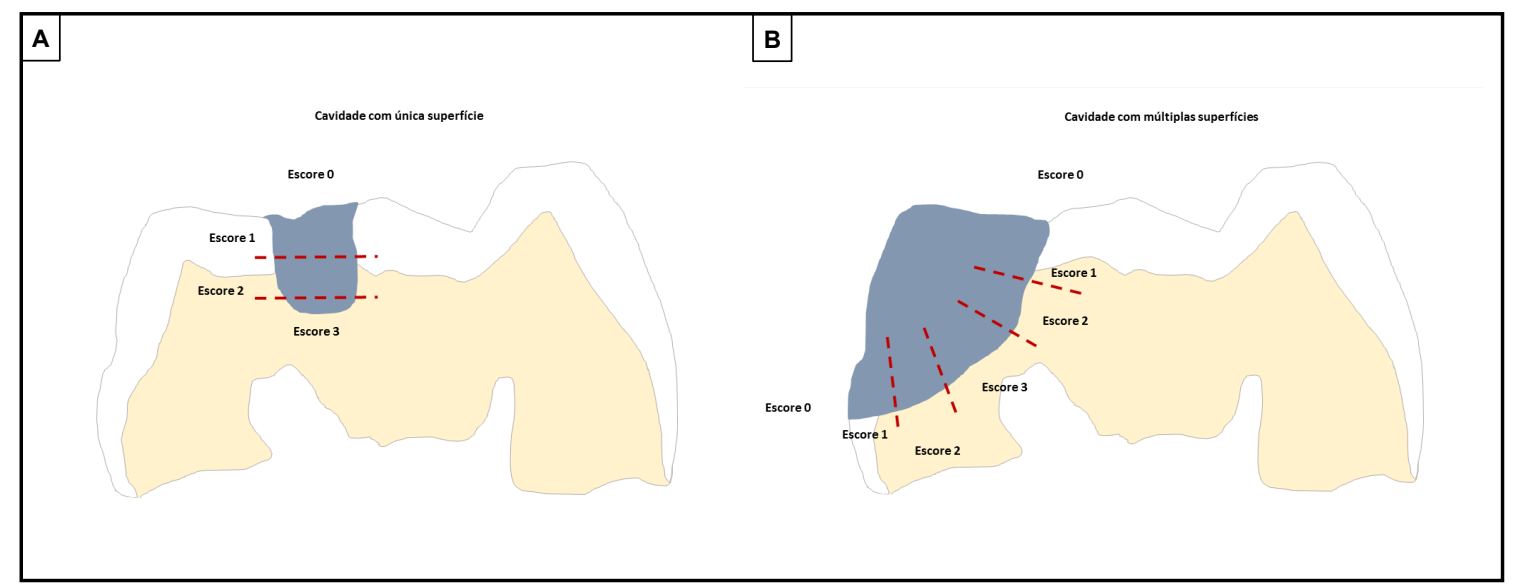

Figura 9. Distribuição espacial das áreas avaliadas e que receberam escores atribuídos à profundidade de penetração da solução de nitrato de prata conforme o numero de superfícies envolvidas: (A) restaurações de única superfície e; (B) restaurações com envolvimento de múltiplas superfícies.

\subsubsection{Análise estatística}

A análise estatística foi conduzida por um bioestatístico experiente com emprego do software IBM SPSS 21.0 (Chicago, IL, EUA). O teste de Fischer e ANOVA foram utilizados para a análise dos dados dos experimentos de microinfiltração com solução de nitrato de prata e dos efeitos das variáveis independentes, enquanto os dados obtidos na microscopia eletrônica de varredura e os efeitos das variáveis independentes foram submetidos aos testes $t$-student e ANOVA. Considerou-se estatisticamente significativo um valor de coeficiente $\alpha=$ 0,05 .

\subsection{RESULTADOS}

\subsubsection{Dentes selecionados e variáveis independentes}

No presente estudo, a amostra analisada compreendeu 19 dentes, distribuídos de acordo com as variáveis de gênero, tipo de material restaurador, idade da restauração e número de superfícies envolvidas, conforme Tabela 9. Não houve diferença estatisticamente significativa na idade média das restaurações entre os dentes restaurados com amálgama e aqueles restaurados com CIV ( $p=0,24)$. Ademais, um maior número de dentes com envolvimento de múltiplas superfícies foi coletado em ambos os grupos estudados. 
Tabela 9 - Variáveis independentes relacionadas aos dentes selecionados para o estudo de selamento marginal por tratamento restaurador realizado.

\begin{tabular}{lcc}
\hline & Amálgama & CIV \\
\hline Idade média da restauração \pm DP* & $2,49 \pm 0,76$ & $2,49 \pm 0,63$ \\
Gênero & 2 & \\
N meninos & 8 & 4 \\
N meninas & & 5 \\
Tipo de superfície & 1 & \\
N superfície única & & 4 \\
N superfícies múltiplas & 9 & 5 \\
\hline
\end{tabular}

*DP - Desvio Padrão; CIV - Cimento de lonômero de Vidro

\subsubsection{Presença de microfendas nas margens das restaurações}

A Tabela 10 demonstra a distribuição das microfendas na interface denterestauração nas réplicas avaliadas por $M E V$ e, quando presente, sua extensão média em $(\mu \mathrm{m})$. Dentes restaurados em amálgama apresentaram extensão média de microfenda de 180,86 $\mu \mathrm{m}$, enquanto aqueles restaurados com CIV pela técnica ART apresentaram extensão média de fenda de $161 \mu \mathrm{m}$. Não houve diferença estatisticamente significativa em relação à presença de microfendas $(p=0,14)$ e sua extensão $(p=0,83)$ quando comparados os grupos de restaurações implementadas.

Ademais, não foram observados efeitos estatisticamente significativos das variáveis número de superfície envolvida $(p=0,32)$, gênero da criança $(p=0,58)$ e idade da restauração $(p=0,64)$ na extensão das microfendas observadas.

O dente que recebeu clinicamente o código 1 do critério ART, do grupo CIV, apresentou microfenda na interface dente-restauração pela análise em MEV, com extensão de $178 \mu \mathrm{m}$, não sendo este valor o maior observado para dentes pertencentes ao mesmo grupo experimental. 
Tabela 10 - Classificação quanto à presença de microfendas nas interfaces dente-restaurações de amálgama e de cimento de ionômero de vidro e média de extensão da microfenda em $\mu \mathrm{m}$, quando presente, obtidas por observação em MEV.

\begin{tabular}{cccc}
\hline Fenda & Ausente & Presente & Extensão $(\boldsymbol{\mu m})$ e SE \\
\hline Amálgama & 1 & 9 & $180,86 \pm 51,55$ \\
CIV & 4 & 5 & $161,00 \pm 75,49$ \\
\hline
\end{tabular}

\subsubsection{Profundidade de penetração da solução de nitrato de prata}

Os escores obtidos após a infiltração da solução de nitrato de prata estão expostos na Tabela 11. Com relação à distribuição dos escores, três dentes restaurados por amálgama e um dente restaurado por CIV pela técnica ART não apresentaram infiltração de solução de nitrato de prata na interface denterestauração. Contudo, dos nove escores máximos de profundidade de penetração do marcador químico, seis pertenciam ao grupo amálgama. Não houve diferença estatisticamente significativa nos escores de penetração da solução de nitrato de prata entre os grupos examinados $(p=0,20)$.

Tabela 11 - Classificações segundo escores de profundidade de penetração da solução de nitrato de prata em dentes restaurados por amálgama, pertencentes ao grupo CRT e restaurados por cimento de ionômero de vidro, pertencentes aos grupos ART e UCT.

\begin{tabular}{cccc}
\hline & Amálgama & CIV & Total \\
\hline Escore & $\mathrm{N}_{\text {dentes }}$ & $\mathrm{N}_{\text {dentes }}$ & $\mathrm{N}_{\text {dentes }}$ \\
$\mathbf{0}$ & 3 & 1 & 4 \\
$\mathbf{1}$ & 0 & 3 & 3 \\
$\mathbf{2}$ & 1 & 2 & 3 \\
$\mathbf{3}$ & 6 & 3 & 9 \\
\hline
\end{tabular}


Assim como para a avaliação no MEV, não foram observados efeitos das variáveis de gênero $(p=0,59)$ e de idade da restauração $(p=0,08)$ na profundidade de infiltração da solução de nitrato de prata nas margens das restaurações, apesar de este último apresentar uma tendência de proporcionalidade indireta entre a idade da restauração e a profundidade de penetração da solução.

Contudo, observou-se um efeito do tipo de superfície na profundidade de infiltração do marcador nas margens das restaurações dos dentes avaliados. Aqueles com envolvimento de múltiplas superfícies apresentaram maior infiltração quando comparados àqueles com envolvimento de única superfície $(p=0,02)$. Do total de nove dentes com penetração de corante ao longo da parede axial (escore 3), oito apresentavam envolvimento de múltipla superfície e apenas um apresentava envolvimento de única superfície.

O dente restaurado por cimento de ionômero de vidro pela técnica ART avaliado clinicamente com o código 1 do critério ART apresentou escore 3 para a infiltração de solução de nitrato de prata.

A Tabela 12 demonstra a comparação entre as metodologias utilizadas. Foram consideradas concordâncias o código 0 para o estudo em MEV e o escore 0 para a infiltração de solução de nitrato de prata e; o código 1 para o estudo em MEV e os escores 1, 2 e 3 para a infiltração de solução de nitrato de prata. Do total de 19 escores possíveis, as metodologias concordaram em 12, demonstrando correlação entre ambas. Apesar desta tendência, estatisticamente esse valor não foi considerado significativo $(p=0,014)$.

Tabela 12 - Correlação das metodologias aplicadas para a análise se microfraturas marginais nas restaurações de amálgama e CIV pela técnica ART.

\begin{tabular}{cccc}
\hline & MEV & MEV & Total \\
& $\mathbf{0}$ & $\mathbf{1}$ & \\
\hline MI - 0 & 1 & 3 & 3 \\
MI - 1 & 3 & 0 & 3 \\
MI - 2 & 0 & 3 & 9 \\
MI - 3 & 1 & 8 & 19 \\
Total & 5 & 14 & \\
\hline
\end{tabular}

MEV - Microscopia Eletrônica de Varredura; MI - Microinfiltração 
A Figura 10 ilustra os experimentos realizados para avaliação do selamento marginal das restaurações de amálgama e de CIV pela técnica ART em alguns dos dentes selecionados para o estudo.

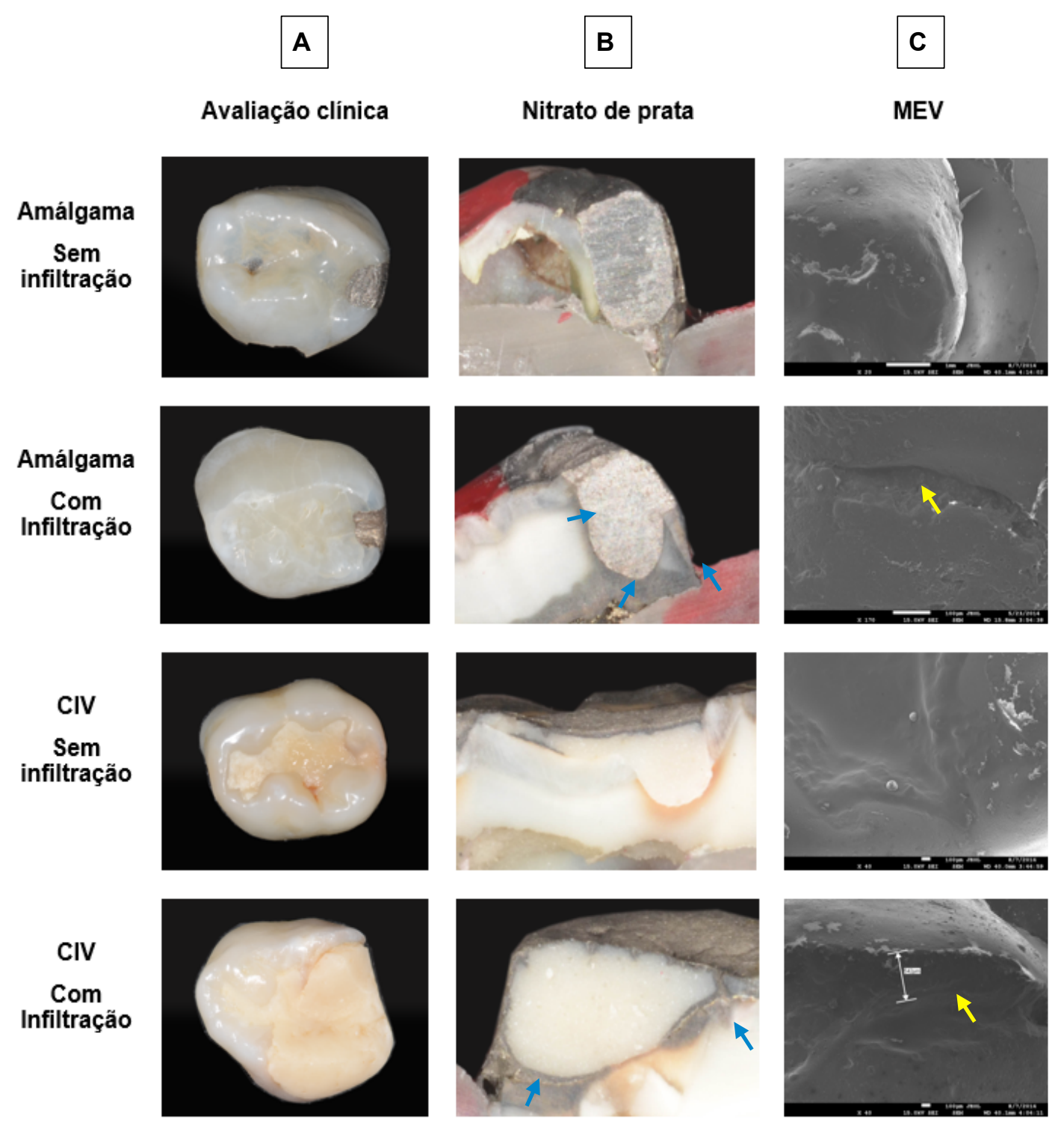

Figura 10 Fotomicrografias de dentes restaurados com amálgama (linhas 1 e 2 ) e com cimento de ionômero de vidro pela técnica ART (linhas 3 e 4)selecionados no estudo. Em A, avaliação clínica das restaurações, onde foram observados códigos 0 conforme critério ART. Em B, secção longitudinal dos dentes com indicação da profundidade de penetração do corante em uma restauração de amálgama (linha 2) e em uma restauração em cimento de ionômero de vidro (linha 4). Em C, fotomicrograficas por microscopia eletrônica de varredura dos dentes selecionados. Setas indicam a presença de fendas. 


\subsection{DISCUSSÃO}

\subsubsection{Metodologia do estudo}

A presente análise é decorrente de um estudo clínico quasi-randomizado cujo objetivo foi avaliar diferentes protocolos terapêuticos no manejo da cárie dentária cavitada em dentina de molares decíduos. Em análise anteriores, o estudo clínico foi considerado de alta validade interna e com improvável viés de seleção ou erro sistemático que pudesse influenciar os resultados obtidos. Tais aspectos, consequentemente, validam a amostra de dentes submetida à análise de microfraturas marginais aqui descritas $(89,101)$.

A coleta dos dentes selecionados para o estudo de microfraturas marginais ocorreu de forma aleatória e decorrente de um processo de esfoliação natural, o que limitou, de forma geral, o número de elementos dentários. No presente estudo, a coleta de um maior número de dentes com envolvimento de múltiplas superfícies vai ao encontro da análise do padrão de esfoliação dos dentes inseridos no estudo clínico, que demonstrou que uma maior proporção de dentes com envolvimento de múltiplas superfícies esfoliou após um período de avaliação de 3,5 anos, independentemente do grupo de protocolo terapêutico ao qual os dentes haviam sido submetidos (101). Em conjunto com a análise do tipo de superfície, a observação da ausência de efeitos das variáveis de gênero e de idade das restaurações nos resultados obtidos validam a coleta realizada.

Outro aspecto metodológico a ser considerado é o fato de se tratar de uma análise ex vivo. Poucos estudos desse tipo têm sido conduzidos, especialmente em pesquisas relacionadas ao manejo de cárie dentária na dentição decídua $(45,102)$. Uma fraca correspondência de resultados in vitro com a performance clínica de materiais restauradores tem sido descrita para a análise de microfraturas marginais; deste modo, avaliações ex vivo fornecem condições reais do ambiente bucal, com interações múltiplas e mais complexas que o ambiente laboratorial, e os resultados obtidos podem refletir diretamente a situação clínica objeto de exame.

Inúmeras metodologias são aplicadas para a análise de microfraturas marginais. A microtomografia computadorizada é um método efetivo para este propósito, uma vez que possibilita uma análise quantitativa tridimensional e nãodestrutiva dos dentes $(103,104)$. Contudo, há limitação da técnica para a avaliação de restaurações metálicas, como as de amálgama, impossibilitando, deste modo, 
sua aplicação no presente estudo. Além disso, a avaliação de microfraturas marginais a partir de réplicas por microscopia eletrônica de varredura associada à infiltração de solução aquosa de nitrato de prata tem se mostrado eficiente, ainda que esta última tenha a tendência de superestimar os resultados, dado o tamanho reduzido das partículas e a sua facilidade de penetração nos tecidos dentais pelo seu $\mathrm{pH}$ ácido $(105,106)$.

\subsubsection{Resultados das avaliações}

Este é o primeiro estudo ex vivo comparando a presença de microfraturas marginais em dentes decíduos restaurados com amálgama e com cimento de ionômero de vidro pela técnica ART. A hipótese de que a ocorrência de microfraturas marginais em molares decíduos restaurados pela técnica ART não difere daquela verificada em molares decíduos restaurados com amálgama não foi rejeitada. Não foram observadas diferenças estatisticamente significativas nas microfraturas marginais entre os grupos de materiais restauradores avaliados, tanto pela microscopia eletrônica de varredura, quanto pela profundidade de penetração de solução aquosa de nitrato de prata.

Estudos clínicos têm demonstrado que restaurações de amálgama e de cimento de ionômero de vidro pela técnica ART em dentes com envolvimento de múltiplas superfícies apresentam menor sobrevida comparativamente àquelas restaurações envolvendo única superfície (71, 72, 87 e 107). Neste estudo, em ambos os grupos de restaurações avaliadas, nos dentes com envolvimento de múltiplas superfícies houve uma infiltração de solução de nitrato de prata significativamente maior que nos dentes com envolvimento de única superfície. Tal constatação indica uma maior susceptibilidade destas restaurações em sofrer fraturas marginais, o que pode, consequentemente, influenciar negativamente na sobrevida das mesmas, corroborando os achados clínicos descritos.

Em restaurações de amálgama, que não possuem adesão química aos tecidos dentários, diferentemente de restaurações com cimento de ionômero de vidro, a presença de microespaçamento na interface dente-restauração é esperada e, portanto, também o é a infiltração da solução de nitrato de prata. No entanto, a formação de produtos de corrosão junto às margens de restaurações de amálgama ao longo do seu envelhecimento é conhecida (108), e tal processo pode explicar a tendência observada no presente estudo, em que as restaurações mais antigas 
apresentaram menor infiltração de solução de nitrato de prata na interface denterestauração, uma vez que os produtos da corrosão poderiam promover o selamento de suas margens com o passar do tempo.

$\mathrm{Na}$ análise ex vivo realizada no presente estudo, observou-se por microscopia eletrônica de varredura a presença de microfendas em ambos os grupos de protocolos restauradores, com extensões médias de 180,86 $\mu \mathrm{m}$ para dentes restaurados com amálgama e $161 \mu \mathrm{m}$ para dentes restaurados com cimento de ionômero de vidro pela técnica ART. Esses espaçamentos observados são maiores que a distância necessária para a passagem de microorganismos cariogênicos, os quais possuem diâmetro aproximado de 0,5 a $1,0 \mu \mathrm{m}(10,109)$ e têm sido relacionados a uma maior susceptibilidade à recorrência de cárie. Entretanto, para a presente investigação, objetivou-se avaliar se o sucesso clínico de restaurações em dentes decíduos estava relacionada à ausência de defeitos marginais. Desta forma, foram selecionados apenas aqueles dentes que foram julgados clinicamente como apresentando restaurações satisfatórias, incluindo a ausência de cárie secundária. Como os resultados mostraram que uma parcela dos dentes avaliados apresentava microfendas, cabe o seguinte questionamento: até onde a constatação de microfraturas marginais nas restaurações prediz o sucesso clínico do tratamento realizado, especialmente em dentes decíduos?

Jokstad, em 2015 (110), afirma que o desenvolvimento de cárie secundária, que é descrito como a maior causa de insucesso de tratamentos restauradores, excluindo-se aqui as restaurações de ionômero de vidro, está muito mais associado à presença de um biofilme cariogênico que à qualidade técnica da restauração em si - caracterizada no presente estudo pela presença de microfraturas marginais. Diante disso e dos resultados obtidos no presente estudo, a busca pelo desenvolvimento de novos materiais restauradores deveria considerar não só fatores como o selamento marginal, mas propriedades biológicas que ajudassem no controle do biofilme cariogênico, o que permitiria, no que se refere aos dentes decíduos, sua esfoliação de forma assintomática e sem recorrência de cárie.

Nesse sentido, os resultados da presente investigação reforçam o que já vem sendo dito há muitos anos, que o tratamento restaurador por si só não é capaz de controlar a doença cárie, fazendo-se necessário associar ao protocolo restaurador ações de promoção e prevenção de saúde bucal que visem desorganizar de forma regular o biofilme por meio da escovação e creme dental fluoretado (32). 


\subsection{CONCLUSÃO}

Não houve diferença, em uma análise ex vivo, na presença de microfraturas marginais entre molares decíduos restaurados com amálgama e aqueles restaurados com cimento de ionômero. No entanto, dentes restaurados com envolvimento de múltiplas superfícies apresentaram maior ocorrência de microinfiltração marginal que aqueles com envolvimento de única superfície. 


\section{CONSIDERAÇÕES FINAIS}

Nos últimos anos, a literatura tem questionado bastante os modelos restauradores convencionais - como o amálgama - de manejo da cárie dentária, os quais têm se mostrado ineficientes e inacessíveis à maioria da população, mesmo em países desenvolvidos. Como reflexo disso, dentes com lesões de cárie permanecem sem tratamento, trazendo prejuízos diversos à população e mantendo o status endêmico da doença. Para contornar esse cenário, especialmente no que se refere à dentição decídua, novos protocolos de abordagem da doença têm sido desenvolvidos, dentre os quais a técnica ART e o protocolo UCT. Como tais técnicas figuram no status de alternativas aos tratamentos convencionais, estudos clínicos que forneçam evidências científicas do comportamento clínico e dos efeitos biológicos desencadeados por elas devem ser conduzidos, a fim de que sua implementação e difusão sejam respaldadas.

No presente trabalho, reflexo de um estudo clínico controlado, quasirandomizado iniciado em 2009, em que foram implementados três protocolos terapêuticos - i) CRT - tratamento convencional com amálgama; ii) ART - técnica de restauração atraumática; e iii) UCT - tratamento ultraconservador - para o manejo de cárie dentária em molares decíduos de crianças de escolas do Paranoá, Brasil, foram avaliadas as taxas de sobrevida e as taxas de esfoliação dos molares decíduos após 3,5 anos de avaliação e a presença de microfraturas marginais na interface dente-restauração dos diferentes materiais restauradores utilizados (amálgama e cimento de ionômero de vidro pela técnica ART) em um estudo ex vivo.

Clinicamente, não foram observadas diferenças nas taxas de sobrevida e nas taxas de esfoliação dos molares decíduos submetidos aos diferentes protocolos terapêuticos após o período de 3,5 anos. Entretanto, em ambos os casos um efeito do número de superfícies que a cavidade de dentina apresentava - se única ou múltipla - foi observado. Dentes com única superfície envolvida apresentaram taxa de sobrevida maior e dentes com múltiplas superfícies envolvidas esfoliaram em maior proporção. Tais achados permitem indicar que o protocolo UCT foi tão eficiente quanto o ART na manutenção dos molares decíduos, de maneira assintomática, até o momento da esfoliação, figurando, assim, como uma alternativa ao tratamento restaurador convencional. 
Por sua vez, a comparação ex vivo de molares decíduos restaurados com amálgama, pertencentes ao grupo CRT, e restaurados com cimento de ionômero de vidro, pertencentes ao grupo ART e UCT, não apresentou diferença na análise de microfraturas marginais por microscopia eletrônica de varredura e por infiltração com solução aquosa de nitrato de prata. Outrossim, o fato de os dentes selecionados terem sido considerados com restaurações clinicamente bem-sucedidas não impossibilitou a ocorrência de microfraturas marginais, sem, contudo, a referida ocorrência estar associada à recorrência de cárie. Tal constatação pode indicar que o controle do biofilme dental seja um fator mais influente na prevenção de cáries secundárias que o selamento marginal em si e, nesse sentido, contribuir para a implementação do protocolo UCT, uma vez que este apresenta a associação do tratamento restaurador com componente de promoção e prevenção de saúde bucal realizado pela escovação diária com creme dental fluoretado.

Diante disso, o presente estudo reforça que o controle da doença cárie, que tem sido buscado ao longo de muitos anos, não será atingido apenas com a inserção de tratamentos restauradores, mas sim com a associação de técnicas que visem desorganizar o biofilme dental de forma frequente. Apesar de ser um protocolo novo e de ainda demandar investigações clínicas e laboratoriais complementares, os dados obtidos nos três estudos apresentados nesta peça técnica fornecem evidências para suportar a implementação do protocolo UCT como uma alternativa aos tratamentos restauradores convencionais, especialmente no âmbito de saúde pública. 


\section{PERSPECTIVAS}

Em uma perspectiva de difusão e implementação do tratamento ultraconservador proposto, espera-se que, nos próximos anos, novos estudos clínicos controlados em populações e realidades diversas da que foi aqui estudada sejam conduzidos. Deste estudo clínico, alguns aspectos avaliados encontram-se em fase final de análise, como o impacto dos diferentes protocolos terapêuticos na percepção da qualidade de vida das crianças e a determinação da densidade mineral da dentina adjacente às cavidades por meio de microtomografia computadorizada, em uma análise ex vivo. Aliados aos resultados descritos nessa tese, tais dados fornecerão ainda mais evidências para o emprego do protocolo UCT, especialmente no âmbito de saúde pública.

Dessarte, a presente tese ressalta a metodologia ex vivo, pouco empregada em pesquisa de cariologia e de tratamentos restauradores. Uma vez que inúmeros ensaios clínicos são conduzidos e, considerando principalmente aqueles que envolvam a dentição decídua, a análise ex vivo pode se tornar uma metodologia interessante ao abrigar a complexidade de interações do microambiente bucal e permitir relações, extrapolações e correlações clínicas nem sempre obtidas por meio da realização de experimentos in vitro.

Por fim, a partir dos dados obtidos no estudo de microfraturas marginais, outro aspecto que deverá ser considerado objeto de análise futura é a necessidade de reparo de restaurações com defeitos marginais que estejam clinicamente livres de cárie secundária na dentição decídua. A prática de re-restauração pode ser minimizada e, juntamente com ela, custos e traumas relacionados ao tratamento odontológico, por meio da implantação de um protocolo de remoção diária de biofilme cariogênico até a esfoliação do dente em comento. 


\section{REFERÊNCIAS BIBLIOGRÁFICAS}

1. Petersen PE. The world oral health report 2003: continuous improvement of oral health in the 21st century-the approach of the WHO global health programme. Community Dent Oral Epidemiol 2003;31 (suppl 1): 3-24.

2. Newbrun E. Cariology. $2^{\text {a }}$ Ed. Baltimore: Williams \& Wilkins, 1983.

3. Keyes $\mathrm{PH}$. The infectious and transmissible nature of experimental dentalcaries. Findings and implications. Arch Oral Biol.1960; (1):304-320.

4. Selwitz RH, Ismail Al and Pitts NB. Dental Caries. Lancet 2007; 369: 51-59.

5. Kidd EAM. Assessment of caries risk. Dent Update 1998; 25(9):385-90.

6. Touger-Decker R and van Loveren C. Sugars and dental caries Am J Clin Nutr 2003; 78(suppl): 881S-92S

7. Newbrun E, Albrektsson TO, Bratthall D, Glantz PJ, Lindhe JT authors. Fluoride in caries Prevention and remineralization of partially demineralized enamel and dentin. Tissue Preservation in Caries Treatment. 2001. $3^{\mathrm{a}}$ ed. Great Britain:Quintessence publication CO.Itd; p. 19.

8. Kidd EAM, Joyston-Bechal S. Essentials of dental caries: The disease and its management. $2^{\mathrm{a}}$ ed. New York: Oxford University Press, 1997.

9. Fejerskov O, Kidd E. Cárie Dentária - A doença e seu tratamento clínico. São Paulo: Santos, 2005.

10. Kidd EA, Fejerskov O. What constitutes dental caries? Histopathology of carious enamel and dentin related to the action of cariogenic biofilms. J Dent Res 2004; 83: C35-38.

11. Pitts NB. Modern concepts of caries measurement. J Dent Res 2004; 83: C43-47.

12. World Health Organization. Oral Health Survey. Basic Methods. WHO; 1997.

13. Ministério da Saúde, Secretaria de Atenção à Saúde, Secretaria de Vigilância em Saúde, Departamento de Atenção Básica, Coordenação Geral de Saúde Bucal, SBBrasil 2010 - Pesquisa Nacional de Saúde Bucal, Brasília: 2011. 
14. Kassebaum NJ, Bernabé E, Dahiya M, Bhandari B, Murray CJL e Marcenes W. Global Burden of Untreated Caries: A Systematic Review and Metaregression J Dent Res 2015 May;94(5):650-8.

15. Bagińska J, Rodakowska E, Wilczyńska-Borawska M, Jamiołkowski J. Index of clinical consequences of untreated dental caries (pufa) in primary dentition of children from north-east Poland. Adv Med Sci. 2013; 58(2):442-7.

16. Baelum V, van Palenstein Helderman WH, Hugoson A, Yee R, Fejerskov O A global perspective on changes in the burden of caries and periodontitis: implications for dentistry. $\mathrm{J}$ Oral Rehab 2007 34:872-906.

17. Leal SC, Bronkhorst EM, Fan M, Frencken JE. Untreated cavitated dentine lesions: impact on children's quality of life.Caries Res. 2012; 46(2):102-6.

18. Sheller, B., Churchill, S. S., Williams, B. J., \& Davidson, B. (2009). Body mass index of children with severe early childhood caries. Pediatric Dentistry, 31(3), 216-221.

19. Pourat N and Nicholson G. Unaffordable Dental Care Is Linked to Frequent School Absences. Los Angeles, CA: UCLA Center for Health Policy Research, 2009.

20. Monse B1, Heinrich-Weltzien R, Benzian H, Holmgren C, van Palenstein Helderman W. PUFA--an index of clinical consequences of untreated dental caries. Community Dent Oral Epidemiol. $2010 \mathrm{Feb} ; 38(1): 77-82$.

21. Yengopal V, Harneker SY, Patel N, Siegfried N. Dental fillings for the treatment of caries in the primary dentition. Cochrane Database Syst Rev. 2009 Abr 15;(2).

22. Fuks $A B$, Ram D, Eidelman E. Clinical performance of esthetic posterior crowns in primary molars: a pilot study. Pediatr Dent. 1999 Nov-Dez;21(7):445-8.

23. Donly KJ, Segura A, Kanellis M, Erickson RL. Clinical performance and caries inhibition of resin-modified glass ionomer cement and amalgam restorations. J Am Dent Assoc. 1999 Out; 130(10):1459-66.

24. Marks LA, Weerheijm KL, van Amerongen WE, Groen HJ, Martens LC. Dyract versus Tytin Class II restorations in primary molars: 36 months evaluation. Caries Res. 1999 Set-Out;33(5):387-92.

25. Osborne JW, Summitt JB, Roberts HW. The use of dental amalgam in pediatric dentistry: review of the literature. Pediatr Dent 2002;24:439-447. 
26. Fuks AB. The use of amalgam in pediatric dentistry. Pediatr Dent 2002;24:448-455.

27. Mackert JR, Wahl MJ. Are there acceptable alternatives to amalgam? J Calif Dent Assoc 2004 32:601-610.

28. United Nations Environment Programme- UNEP, 2013. Mercury use in Hospitals and Dentistry.http://www.unep.org/hazardoussubstances/Portals/9/Mercury/Documents/Publications/Awar enessRaisingPack/Presentations/Module_4_Mercury_And_Health_Care_Health_Care_Workers.pdf

29. Waggoner WF. Restoring primary anterior teeth. Pediatr Dent. 2002 Set -Out; 24(5):511-6.

30. García-Godoy F. Resin-based composites and compomers in primary molars. Dent Clin North Am. 2000 Jul; 44(3):541-70.

31. Donly KJ. Restorative Dentistry for children. Dent Clin North Am. 2013 57:75-82.

32. Leal SC Minimal intervention dentistry in the management of the paediatric patient. $\mathrm{Br}$ Dent J. 2014 Jun 13;216(11):623-7.

33. Frencken JE, Leal SC, Navarro MF. Twenty-five-year atraumatic restorative treatment (ART) approach: a comprehensive overview. Clin Oral Invest 2012 16:1337-1346.

34. Frencken JE, Holmgren CJ. How effective is ART in the management of dental caries? Community Dent Oral Epidemiol. 1999 Dec;27(6):423-30.

35. Molina GF, Cabral RJ, Frencken JE. The ART approach: clinical aspects reviewed. J Appl Oral Sci. 2009;17 Suppl:89-98.

36. Farag A, van der Sanden WJM, Abdelwahab H, Frencken JE. Survival of ART restorations assessed using selected FDI and modified ART restoration criteria. Clin Oral Invest 2011 15:409-415.

37. Carvalho TS, Sampaio FC, Diniz A, Bonecker M, van Amerongen WE. Two years survival rate of Class II ART restorations in primary molars using two ways to avoid saliva contamination International Journal of Paediatric Dentistry 2010; 20: 419-425.

38. Frencken JE, Peters MC, Manton DJ, Leal SC, Gordan VV, Eden E. Minimal intervention dentistry for managing dental caries - a review: report of a FDI task group. Int Dent J. 2012 Oct;62(5):223-43. 
39. Tickle M, Milson K, King D, Kearney-Mitchell P, Blinkhorn A. The fate of the carious primary teeth of children who regularly attend the general dental service. Br Dent J 2002; 192: 219-23.

40. Foley J. Alternative treatment strategies for carious primary teeth: an overview of the evidence. Eur Arch Paediatr Dent. 2006;7:73-80.

41. Hobdell M, Petersen PE, Clarkson J, Johnson N. Global goals for oral health 2020. Int Dent J. 2003;53:285-8.

42. Duangthip D, Jiang $\mathrm{M}$, Chu $\mathrm{CH}$, Lo EC. Non-surgical treatment of dentin caries in preschool children--systematic review.BMC Oral Health. 2015 Apr 3;15:44.

43. Kidd EAM. Should deciduous teeth be restored? Reflections of a cariologist. Dent Update 2012 39:159-166.

44. Black GV. A work on operative dentistry. 1908 Chicago: Medico Dental.

45. Mei ML, Ito L, Cao Y, Lo EC, Li QL, Chu CH. An ex vivo study of arrested primary teeth caries with silver diamine fluoride therapy. J Dent. 2014 Apr;42(4):395-402.

46. Chu CH, Gao SS, Li SK, Wong MC, Lo EC The effectiveness of the biannual application of silver nitrate solution followed by sodium fluoride varnish in arresting early childhood caries in preschool children: study protocol for a randomised controlled trial. Trials. 2015 Sep 25;16(1):426.

47. Johansson E, van Dijken JW, Karlsson L, Andersson-Wenckert I. Treatment effect of ozone and fluoride varnish application on occlusal caries in primary molars: a 12-month study. Clin Oral Investig. 2014 Sep;18(7):1785-92.

48. Duangthip $\mathrm{D}$, Chu $\mathrm{CH}$, Lo $\mathrm{CM}$. A randomized clinical trial on arresting dentine caries in preschool children by topical fluorides-18 month results. J Dent. 2015 May 30 . doi: 10.1016/j.jdent.2015.05.006. [Epub ahead of print]

49. Lo EC, Schwarz E, Wong MC. Arresting dentine caries in Chinese preschool children. Int J Paediatr Dent. 1998;8:253-60.

50. Levine RS, Pitts NB, Nugent $Z$. The fate of 1,587 unrestored carious deciduous teeth: a retrospective general dental practice based study from northern England. Br Dent J 2002 193:99-103.

51. Distrito Federal - Síntese de informações socioeconômicas, 2010/ Companhia de Planejamento do Distrito Federal (CODEPLAN), Brasília: Codeplan, 2010. 
52. Figueiredo MJ, de Amorim RG, Leal SC, Mulder J, Frencken JE. Prevalence and severity of clinical consequences of untreated dentine carious lesions in children from a deprived area of Brazil. Caries Res 2011 45:435-442.

53. de Amorim RG, Figueiredo MJ, Leal SC, Mulder J, Frencken JE. Caries experience in a child population in a deprived area of Brazil, using ICDAS II. Clin Oral Investig. 2012 Abr;16(2):513-20.

54. Topaloglu-Ak A, Eden E, Frencken JE, Oncag O Two years survival rate of class II composite resin restorations prepared by ART with and without a chemomechanical caries removal gel in primary molars. Clin Oral Investig 2009; 13:325-332

55. de Menezes Abreu DM, Leal SC, Mulder J, Frencken JE. Patterns of dental anxiety in children after sequential dental visits.Eur Arch Paediatr Dent. 2011

56. de Menezes Abreu DM, Leal SC, Mulder J, Frencken JE. Dental anxiety in 6-7-year-old children treated in accordance with conventional restorative treatment, ART and ultra-conservative treatment protocols. Acta Odontol Scand. 2011 Nov;69(6):410-6.

57. de Menezes Abreu DM, Leal SC, Mulder J, Frencken JE. Pain experience after conventional, atraumatic, and ultraconservative restorative treatments in 6- to 7-yr-old children. Eur J Oral Sci. 2011 Abr;119(2):163-8.

58. de Menezes Abreu DM, Leal SC, Frencken JE. Self-report of pain in children treated according to the atraumatic restorative treatment and the conventional restorative treatment--a pilot study.J Clin Pediatr Dent. 2009 Winter;34(2):151-5.

59. Leal SC, Bronkhorst EM, Fan M, Frencken JE. Effect of different protocols for treating cavities in primary molars on the quality of life of children in Brazil--1 year follow-up. Int Dent J. 2013 Dec;63(6):329-35.

60. Hilgert LA, de Amorim RG, Leal SC, Mulder J, Creugers NH, Frencken JE. Is high-viscosity glass-ionomer-cement a successor to amalgam for treating primary molars? Dent Mater. 2014 Oct;30(10):1172-8.

61. de Amorim RG, Leal SC, Mulder J, Creugers NH, Frencken JE Amalgam and ART restorations in children: a controlled clinical trial. Clin Oral Investig. 2014 Jan;18(1):117-24.

62. Hilgert LA, Leal SC, Mulder J, Creugers NH, Frencken JE. Caries-preventive Effect of Supervised Toothbrushing and Sealants. J Dent Res. 2015 Sep;94(9):1218-24. 
63. Ryge G Clinical criteria. Int Dent J 1980; 30:347-358.

64. Hickel R, Roulet JF, Bayne S, Heintze SD, Mjör IA, Peters M, Rousson V, Randall R, Schmalz G, Tyas M, Vanherle G. Recommendations for conducting controlled clinical studies of dental restorative materials. Science Committee Project 2/98--FDI World Dental Federation study design (Part I) and criteria for evaluation (Part II) of direct and indirect restorations including onlays and partial crowns. J Adhes Dent. 2007;9 Suppl 1:121-47.

65. Lo ECM, Luo Y, FanMW,Wei SHY Clinical Investigation of two glass ionomer restoratives used with atraumatic restorative treatment approach in china: two years results. Caries Res 2001; $35: 458-463$

66. Frencken JE, Pilot $\mathrm{T}$, Songpaisan $\mathrm{Y}$, Phantumvanit $\mathrm{P}$. Atraumatic restorative treatment (ART): rationale, technique, and development. J Public Health Dent 1996;56:135-40.

67. Kidd EA. Microleakage: a review. J Dent. 1976 Sep;4(5):199-206.

68. Ferreira MC, Vieira RS. Marginal leakage in direct and indirect composite resin restorations in primary teeth: an in vitro study. J Dent. 2008 Mai 36(5):322-5.

69. Yadav G, Rehani U, Rana V. A Comparative Evaluation of Marginal Leakage of Different Restorative Materials in Deciduous Molars: An in vitro Study. Int J Clin Pediatr Dent. 2012 May;5(2):101-7.

70. Heintze SD Systematic reviews: I. The correlation between laboratory tests on marginal quality and bond strength. II. The correlation between marginal quality and clinical outcome. J Adhes Dent. 2007;9 Suppl 1:77-106.

71. Mickenautsch S, Yengopal V, Banerjee A Atraumatic restorative treatment versus amalgam restoration longevity: a systematic review. Clin Oral Invest 2010; 14:233-240.

72. Raggio DP, Hesse D, Lenzi TL, Guglielmi CAB, Braga MM Is atraumatic restorative treatment an option for restoring occlusoproximal caries lesions in primary teeth? A systematic review and metaanalysis. Int J Paediatr Dent 20122013 Nov;23(6):435-43.

73. Pan American Health Organization (2006) Oral health of low-income children. Procedures for atraumatic restorative treatment. Final report. PAHO, Washington.

74. Cox DR Regressionmodels and life tables (with discussion). J R Stat Soc B 1972; 34:187220. 
75. Hougaard P. Frailty models for survival data. Lifetime Data Anal 1995; 1:255-273.

76. Efron B The jackknife, the bootstrap, and other resampling plans. SIAM-NSF, Philadelphia, 1982.

77. Schulz KF, Grimes DA Blinding in randomized trials: hiding who got what. Lancet 2002; 359:696-700.

78. Raskin A, Setcos JC, Vreven J, Wilson NHF Influence of the isolation method on the 10-year clinical behaviour of posterior resin composite restorations. Clin Oral Invest 2000; 4:148-152

79. Kemoli AM, van Amerongen WE Influence of the cavity-size on the survival rate of proximal ART restorations in primary molars. Inter J Paediatr Dent 2009; 19:423-430.

80. Carvalho TS, Sampaio FC, Diniz A, Bönecker M, van Amerongen WE Two year survival rate of class II ART restorations in primary molars using two ways to avoid saliva contamination. Inter J Paediatr Dent 2010; 20:419-425.

81. Yengopal V, Mickenautsch S, Berazza AC, Leal SC Caries preventive effect of glass ionomer and resin-based fissure sealants on permanent teeth: a meta analysis. J Oral Sci 2009; 51:373-382.

82. van Gemert-Schriks MCM, van Amerongen WE, ten Cate JM, Aartman IHA. The effect of different dental treatment strategies on the oral health of children: a longitudinal randomised controlled trial. Clin Oral Invest 2008;12:361-368.

83. Curnow MMT, Pine CM, Burnside G, Nicholson JA, Chesters RK. A randomized controlled trial of the efficacy of supervised toothbrushing in high-caries-risk children. Caries Res 2002; 36:294300.

84. Gruythuysen RJ Non-restorative cavity treatment. Managing rather than masking caries activity. Ned Tijdschr Tandheelkd 2010; 117:173-180.

85. Dekkers OM, von Elm E, Algra A, Romjin JA, Vandenbroucke JP How to assess the external validity of therapeutic trials: a conceptual approach. Inter J Epidemiol 2010; 39:89-94.

86. Hu X, Chen X, Fan M, Mulder J, Frencken JE. What happens to cavitated primary teeth over time? A 3.5-year prospective cohort study in China. Int Dent J 2013;63:183-8. 
87. Mickenautsch S, Yengopal V. Failure rate of high-viscosity GIC based ART compared with that of conventional amalgam restorations-evidence from an update of a systematic review. SADJ 2012;67:329-31.

88. Innes NP, Evans DJ, Stirrups DR. Sealing caries in primary molars: randomized control trial, 5-year results. J Dent Res 2011;90:1405-10.

89. Mijan M, de Amorim RG, Leal SC, Mulder J, Oliveira L, Creugers NH et al. The 3.5-year survival rates of primary molars treated according to three treatment protocols: a controlled clinical trial. Clin Oral Investig 2014;18:1061-9.

90. Wedl JS, Danias S, Schmelzle R, Friedrich RE. Eruption times of permanent teeth in children and young adolescents in Athens (Greece). Clin Oral Investig 2005;9:131-4.

91. Bayrak S, Sen Tunc E, Tuloglu N, Acikgoz A. Timing of permanent teeth eruption in Turkish children. J Clin Pediatr Dent 2012;37:207-11.

92. Parner ET, Heidmann JM, Vaeth M, Poulsen S. A longitudinal study of time trends in the eruption of permanent teeth in Danish children. Arch Oral Biol 2001;46:425-31.

93. Stephenson J, Chadwick BL, Playe RA, Treasure ET. A competing risk survival analysis model to assess the efficacy of filling carious primary teeth. Caries Res 2010;44:285-93.

94. Leroy R, Bogaerts K, Lesaffre E, Declerck D. Impact of caries experience in the deciduous molars on the emergence of the successors. Eur J Oral Sci 2003;111:106-10.

95. Northway WM, Wainright RL, Demirjian A. Effects of premature loss of deciduous molars. Angle Orthod 1984;54:295-329.

96. Wadenya RO, Yego C, Mante FK. Marginal microleakage of alternative restorative treatment and conventional glass ionomer restorations in extracted primary molars.J Dent Child 2010 Jan-Abr; $77(1): 32-5$.

97. Costa JF, Siqueira WL, Loguercio AD, Reis A, Oliveira Ed, Alves CM, Bauer JR, Grande RH. Characterization of aqueous silver nitrate solutions for leakage tests.J Appl Oral Sci. 2011 MayJun;19(3):254-9.

98. Heintze S Forjanic M, Cavalleri. Microleakage of Class II restorations with different tracers-comparison with SEM quantitative analysis. J. Adhes Dent. 2008 Aug;10(4):259-67. 
99. Pashley DH. Clinical considerations of microleakage. J Endod. 1990 Feb;16(2):70-7.

100. Neves AA, Jaecques S, Van Ende A, Cardoso MV, Coutinho E, Lührs AK, Zicari F, Van Meerbeek B. 3D-microleakage assessment of adhesive interfaces: exploratory findings by $\mu C T$. Dent Mater. 2014 Aug;30(8):799-807.

101. Mijan MC, de Amorim RG, Mulder J, Frencken JE, Leal SC: Exfoliation rates of primary molars submitted to three treatment protocols after 3.5 years. Community Dent Oral Epidemiol. 2015, Jun;43(3):232-9.

102. Soviero VM, Paris S, Leal SC, Azevedo RB, Meyer-Lueckel H. Ex vivo evaluation of caries infiltration after different application times in primary molars. Caries Res. 2013;47(2):110-6.

103. Eden E, Topaloglu-Ak A, Cuijpers V, Frencken JE. Micro-CT for measuring marginal leakage of Class II resin composite restorations in primary molars prepared in vivo. Am J Dent. 2008 Dec;21(6):393-7.

104. Chen X, Cuijpers VM, Fan MW, Frencken JE. Validation of micro-CT against the section method regarding the assessment of marginal leakage of sealants. Aust Dent J. 2012 Jun;57(2):1969.

105. Amarante de Camargo DA, Sinhoreti MA, Correr-Sobrinho L, de Sousa Neto MD, Consani S. Influence of the methodology and evaluation criteria on determining microleakage in dentin-restorative interfaces. Clin Oral Investig. 2006 Dec;10(4):317-23.

106. Hilton TJ Can modern restorative procedures and materials reliably seal cavities? In vitro investigations, part 2. Am J Dent 2002; 15:279-289

107. de Amorim RG, Leal SC, Frencken JE. Survival of atraumatic restorative treatment (ART) sealants and restorations: a meta-analysis. Clin Oral Investig. 2012 Apr;16(2):429-41.

108. Pickard H. M. and Gaynford J. J. Leakage at the margins of amalgam restorations. Br. Dent. J. $1965 ; 119,69-77$.

109. Rosan B, Lamont RJ. Dental plaque formation. Microbes Infect. 2000 Nov;2(13):1599-607.

110. Jokstad A Secondary caries and microleakage Dent Mater. 2015 Sep 27. doi: 10.1016/j.dental.2015.09.006. [Epub ahead of print] 


\section{ANEXO A - Comitê de Ética em Pesquisa}

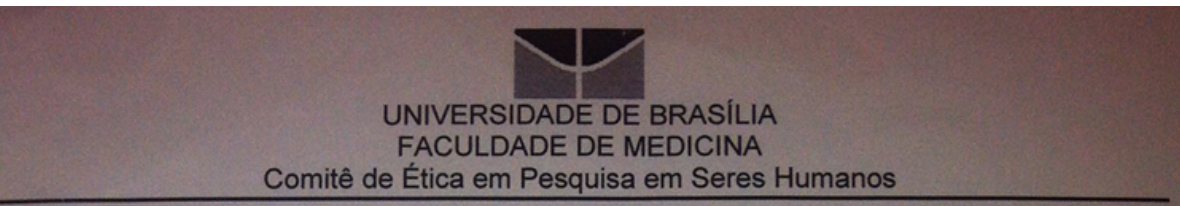

ANÁLISE DE PROJETO DE PESQUISA

Registro de Projeto: CEP-FM 081/2008.

Título: "Relação custo-benefício de abordagens de cuidados bucais em uma população de crianças brasileiras cárie-ativas."

Pesquisador Responsável: Rodrigo Ferreira Silva Guedes de Amorim.

Documentos analisados: Folha de rosto, carta de encaminhamento, declaração de responsabilidade, protocolo de pesquisa, termo de consentimento livre e esclarecido, cronograma, bibliografia pertinente e currículo (s) de pesquisador (es).

Data de entrega: $12 / 11 / 2008$.

Proposição do (a) relato (a)

( X ) Aprovação

( ) Não aprovação.

Data da primeira análise pelo CEP-FM/UNB: 19/11/2008.

Data do parecer final do projeto pelo CEP-FM/UNB: 09/12/2008.

PARECER

Com base na Resolução CNS/MS n $196 / 96$ e resoluções posteriores, que regulamentam a matéria, o Comitê de Ética em Pesquisa da Faculdade de Medicina da Universidade de Brasília decidiu APROVAR, na reunião ordinária de 25/03/2009, conforme parecer do (a) relator (a), o projeto de pesquisa acima especificado, quanto aos seus aspectos éticos.

1. Modificações no protocolo devem ser submetidas ao CEP, assim como a notificação imediata de eventos adversos graves;

2. O (s) pesquisador (es) deve (m) apresentar relatórios periódicos do andamento da pesquisa ao CEP-FM.

Brasília, 26 de Março de 2009.

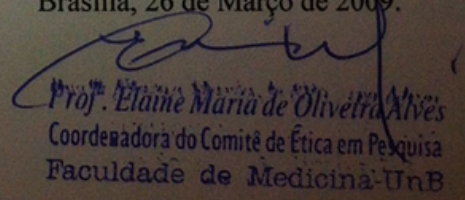




\section{ANEXO B - Termo de Consentimento}

\section{TERMO DE CONSENTIMENTO LIVRE E ESCLARECIDO}

O (a) seu (sua) filho (a) está sendo convidado (a) para participar, como voluntário, em um estudo sobre o tratamento da cárie dentária. O principal pesquisador responsável por essa pesquisa é o Dr. Rodrigo Ferreira Silva Guedes de Amorim (CRO-DF 5771; telefones para contato: 34428484 / 8476 4457). A duração prevista da pesquisa é de 5 anos.

O objetivo do estudo é avaliar 3 tipos de tratamento para a cárie em crianças, e saber qual deles é o melhor, mais confortável e que gera menor custo para ser feito. Um grupo de crianças receberá tratamento através de restaurações em amálgama e selantes resinosos para proteger os dentes permanentes. Outro grupo receberá tratamento através da técnica ART, que consiste em remover a cárie com instrumentos manuais apenas, sem necessidade de brocas. Neste grupo, tanto as restaurações como os selantes serão feitos com um material chamado ionômero de vidro, capaz de liberar flúor. O último grupo receberá restaurações ART nas lesões de cárie pequenas. As lesões que acontecem entre um dente e outro, nos dentes de leite, serão deixadas abertas. Para que a cárie não aumente nestes dentes, as crianças receberão escovação supervisionada nos dias de aula, feita por uma assistente de dentista treinada especificamente para isso. Após o tratamento, as crianças serão acompanhadas pelos dentistas por um período de 5 anos. Caso haja nova necessidade de novo tratamento, ele será executado.

Alguns dentes tratados, em qualquer um dos três grupos, podem apresentar, com o passar do tempo, dor e/ou sinal de infecção, significando que a cárie evoluiu. Estes são os riscos / desconfortos possíveis de acontecer durante a pesquisa. Neste caso, o dente de leite será extraído.

Os benefícios que sua criança irá obter com a pesquisa são: reabilitação bucal e garantia de acompanhamento gratuito por 5 anos. Para a comunidade em geral, esta pesquisa ajudará a encontrar a melhor forma de tratamento da cárie em crianças, em que seja possível o governo brasileiro investir.

A participação de seu (sua) filho (a) no estudo não é obrigatória, e você poderá desistir em qualquer momento sem que haja nenhum prejuízo para você ou para sua criança. Os dados obtidos nesta pesquisa poderão ser utilizados para divulgação em trabalhos científicos, mas a identidade e privacidade da criança serão preservadas.

Após ser devidamente esclarecido (a) e ter compreendido todas as informações acima citadas, se aceitar fazer parte do estudo, assine ao final deste documento, que está em duas vias. Uma delas é sua e a outra é dos pesquisadores responsáveis pelo estudo. Caso não aceite participar, nem você nem sua criança serão penalizados de forma alguma.

Brasília, $\mathrm{de}$ de 2010.

Nome do responsável legal: 
APÊNDICE A

The 3.5-year survival rates of primary

molars treated according to three treatment protocols: a controlled clinical trial

Maite Mijan, Rodrigo Guedes de Amorim, Soraya Coelho Leal, Jan Mulder, Luciana Oliveira, Nico H. J. Creugers \& Jo E. Frencken

Clinical Oral Investigations

ISSN 1432-6981

Clin Oral Invest

DOI 10.1007/s00784-013-1077-1

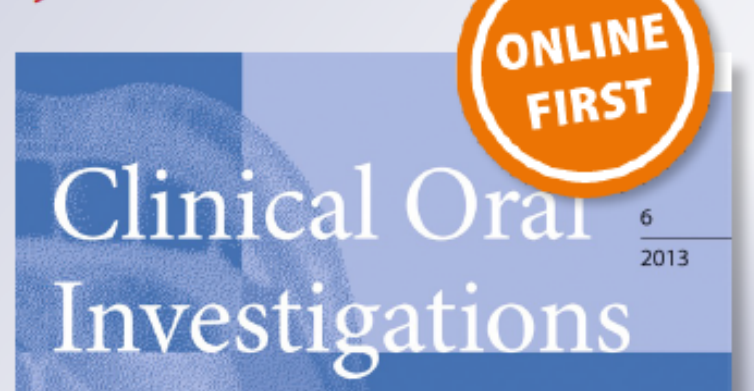

Q Springer

酯 Springer 
Clin Oral Invest

DOI 10.1007/s00784-013-1077-1

ORIGINAL ARTICLE

\section{The 3.5-year survival rates of primary molars treated according to three treatment protocols: a controlled clinical trial}

Maite Mijan - Rodrigo Guedes de Amorim •

Soraya Coelho Leal - Jan Mulder - Luciana Oliveira •

Nico H. J. Creugers • Jo E. Frencken

Roceivod: 17 April 2013 / Aocepted: 24 July 2013

(C) Springer-Verlag Berlin Heidelberg 2013

\begin{abstract}
Objectives This study aimed to test the hypothesis that there is no difference in the survival rates of molars treated according to the conventional restorative treatment (CRT) using amalgam, atraumatic restorative treatment (ART) using highviscosity glass ionomer, and ultraconservative treatment (UCT) protocol after 3.5 years.

Materials and methods Cavitated primary molars were treated according to CRT, ART, and UCT (small cavities were restored with $\mathrm{ART}$ and medium/large cavities were daily cleaned with toothpaste/toothbrush under supervision). Molar extractions resulting from toothache, sepsis, or pulp exposure were failures. The Kaplan-Meier method was used to estimate the survival curves.

Results The numbers of treated teeth, among the 302 6-7year-old children, were 341 (CRT), 244 (ART), and 281 (for UCT group: 109 small ART, 166 open cavities, and 6 combinations). Protocol groups were similar at baseline regarding gender and mean decayed missing filled tooth score, but not
\end{abstract}

M. Mijan - R, G, de Amorim - J, Mulder - J, E, Frencken (ब্ব) Department of Global Oral Health, College of Dental Sciences, Radboud University Nijmegen Medical Centre, P.O. Box 9101 , $6500 \mathrm{HB}$ Nijmegen, The Netherlands

e-mail: j.frencken@dent umen.nl

M. Mijan · S. C. Leal

Department of Pediatric Dentistry, School of Health Sciences, University of Brasilia, Brasilia, Brazil

L. Oliveira

Department of Pediatric Dentistry, São Leopoldo Mandic School of Dentistry, Campinas, Brazil

N. H. J. Creugers

Department of Oral Rchabilitation, College of Dental Sciences, Radboud University Nijmegen Modical Centre, 6500 HB Nijmegen, The Netherlands regarding age and type of surface. The numbers of molars extracted were 22 (CRT), 16 (ART), and 26 (UCT). Fistulae were most often recorded. After 3.5 years, the cumulative survival rate \pm standard error for all molars treated was $90.9 \pm 2.0 \%$ with CRT, $90.4 \pm 2.4 \%$ with ART, and $88.6 \pm 1.9 \%$ with UCT $(p=0.13)$. Only a type of surface effect was observed over the 3.5-year period: survival rates for molars were higher for single- than for multiple-surface cavities.

Conclusion There was no difference in the cumulative survival rates of primary molars treated according to the CRT, ART, and UCT protocols over a 3.5-year period.

Clinical relevance Keeping cavities in primary molars biofilmfree might be another treatment option alongside restoring such cavities through conventional and ART protocols.

Keywords Dental caries + Tooth survival + Amalgam restorations - Atraumatic restorative treatment - Tooth exfoliation - Tooth brushing - Primary dentition

\section{Introduction}

The 2010 national oral health survey in Brazil revealed that the d-component contributed to about $80 \%$ of the mean decayed missing filled tooth (dmft) score of 5-year-old children [1], implying a low coverage of restorative care among the young. This situation appears to be similar to that in other countries. According to the WHO database, on average, $72 \%$ of cavitated dentine carious lesions in primary teeth are untreated in high-income countries and $95 \%$ in low-income countries [2]. These figures imply for the majority of children in the world, the failure of preventive caries care and that of conventional restorative treatment (CRT) using rotary equipment, in keeping primary teeth healthy and functional until exfoliation. 
One option available for increasing the accessibility of preventive and restorative care for these children is the use of atraumatic restorative treatment (ART). In terms of restoration survival, the ART performs as well as CRT using amalgam [3] and resin composites [4]. However, ART is better accepted by young children and, as it can be applied in places lacking electricity and running water, their access to preventive and restorative caries care can be increased through its use [5]. Furthermore, ART restorations are more cost-effective than CRT restorations after 2 years [6]. However, the problem of the magnitude of the absence of appropriate caries care for most of the children in the world cannot be solved solely through the introduction of ART. Other innovations need to be developed if the burden of dental cavities in child populations is to be reduced internationally.

In 2012, Kidd [7] postulated the question as to whether all cavitated dentine carious lesions in primary teeth needed to be restored. She argued that the most important treatment for preventing carious lesion development and for arrestment of a cavitated dentine carious lesion is controlling the oral biofilm. The biofilm in cavitated dentine carious lesions can be managed through placement of a restoration. But that treatment in itself does not ensure good control of the biofilm after restoration. As biofilm control is so essential in managing dental caries, could its control in cavitated teeth also be achieved through regular removal from accessible tooth cavities as part of the process of daily toothbrushing? This suggestion is not new: Black recommended toothbrushing for removing plaque in open cavities in buccal surfaces [8]. He even suggested the opening of cavities in buccal surfaces that were insufficiently accessible for plaque removal. In view of the current poor status of oral health in most of the young populations in the world and the lack of sufficient dental professionals in many countries, the suggestion that cavities should be made free of biofilm through cleaning of the teeth was considered to be worth pursuing.

In an attempt to find an appropriate method of curbing the high prevalence of unmet caries problems in primary dentitions in youngsters in Brazil, a treatment protocol was developed and termed ultraconservative treatment (UCT). It is developed on the strength of the restorative aspect of ART which is to restore small tooth cavities successfully in a patient-friendly way [5] and to remove biofilm from, mainly medium and large, accessible tooth cavities using toothbrushes and toothpaste. The reason for restoring small cavities is that they cannot be cleaned properly. Such a protocol highlights the presence of a cariogenic biofilm as the main etiologic factor in the development of a carious lesion, which implies that dental biofilm ought to be at best removed or at least disturbed daily. No prospective study on the effectiveness of the UCT was available in the literature.

The hypothesis tested was that there is no difference in the cumulative survival rates of primary molars treated according to the CRT, ART, and the UCT protocols over a 3.5-year period.

\section{Material and methods}

\section{Study design}

The controlled clinical trial, using a parallel group design, was carried out in all the six public primary schools of Paranoá, a socially deprived suburban area of Brasilia, the capital of Brazil. The sample of subjects for the present investigation was nested in an oral health epidemiological survey of 6- and 7-year-old children attending these schools [9]. The inclusion criteria were (1) good general health and (2) at least two cavitated dentine carious lesions in primary molars without pain and signs of pulp involvement. The trial was approved by the Research Ethics Committee of the University of Brasilia Medical School (reference 081/2008) and was registered at the Dutch Trial Registration Centre (reference 1699). Only children whose parents/guardians signed an informed consent form that explained the voluntary nature of participation and the content of the trial were included in the study.

Children were allocated to three treatment protocol groups: CRT using amalgam as the control group and ART and UCT as the test groups, using cluster randomization with the school as the unit. As only two of the six schools had a dental unit with rotary equipment, these schools constituted the CRT group. The remaining four schools were randomly allocated to ART and UCT groups by the flip of a coin.

Treatment protocols

Clinical procedures in the three treatment groups followed a standardized protocol developed after a pilot study used for training and calibrating the operators.

Conventional restorative treatment (CRT) protocol Isolation was obtained, using cotton wool rolls and a suction device. Dentine carious cavities were treated with rotary instruments and restored with amalgam (Permite Regular Set 8 ; SDI, Melbourne, Australia), which is the common practice in most Brazilian public oral health centers. Cavity preparation followed Black's principles of cavity design, flat floors and straight walls, but without "extension for prevention." In deep cavities, assessed clinically as the closeness of the cavity floor to the pulp chamber, a fast-setting $\mathrm{Ca}(\mathrm{OH})_{2}$ (Hydro C, Dentsply, São Paulo, Brazil) liner was applied. In proximal cavities, a wooden wedge and a steel matrix band (Injecta", Diadema, São Paulo, Brazil) in a Tofflemire matrix retainer (Golgran, São Paulo, Brazil) were used. 


\section{Author's personal copy}

Clin Oral Invest

Atraumatic restorative treatment (ART) protocol Isolation was obtained, using cotton wool rolls. Dentine carious cavities were restored, using ART and a high-viscosity glass ionomer (Ketac Molar EasyMix \$, 3M ESPE, Seefeld, Germany). Cavities were accessed and prepared with hand instruments only (ART Kit; Henry Schein, Chicago, USA). In deep cavities, a $\mathrm{Ca}(\mathrm{OH})_{2}$ liner was applied. In proximal cavities, a wooden wedge and a steel matrix band (Injecta ${ }^{\text {}}$ ) in a Tofflemire matrix retainer $\left(\right.$ Golgran $\left.{ }^{8}\right)$ were used. The cleaned cavity was then conditioned for $10 \mathrm{~s}$ with a wet cotton wool pellet dipped in the glass ionomer liquid, washed for $5 \mathrm{~s}$ with a wet cotton wool pellet, and dried for $5 \mathrm{~s}$ with a dry cotton wool pellet. The trained chairside assistant mixed the glass ionomer on a glass plate with a metal spatula according to the manufacturer's instructions. The mixture was inserted in the cavity in a few increments, using the ART applier/carver instrument (ART $\mathrm{Kit}^{\mathrm{F}}$ ), overfilled, and pressed down by a petroleumjelly-coated finger [10]. The bite was checked and excess mater ial was removed with the ART applier/carver instrument. The restoration was coated with petroleum jelly and the child was asked not to eat for at least $1 \mathrm{~h}$.

Ultraconservative treatment (UCT) protocol Small dentine carious cavities were treated according to the ART protocol. Medium-sized dentine carious cavities in primary molars were not restored but enlarged with a hatchet (Henry Schein ${ }^{2}$ ), to facilitate plaque removal with a toothbrush and fluoridated toothpaste $(1,000 \mathrm{ppm})$. Large dentine carious cavities in primary molars were also left unrestored and cleaned as described for medium-sized cavities. The criterion for enlarging multiple surfaces cavities was to create free access for the bristles of the toothbrush in buccolingual direction, allowing the cavities to be cleaned. For single-surface cavities, the intention was to remove overhanging enamel. The three operators were trained and calibrated in doing the enlargement in a pilot study. They removed the unsupported enamel that could be fractured easily using a hatchet.

During the 3.5-year trial, a trained dental assistant supervised the toothbrushing daily on schooldays and taught children how to perform the buccolingual toothbrushing technique on all nonrestored cavities. The assistant was trained in detecting plaque. She repeated the brushing demonstration if a child's teeth were found unclean. Children were advised to clean their teeth during vacations as well as during the school terms. The classification of cavity size in primary molars was based on a previous study [11]. For proximal cavities, one-half of the occlusal surface was taken as the reference for the measurement of cavity size, whereas for occlusal cavities, the whole occlusal surface was taken as the reference. Small cavities covered less than one-third of the reference for measurement, medium-sized cavities covered between one-third and two-third, and large cavities covered more than two-third.
Implementation

Children were treated on the school premises by three pediatric dentists trained in applying the two different restorative approaches and cleaning tooth cavities with a toothpaste and toothbrush, in the week before the study commenced, during May-July 2009. In the ART and the UCT groups, a portable treatment bed and a portable source of operating light were used. Chairside assistants assisted the dentists during all clinical procedures. Anterior decayed teeth were referred to a nearby public health clinic for restoration.

Before the treatment commenced, all children received an oral hygiene kit containing a toothbrush, fluoridated dentifrice, plaque disclosing dentifrice, and dental floss. They were collectively taught how to use the kit and were informed about good diet habits. A brochure showing how to clean the teeth effectively was presented to them, and they were told to show it to their parents/caretakers.

After completion of the treatment, children's parents/ caretakers were advised to contact the operators or the principal of the school in case of toothache or the occurrence of a swelling alongside the tooth. In both situations, the affected tooth was extracted by one of the operators and the reason for extraction was recorded. During the trial period, one dental assistant visited the schools from the CRT and ART groups monthly and the UCT group daily and consulted the principal if any complaint had been received.

\section{Evaluation}

Tooth survival was assessed by two independent and calibrated evaluators, who were trained pediatric dentists, after 6 months and 1,2,3, and 3.5 years. Teeth were assessed according to the pufa index, which covers pulpal involvement and the presence of an ulceration, a fistula, or an abscess [12]. In case of a positive score, the evaluator recorded the tooth for extraction, which was done by one of the operators. Children were further asked about having toothache and were asked why a tooth was absent: whether it had been exfoliated or extracted.

Statistical analysis

A power calculation using an $\alpha$ of 0.05 and a $1-\beta$ of 0.8 preceded the sampling procedure. On the basis of an expected $10 \%$ increase in the survival rate of nonrestored teeth, from $82 \%[13]$ to $92 \%$, the sample size would be 173 teeth per group. Having children included in the study with at least 2.5 teeth needing treatment per child, the number of children required was 70 per group. Considering a $10 \%$ correction for dependency on treatments within a child, and an estimated $8 \%$ annual withdrawal of children, the required sample size was 97 children or 239 teeth per treatment protocol group after 3.5 years. 


\section{Author's personal copy}

Clin Oral Invest

All collected data were inserted into a data entry program especially designed for the trial. Missing data were entered with plausible values being either based on no error, a distinct moment of failure, or censored observation. In all but two cases, the distinct moment of failure could not be determined. The decision was made to allocate these missing observations alternately to "having survived" and "failed."

The analyses were performed following the per protocol approach, by a biostatistician using the SAS version 9.2 software. The dependent variable was the survival rate of primary molars treated according to the three treatment protocols (CRT, ART, UCT). The independent variables were age $(6,7)$, gender, mean dmft score at baseline, type of surface (single, multiple), and operator (1-3). A treated tooth failed if it had subsequently been extracted because of toothache, dental sepsis (fistula/abscess), or pulp exposure. Exfoliated teeth and those extracted by another dentist were censored. The proportional hazard rate regression model [14] with frailty correction [15] was used to calculate cumulative survival rates of treated teeth and to analyze the effect of independent variables on the dependent variable over the 3.5-year period. A tooth presenting a single- and a multiple-surface cavity was considered as having a multiple-surface cavity. A tooth presenting more than one single-surface cavity was considered as having a single-surface cavity. The Wald test was used in testing for differences between these 3.5-year cumulative survival rates and for the effects of the independent variables on the survival curves. The Jackknife method was used for correction for dependency of treated teeth within each child. Then, $t$ test was used in testing differences between interval survival rates [16]. Statistical significance was set at $\alpha=0.05$.

\section{Results}

Disposition of subjects

The sample consisted of 302 children. The results of the background variables are presented according to the treatment protocol group in Table 1. The UCT group was divided over 109 teeth treated with ART, 166 teeth in which the cavity was cleaned with toothpaste and toothbrush, and 6 teeth that contained both an ART restoration and a nonrestored cavity cleaned with toothpaste and toothbrush. No effect of gender $(p=0.71)$ and mean dmft score $(p=0.75)$, but an effect of type of surface $(p=0.03)$ and of age $(p<0.0001)$ among children in the treatment protocol groups was observed at baseline. Children from the CRT group were, on average, 0.2 years younger than those of the ART and UCT groups. There were proportionally fewer molars with a multiple-surface cavity in the CRT than in the ART and UCT protocol groups.

The overall 3.5-year lost-to-follow-up rate of children was $52.0 \%$. The lost-to-follow-up rates over the 3.5 -year period of

\begin{tabular}{llll}
\multicolumn{4}{l}{ Table 1 Background variables according to treatment protocol group } \\
\hline & CRT & ART & UCT \\
\hline $\begin{array}{l}\text { Mean age } \pm \text { SD } \\
\text { Gender }\end{array}$ & $6.7 \pm 0.4$ & $6.9 \pm 0.4$ & $6.9 \pm 0.4$ \\
$\quad$ Boys $(N)$ & 67 & 49 & 47 \\
$\quad$ Girls $(N)$ & 59 & 36 & 44 \\
Mean dmft score \pm SD & $5.8 \pm 3.2$ & $5.8 \pm 2.7$ & $5.5 \pm 2.6$ \\
Type of surface & & & \\
Single surface $(N)$ & 103 & 56 & 62 \\
$\quad$ Multiple surfaces $(N)$ & 238 & 188 & 219 \\
\hline
\end{tabular}

$C R T$ conventional restorative treatment, $A R T$ atraumatic restorative treatment, UCT ultraconservative treatment, $N$ number, $S D$ standard deviation

children who were really absent was $12.2 \%$, while the rate for children who were present but had all study teeth exfoliated and/or extracted was $39.7 \%$. The nonresponse analysis revealed no effect for age $(p=0.28)$, gender $(p=0.29)$, and baseline mean $\mathrm{dmft}$ scores $(p=0.70)$.

A Consolidated Standards of Reporting Trials (CONSORT) flow diagram is presented in Fig. 1. During treatment procedure, operators excluded a higher proportion of cavitated teeth in the CRT (34 \%) and ART (27.3\%) protocol groups than in the UCT (17.6\%) protocol group because of pulp involvement.

\section{Survival of primary molars}

Table 2 shows the cumulative survival rates and Jackknife standard error of all treated primary molars by the treatment protocol group and interval period. No evaluation data were available from 10 children who had had 23 teeth treated. The Wald test showed no statistically significant difference among the three treatment protocol groups in cumulative survival rates for all treated primary molars $(p=0.13)$. Over the 3.5 year period, no effect of age $(p=0.41)$, gender $(p=0.93)$, operator $(p=0.30)$, and baseline mean dmft score $(p=0.94)$ was observed on the cumulative survival rates of all treated primary molars among the three treatment protocol groups (Walt test). Only a type of surface effect was observed $(p=0.009)$, showing that molars treated for having a singlesurface cavity survived longer than molars treated for having a multiple-surface cavity.

An additional analysis was carried out because almost every extracted tooth had been treated for a multiple-surface cavity. Table 3 shows the cumulative survival rates and Jackknife standard error of treated primary molars with multiplesurface cavities according to the treatment protocol group and interval period. No statistically significant difference among the three treatment protocol groups was observed in the 3.5year cumulative survival rates of primary molars treated for having a multiple-surface cavity $(p=0.29)$; neither did the 


\section{Author's personal copy}

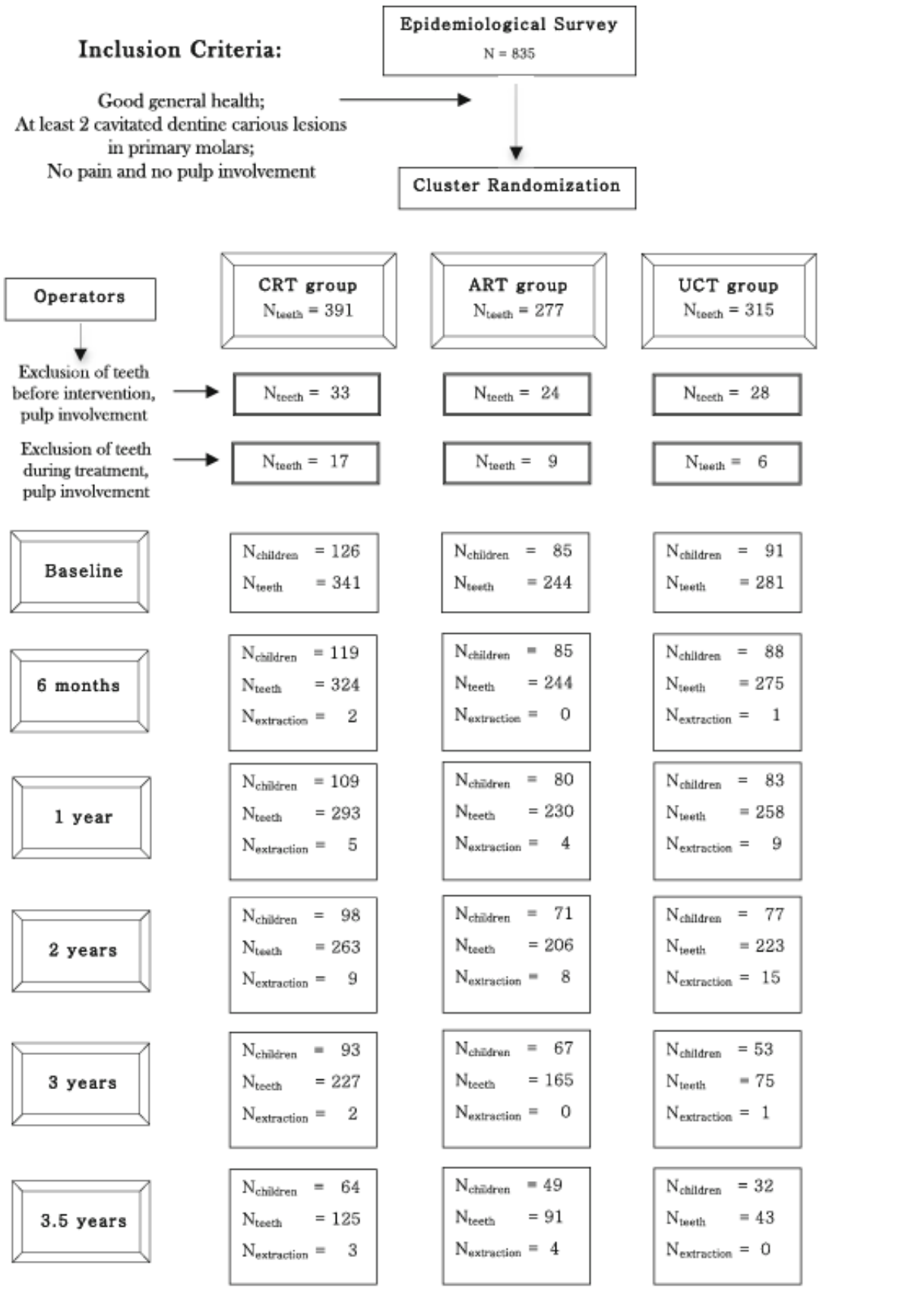

Fig. 1 CONSORT flow diagram of the controlled clinical trial. $C R T$ conventional restorative treatment, $A R T$ atraumatic restorative treatment, $U C T$ ultraconservative treatment, $N$ number 
Author's personal copy

Clin Oral Invest

Table 2 Cumulative survival
rates (in percent) and Jackknife
standard cror (SE) of all treated
primary molars, by treatment
protocolgroup and interval period
Nnumber of tecth, $N_{X}$ cumulative
number of extractions

\begin{tabular}{|c|c|c|c|c|c|c|c|c|c|c|c|c|}
\hline \multirow[t]{2}{*}{ Interval period (years) } & \multicolumn{4}{|c|}{ CRT group } & \multicolumn{4}{|c|}{ ART group } & \multicolumn{4}{|c|}{ UCT group } \\
\hline & $N$ & $N_{\mathrm{X}}$ & $\%$ & $\mathrm{SE}$ & $N$ & $N_{\mathrm{X}}$ & $\%$ & SE & $N$ & $N_{\mathbf{x}}$ & $\%$ & SE \\
\hline $0.0-0.5$ & 324 & 2 & 99.4 & 0.4 & 244 & 0 & 100.0 & 0.0 & 275 & 1 & 99.6 & 0.0 \\
\hline $0.5-1.0$ & 293 & 7 & 97.7 & 0.9 & 230 & 4 & 98.3 & 0.8 & 258 & 10 & 96.2 & 1.3 \\
\hline $1.0-2.0$ & 263 & 16 & 94.4 & 1.4 & 206 & 12 & 94.5 & 1.6 & 223 & 25 & 89.7 & 1.9 \\
\hline $2.0-3.0$ & 227 & 19 & 93.1 & 1.5 & 165 & 12 & 94.5 & 1.6 & 75 & 26 & 88.6 & 1.9 \\
\hline $3.0-3.5$ & 125 & 22 & 90.9 & 2.0 & 91 & 16 & 90.4 & 2.4 & 43 & 26 & 88.6 & 1.9 \\
\hline
\end{tabular}

background variables show a statistically significant effect $(p>0.05)$.

Over the 3.5-year period, a total of 22 (CRT), 16 (ART), and 26 (UCT) primary molars were extracted. Six extracted teeth had a single-surface restoration: two with CRT, one with ART, and three with UCT. All other extracted teeth concerned multiple-surface restorations. Table 4 shows the frequency distribution of reasons for extraction of all treated primary molars, by the treatment protocol groups. The presence of a fistula was the main reason for tooth extraction over all the groups.

\section{Discussion}

\section{Research methodology}

Cluster randomization was used, with school as the unit, because two schools were equipped for rendering conventional restorative treatment. Whether this quasi-randomization process created a selection bias depends on whether the treatment effect variables, such as socioeconomic status (SES) of the children, caries status, age, and type of surface, disturbed the study outcomes. The epidemiological survey, conducted in all the schools present in the study area, showed neither a significant difference between the children of the three treatment protocol groups in relation to SES and caries status nor a significant differ ence regarding type of surface [9]. The only difference observed was that children from the CRT group were, on average, 0.2 years younger than those from the other two treatment protocol groups. As there was no significant difference in mean dmft scores among the children of the three treatment protocol groups, the small difference in age is not likely to have influenced the study outcome. Despite the fact that a common randomization process was not attained, it appears unlikely that the present study design caused selection bias.

In addition to the apparent absence of selection bias, the level of blinding needs to be discussed. Blinding of operators and evaluators could not be performed, as the restorative procedure, dental materials, and open cavities were clearly distinguishable. In order to ensure high quality of data collection, the evaluators were the same throughout the study period and were calibrated prior to each of the evaluation time points. As the absence of a tooth is easily identifiable by a pediatric dentist and as tooth symptoms were reported to the study dentist responsible during evaluation periods, the absolute number given for teeth extracted and those exfoliated can be regarded as highly reliable. This situation presumpted the need for an inter-examiner consistency test. Blinding of the patients was most probably obtained, as the large majority of the children had had no prior experience in dental care, even those from the schools which had a dental unit as no oral health program had been instituted because for years, no dentist or

Table 3 Cumulative survival rates (in percent) and Jackknife standard enor (SE) of treated primary molars with multiple-surface cavities, by treatment protocol group and interval period

\begin{tabular}{|c|c|c|c|c|c|c|c|c|c|c|c|c|}
\hline \multirow[t]{2}{*}{ Interval period (years) } & \multicolumn{4}{|c|}{ CRT group } & \multicolumn{4}{|c|}{ ART group } & \multicolumn{4}{|c|}{ UCT group } \\
\hline & $N$ & $N_{\mathbf{x}}$ & $\%$ & SE & $N$ & $N_{x}$ & $\%$ & SE & $N$ & $N_{x}$ & $\%$ & SE \\
\hline $0.0-0.5$ & 238 & 2 & 99.2 & 0.6 & 188 & 0 & 100.0 & 0.0 & 219 & 1 & 100.0 & 0.0 \\
\hline $0.5-1.0$ & 215 & 7 & 96.9 & 1.2 & 176 & 4 & 97.7 & 1.1 & 207 & 9 & 95.7 & 1.3 \\
\hline $1.0-2.0$ & 193 & 16 & 92.4 & 2.1 & 156 & 11 & 93.4 & 2.0 & 174 & 23 & 88.0 & 2.1 \\
\hline $2.0-3.0$ & 161 & 18 & 91.2 & 2.1 & 120 & 11 & 93,4 & 2,0 & 38 & 23 & 88.0 & 2.1 \\
\hline $3.0-3.5$ & 80 & 20 & 89.0 & 2.1 & 68 & 15 & 88.0 & 2.7 & 22 & 23 & 88.0 & 2.1 \\
\hline
\end{tabular}

$N$ number of tecth, $N_{X}$ cumulative number of extractions 
Table 4 Frequency distribution (in numbers $=N$ ) of reasons for extraction of treated primary molars, by treatment protocol group

\begin{tabular}{llll}
\hline Reasons for extraction & $\begin{array}{l}\text { CRT group } \\
N\end{array}$ & $\begin{array}{l}\text { ART group } \\
N\end{array}$ & $\begin{array}{l}\text { UCT group } \\
N\end{array}$ \\
\hline Pulp exposure & 8 & 1 & 9 \\
Fistula & 2 & 1 & 11 \\
Abscess & 4 & 2 & 4 \\
Toothache & 8 & 2 & 1 \\
Don't know & 0 & 0 & 1 \\
\hline
\end{tabular}

dental hygienist had been employed. The statistician could not be completely blinded as some children from the UCT group received treatment both through a restoration and through biofilm control with toothbrush and toothpaste. Despite the recommendation to achieve blinding on all four aspects, the nature of the present study did not allow for blinding of operator, evaluator, and statistician. However, the best level of blinding possible in studies of this nature was achieved [17].

Neither X-rays nor rubber dams were used. These aspects need to be discussed, as in a number of countries, the use of a rubber dam with amalgam is mandatory while in many others, it is not. The use of a rubber dam with amalgam, in comparison to isolation with cotton rolls for restoring cavitated teeth in primary and permanent dentitions, has not yielded proven statistically significantly different results for restoration characteristics and longevity of restorations $[18,19]$. In addition, it has been hypothesized that the absence of rubber dam should lead to a higher pulp inflammation and, therefore, could create a technique bias, as more extractions would be performed in teeth isolated with cotton rolls than in those isolated with a rubber dam. However, no statistically significant difference in pulp inflammation was observed between restorations using rubber dams and those using cotton rolls [20]. Another aspect was the absence of $\mathrm{X}$-rays in caries diagnosis. As described in the CONSORT flow diagram, the exclusion of teeth due to pulpal involvement relied both on a clinical assessment and on the treatment process. Having this combination available in an environment such as a school in a deprived area tremendously reduces the need for X-rays which would be difficult to use in such environments anyway, as it cannot meet the going standard and it is financially demanding. In Brazil, most public health centers have no X-ray machine and that might be the case in many countries where the UCT protocol would be an option. A reasonable assumption in view of the above is that no technical bias influenced the outcomes of tooth survival rates in the present study.

Compared to other longer-term trials in children [21, 22], the 3.5-year lost-to-follow-up percentage of children was low $(12.2 \%)$ and meets the quality criteria for publications eligible for inclusion in systematic reviews (30\%) [23]. Missing values were accounted for through the use of an imputation method that was applied straightforwardly in most cases. These two aspects allowed the most accurate estimation of tooth survival rates. Extraction of a primary molar by a dentist other than the operators was considered a censored observation, because the reason for extraction could not be determined. It might well be possible that a primary molar was extracted by another dentist for reasons other than the criteria for extraction used in the present study. This situation was particularly applicable to nonrestored primary molars from the UCT group and to primary molars presenting a failed (broken/ lost) restoration in the CRT and ART groups. Censoring study teeth that have been treated by nonstudy dentists is also applied in estimating survival rates of restorations assessed according to the United States Public Health Service criteria [24]. The statistical analysis used took care of the dependency of data within a child. Because the cluster covered only two schools, a mixed effectmodel, which is usually used in cluster randomized study designs, was not considered appropriate. Therefore, only the proportional hazard model with frailty corrections for children was used.

Considering the nature of the present study, it is doubtful that any systematic error existed and influenced the study outcomes. Consequently, the internal validity of this controlled clinical trial is considered high.

\section{Main findings}

The study showed that managing dentine carious cavities in primary molars according to the UCT protocol (restoring small-sized cavities with ART and regularly cleaning medium and large cavities) is as effective in generating retention of primary molars as is restoration of these cavities according to the CRT and ART protocols. The study also showed that there was no difference in the cumulative survival rates of teeth treated according to the CRT and ART treatment protocols.

Extraction was the study outcome variable. The number of extractions per protocol group was influenced by the exclusion of pulp-involved cavitated teeth during the treatment session and, in particular, during excavation. In the CRT and ART protocol groups, carious lesion progression into the pulp could be assessed more easily, as operators had to actively remove carious tissues from cavities. In the UCT group, assessment of a possible pulp involvement was more difficult, as carious tissues were removed through toothbrushing, which is less effective than rotary and manual removal. That fact may be a reason for the higher number of extracted teeth in the UCT group. This assumption is supported by the proportion of teeth excluded from the study during the treatment session, which was much higher in the CRT and ART than in the UCT protocol group. The level of tooth extraction could also have been influenced by the cavity cleaning technique employed. Where fistula was the main reason in the ART and UCT 
groups, pulp exposure and toothache were the main reasons for extraction of teeth treated according to the CRT protocol.

This study is the first to have investigated the effectiveness of a protocol consisting of a combination of restoration and cleaning of cavitated posterior primary teeth on a longitudinal basis, as far as is known. This makes comparison with other studies difficult. However, a related investigation was done, using CRT, ART, extraction only, and no-treatment groups, in a child population with an average age of 6.1 years, in the Suriname rainforest $[25]$. That study used different study outcome variables from those of the present one. The outcome of that study differed from that of the present study: in the Suriname study, a higher proportion of pulp-involved teeth were observed in the no-treatment group than in the CRT group. The absence of biofilm control in the no-treatment group may have accounted for this. The authors concluded that the CRT protocol was the strategy of choice for application in an oral health program for these children, with extraction of pulp-involved teeth as the second-best strategy [25].

A few retrospective studies on this topic are available. The survival rate of teeth treated according to the UCT protocol in the present study $(89.7 \%$ ) after 2 years is higher than that ( $82 \%)$ in the study undertaken by Levine et al. [13]. They evaluated the survival rate of nonrestored primary teeth managed by regular reinforcement of simple dietary and toothbrushing advice, in a private practice setting, over an average period of 2 years. The same survival rate of exfoliation $(82 \%)$ was reported for untreated primary molars attended to in the public health service [26]. The paper does not disclose the survival period. The difference in outcomes between these two retrospective studies and the present one can most probably be attributed to the fact that small cavities in the UCT group were restored and open cavities were cleaned under supervision during schooldays.

The outcomes of the studies presented above support the reflections expressed by Kidd [7]. Progression of carious lesions might be controlled by cleaning open cavities thoroughly until teeth exfoliate naturally. The advantages of this approach include the low level of pain and anxiety experienced during the clinical intervention [27] and the opportunity for increasing access to dental health in deprived areas such as that described above, at low cost.

The UCT was carried out on children aged 6-7 years who had, on average, 4-5 years to go before all primary teeth would be exfoliated or extracted. It can be argued that if treatment was delivered earlier, the number of extractions would be lower, as dental caries is an age-related disease. However, it might prove more difficult to clean open cavities in the teeth of younger children.

The performance of the UCT protocol was, for a large part, attributed to the supervision of toothbrushing by a trained assistant during the 220 schooldays per year. Would this supervision scheme prove realistic? Further studies should be carried out on the effectiveness of the UCT protocol in children less than 6 years old and on the effectiveness of a different supervision scheme based, for example, on decreasing incremental visits in association with support for homebased dental care [28]. That could be accompanied by an application of fluoride varnish or of a thin layer of glass ionomer over the floor of deep cavities only [29].

Whether the results of the present study can be generalized to other child populations is difficult to surmise as external validity is a complex reflection in which prior knowledge, statistical considerations, biological plausibility, and eligibility criteria are all relevant [30]. Being the first study assessing the effectiveness of the UCT protocol, this question might be answered if studies in similar population groups using the same methodology as used in the present study have reported the outcomes.

In conclusion, there was no difference in the 3.5-year survival rates of primary molars treated according to the CRT, ART, and UCT protocols. As the conventional restorative treatment is not very suitable for use in deprived areas, appropriate alternative approaches should be used in managing the burden of cavitated dentine carious lesions in primary teeth. The ultraconservative treatment protocol tested in the present study might become a new option, in addition to the existing ART approach, for guiding cavitated teeth to symptomless exfoliation. Further research on the application of UCT is still required.

Acknowledgments Authors thank Danielle Mattos de Menezes Abreu for performing the treatment; Gabriela Lopes for performing the evaluations; assistants for their kind assistance, FAP-DF and Radboud University Nijmeg en for providing financial support; ABCD-DF for their logistic support, the local Educational Department; directors, teachers, and students of the schook; and 3M ESPE for providing the glass ionomer.

Conflict of interest None of the authors have any financial or personal conflict of interests to declare.

\section{References}

1. Brazilian Ministry of Health (2010) Projoct Oral Health Brazil 2010 - national survey on oral health. http $/ / 189.28 .128 .100$ dab/ docs/geral/apresentacao_SB2010.pdf

2. Bachum V, van Palenstein Helderman WH, Hugoson A, Yee R, Fejerskov $O$ (2007) A global perspective on changes in the burden of caries and periodontitis: implications for dentistry. J Oral Rechab 34:872-906

3. Mickenautsch S, Yengopal V, Banejee A (2010) Atraumatic restorative treatment versus amalgam restoration longevity: a systematic review. Clin Oral Invest 14:233-240

4. Raggio DP, Hesse D, Lenzi TL, Guglielmi CAB, Braga MM (2012) is atraumatic restorative treatment an option for restoring ooclusoproximal caries kesions in primary tecth? A systematic review and metr-analysis Int J Paediat Dent, doi:10.1111/ipd.12013 
5. Frencken JE, Leal SC, Navano MF (2012) Twenty-five-year atraumatic restorative treatment (ART) approach: a comprehensive overview. Clin Oral Invest 16:1337-1346

6. Pan American Health Organization (2006) Oral health of low-income children. Procedures for atraumatic restorative treatment. Final roport. PAHO, Washington

7. Kidd EAM (2012) Should deciduous teeth be restored? Refloctions of a cariologist. Dent Update 39:159-166

8. Black GV (1908) A work on operative dentistry. Medico Dental, Chicago

9. de Amorim RG, Figueiredo MJ, Leal SC, Mulder J, Frencken JE (2012) Caries experience in a child population in a deprived area of Brazil, using ICDAS II. Clin Oral Invest 16:513-520

10. Frencken JE, Pílot T, Songpaisan Y, Phantumvanit P (1996) Atraumatic restorative treatment (ART): rationak, technique, and development. J Public Health Dent 56:135-140

11. Topalog hu-Ak A, Eden E, Frencken JE, Oncag O (2009) Two years survival rate of class II composite resin restorations prepared by ART with and without a chemomechanical caries removal gel in primary molars. Clin Oral Investig 13:325-332

12. Figueiredo MJ, de Amorim RG, Leal SC, Mulder J, Frencken JE (2011) Prevalence and severity of clinical consequences of untreated dentine carious lesions in children from a deprived area of Brazil. Caries Res 45:435-442

13. Levine RS, Pitts NB, Nugent Z (2002) The fate of 1,587 unrestored carious dociduous teeth; a retrospective general dental practice basel study from northern Eng hand. Br Dent J 193:99-103

14. Cox DR (1972) Regression modek and life tables (with discussion). J R Stat Soc B 34:187-220

15. Hougaard P (1995) Frailty models for survival data. Lifetime Data Anal $1: 255-273$

16. Efron B (1982) The jackknife, the bootstrap, and other resampling plans. SIAM-NSF, Philadelphia

17. Schulz KF, Grimes DA (2002) Blinding in randomized trials: hiding who got what. Lancet 359:696-700

18. Raskin A, Setcos JC, Vreven J, Wilson NHF (2000) Influence of the isolation method on the 10-year clinical behaviour of posterior resin composite restorations. Clin Oral Invest 4:148-152
19. Kemoli AM, van Amerongen WE (2009) Influence of the cavity-size on the survival rate of proximal ART restorations in primary molars Inter J Paediat Dent 19:423-430

20. Carvalho TS, Sampaio FC, Diniz A, Bönecker M, van Amerongen WE (2010) Two year survival rate of chss II ART restorations in primary molars using two ways to avoid saliva contamination. Inter J Paediat Dent 20:419-425

21. Taifour D, Frencken JE, Beiruti N, van 't Hof MA, Truin GJ (2002) Effoctiveness of glass-ionomer (ART) and amal gam restorations in the deciduous dentition-results after 3 years. Caries Res 36:437-444

22. van Gemert-Schriks MCM, van Amerongen WE, ten Cate JM, Aartman IHA (2007) Three-year survival of single- and two-surface ART restorations in a high-caries child population. Clin Oral Invest $11: 337-343$

23. Yengopal V, Mickenautsch S, Berazza AC, Leal SC (2009) Cariespreventive effect of glass ionomer and resin-based fissure sealants on permanent toeth: a meta analysis. J Oral Sci 51:373-382

24. Ryge G (1980) Clinical criteria. Int Dent J 30:347-358

25. van Gemert-Schriks MCM, van Amerongen WE, ten Cate JM, Aartman IHA (2008) The effect of different dental treatment strategies on the oral health of children; a bngitudinal randomised controlked trial. Clin Oral Invest 12:361-368

26. Tickle M, Milsom K, King D, Keamey-Mitchell P, Blinkhorn A (2002) The fate of the carious primary tecth of children who regularly attend the general dental service. Br Dent J 192:219-223

27. de Menezes Abreu DM, Leal SC, Mulder J, Frencken JE (2011) Pain experience after conventional, atraumatic, and ultraconservative restorative treatments in 6- to 7-yr-old children. Eur J Oral Sci 119:163-168

28. Cumow MMT, Pine CM, Bumside G, Nicholson JA, Chesters RK (2002) A randomized controllod trial of the efficacy of supervised toothbrushing in high-eavies-risk children. Caries Res 36:294-300

29. Gruythuysen RJ (2010) Non-restorative cavity treatment. Managing rather than masking caries activity. Nod Tijdschr Tandhoelkd $117: 173-180$

30. Dekkers OM, von Elm E, Algra A, Romjin JA, Vandenbroucke JP (2010) How to assess the extemal validity of therapeutic triak: a conceptual approach. Inter J Epidemiol 39:89-94 
APÊNDICE B

\section{Exfoliation rates of primary molars submitted to three treatment protocols after} 3.5 years

\author{
Maite C. Mijan 12, Rodrigo G. de Amo- \\ rim $^{2}$, Jan Mulder', Jo E. Frencken ${ }^{2}$ and \\ Soray a C Leal ${ }^{2}$ \\ "Department of Gbbal Onal Heakth, College \\ of Dental Sciences, Radboud University \\ Medical Centre, Nijegen, The Netherlands. \\ "Department of Ped iatric Dentistry, School \\ of Health Sciences Univenity of Braslis, \\ Bravilia, Brasil
}

Mijan MC, de Amorim RG, Mulder J, Frencken JE, Leal SC. Exfoliation rates of primary molars submi tted to three treatment protocols after 3.5 years. Community Dent Oral Epidemiol 2015. 0 2015 John Wiley \& Sons A/S. Published by John Wiley \& Sons Ltd.

Abstract - Objective: The aim of the study was to evalua te the exfoliation pattern of primary molars treated according to three treatment protocols. The hypothesis tested was that there is no difference in the exfoliation pattern of primary molars treated according to conventional restorative treatment using amalgam (CRT), atraumatic restora tive treatment using high-viscosity glassionomer (ART), and ultraconservative treatment (UCT). The latter consisted of restoring small cavities with ART and deaning medium/large nonrestored cavities daily with toothpaste/toothbrush under supervision. Methods: A sample of 302 children aged 6-7 years from a suburban area of Brasilia was followed up for 3.5 years. The numbers of treated molars were 341 (CRT), 244 (ART), and 275 (UCT). Exfoliation rates were obtained using the PHREG procedure. Differences between the three treatment protocol groups were tested using the Wald test. Results: After 3.5 years, there was no difference over the exfoliation rates of all primary molars as $51.0 \%$ (CRT), 48.7\% (ART), and 48.1\% (UCT) had exfoliated at the overall period $(P=0.37$ ). Teeth with multiple-surfaces treatment had exfol iated in a higher proportion than teeth with single-surface treatments for all the three treatment groups $(P=0.04)$. Conclusion: The three treatment protocols led to similar exfoliation pattems of all primary molars after 3.5 years.

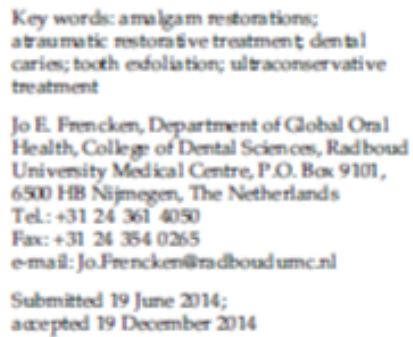

Data collected by the World Health Organization (WHO) showed that the large majority of cavitated dentine carious lesions in primary teeth of 5-yearolds were left unrestored (1). This finding reflects, in part, the inability of the conventional drill and fill treatment concept to manage such cavitated carious lesions.

A decade ago, two retrospective studies reported the fate of cavitated carious primary teeth until exfoliation. They revealed that $82 \%$ of such teeth exfoliated without symptoms $(2,3)$. This finding is supported by a recently published prospective study into the natural course of cavitated primary teeth among on average 8-year-olds (4). After 3.5 years, only $7 \%$ of such teeth had been restored. Of the $93 \%$ with open cavities, $81.5 \%$ exfoliated without symptoms. Considering the billions of such cavitated primary teeth present in child populations in the world, these referred studies feed the thought that not all cavitated carious lesions need to be treated restoratively, and if needed, that it is not necessarily performed in the traditional restorative manner (5).

Altemative restorative care approaches have been suggested. One such approach is the atraumatic restorative treatment (ART) (6). Among 
Mijan et al.

children, ART is better accepted (7) and it produces the same quality restorations in both primary and permanent teeth over time compared to the traditional restorative approach using amalgam (8) and compared to composite resin restorations in primary teeth (9). But in using this alternative, the large unmet need of cavitated primary teeth might not be sufficiently dealt with. Other suggested altematives concern sealing in carious lesions in primary teeth with a prefabricated stainless steel crown (10) or widening cavities for allowing cavity cleaning in conjunction with the application of fluoride varnish or a glass-ionomer cement liner (11). The evidence for the effectiveness of these altematives is still weak.

The latest alternative in safeguarding exfoliation of cavitated primary teeth without symptoms concems a combination of the ART approach, for restoring small size cavities, and that of daily plaque removal with tooth brush and toothpaste from medium-and large-sized cavities. This protocol is called ultraconservative treatment (UCT) (12). Compared to the amalgam conventional restorative treatment (CRT) and the ART protocols, the UCT protocol was as good as the two restorative protocols in treating cavitated primary teeth without causing symptoms over a period of 3.5 years (12). However, it is unknown whether UCT treated primary teeth exfoliate earlier than those treated according to the CRT and ART protocols which warranted a secondary analysis to the study by Mijan (12).

The hypothesis tested was that the exfoliation rates of primary molars treated according to the UCT protocol are no different than those of primary molars treated according to the CRT and ART protocols over a period of 3.5 years.

\section{Material and methods}

The trial was approved by the Research Ethics Committee of the University of Brasilia Medical School (reference 081/2008) and was registered at the Dutch Trial Registration Centre (reference 1699). The methodology of the present investigation has been described in details elsewhere (12). A summary is presented underneath.

\section{Study design}

The controlled clinical trial, using a parallel group design, was carried out in all the six public primary schools of a socially deprived suburban area (Paranoa) of Brasilia, Brazil. The sample of subjects for the present investigation was nested in an oral health epidemiological survey of 6-and 7-year-old children attending these schools (13). Only children whose parents/guardians signed an informed consent form that explained the voluntary nature of participation and the content of the trial were included in the study.

Children were allocated to three treatment protocol groups: CRT as the control group and ART and UCT as the test groups. The unit of sampling was the school. As only two of the six schools had a dental unit with rotary equipment, these schools constituted the CRT group. The remaining four schools were randomly allocated to ART and UCT groups by the flip of a coin.

\section{Treatment protocols}

Clinical procedures in the three treatment groups followed a standardized protocol developed after carrying out a pilot study that served for training and calibrating the operators.

Conventional restonatioe treatment protocol. Dentine carious cavities in primary teeth were treated with rotary instruments and restored with amalgam (Permite Regular set"; SDI, Melbourne, Vic, Australia). Cavity outline followed Black's principles of cavity design, but without 'extension for prevention'. In deep cavities, a $\mathrm{Ca}(\mathrm{OH})_{2}$ liner (Hydro $\mathrm{C}^{*}$; Dentsply, Petrópolis, Rio de Janeiro, Brazil) was applied. In proximal cavities, a wooden wedge and a steel matrix band (Injecta ${ }^{*}$; Diadema, Sáo Paulo, Brazil) in a Tofflemire matrix retainer (Golgran", São Paulo, Brazil) were used.

Atratematic restonatioe treatment protocol. Dentine carious cavities in primary teeth were restored, using the ART technique as described by Frencken et al. (6) using only hand instruments and a highviscosity glass-ionomer (Ketac Molar EasyMix ${ }^{*}$; 3M ESPE, Seefeld, Germany). A trained dental assistant mixed the glass-ionomer on a glass plate with a metal spatula.

For both CRT and ART protocols, a $\mathrm{Ca}(\mathrm{OH})_{2}$ liner (Hydro $\mathrm{C}^{3}$; Dentsply) was applied in deep cavities. In proximal cavities, a wooden wedge and a steel matrix band (Injecta ${ }^{\circ}$ ) in a Tofflemire matrix retainer (Golgran") were used.

Ultraconservative treatment protocol. Small dentine carious cavities were treated according to the ART in the same manner as described for the ART protocol. Medium-sized dentine carious cavities in 
primary molars were not restored, but enlarged with a hatchet (Henry Schein ${ }^{*}$, Chicago, II., USA) to facilitate plaque removal with a toothbrush and fluoridated toothpaste (1000 ppm). Large dentine carious cavities in primary molars were also left unrestored and cleaned as medium-sized cavities. A trained dental assistant supervised the tooth brushing daily on schooldays during the 35 years of the trial and instructed children to perform a bucco-lingual technique of tooth brushing on all nonrestored cavities. The assistant was trained in detecting plaque. She repeated the demonstration of how to brush, if the child's teeth were found unclean. Children were advised to clean their teeth during vacations as instructed while in school. The classification of cavity size in primary molars was based on a previous study (14).

\section{Implementation}

Three pediatric dentists treated children on the school premises during May-July 2009. In the ART and the UCT groups, a portable treatment bed and a portable source of operating light were used. Chairside assistants assisted the dentists during all clinical procedures. Anterior decayed teeth were referred to a nearby public health clinic for restoration.

Before the treatment, all children received an oral hygiene kit containing a toothbrush, fluoridated dentifrice, plaque disclosing dentifrice, and dental floss. They were instructed collectively how to use the kit and were informed about good diet habits. A brochure showing how to clean the teeth effectively was presented to them and they were told to show it to their parents/caretakers. During the trial, one dental assistant visited the schools from CRT and ART groups monthly and consulted the principal if any complaint had been received.

\section{Evaluation}

Tooth exfoliation assessment was carried out by two independent and calibrated evaluators after 6 months, 1, 2, 3, and 3.5 years. Teeth were further assessed according to the pufa-index (15). Children were asked about having (had) toothache and why a tooth was not present anymore: either exfoliated or extracted.

\section{Statistical analysis}

A power calculation for determining the sample size of the tooth survival comparison study revealed a sample size of 97 children or 239 teeth per treatment protocol group after 3.5 years (13).
All collected data were inserted into a data entry program especially designed for the trial. Seven data were missing of which five were imputed because there was no error, presence of a distinct moment of failure, or a censored observation. For the other two data, the distinct moment of failure could not be determined and a decision was made to allocate these two missing observations alternately to 'having survived' and having failed'.

The analyses were performed following the per protocol approach, by a biostatistician using SAS version 9.2 software (SAS, Cary, NC, USA). The dependent variable was the survival rate of primary molars until exfoliation that had been treated according to the three treatment protocols (CRT, ART, and UCT). The independent variables were age at baseline (6-7 years), gender, mean dmft score at baseline, type of surface (single, multiple), operator (1-3), and type of molar (1st, 2nd). A treated tooth was extracted because of toothache, dental sepsis (fistula/abscess), or pulp exposure. Such extracted teeth, those extracted by another dentist and those still present were censored. The proportional hazard rate regression model (16) with frailty correction (17) was used to calculate cumulative survival rates of exfoliated teeth and to analyze the effect of independent variables on the dependent variable over the 3.5 -year period. A tooth presenting a single- and a multiple-surface cavity was considered as having a multiplesurface cavity. A tooth presenting more than one singlesurface cavity was considered as having a singlesurface cavity. The Wald test was used in testing for differences between the 3.5-year cumulative survival rates of exfoliated teeth and for the effects of the independent variables on these rates. The Jackknife method was used for correction for dependency of treated teeth within each child. Then the t-test was used in testing differences between interval survival rates (18). Statistical significance was set at $\alpha=0.05$.

\section{Results}

Disposition of subjects

A CONSORT flow diagram is presented in Fig. 1. The sample consisted of 302 children. The background variables by treatment protocol groups are presented in Table 1. The UCT group consisted of 109 teeth treated with ART, 166 teeth in which the cavity was cleaned with toothpaste/toothbrush, and six teeth that contained both an ART restora- 
Mijan et al.
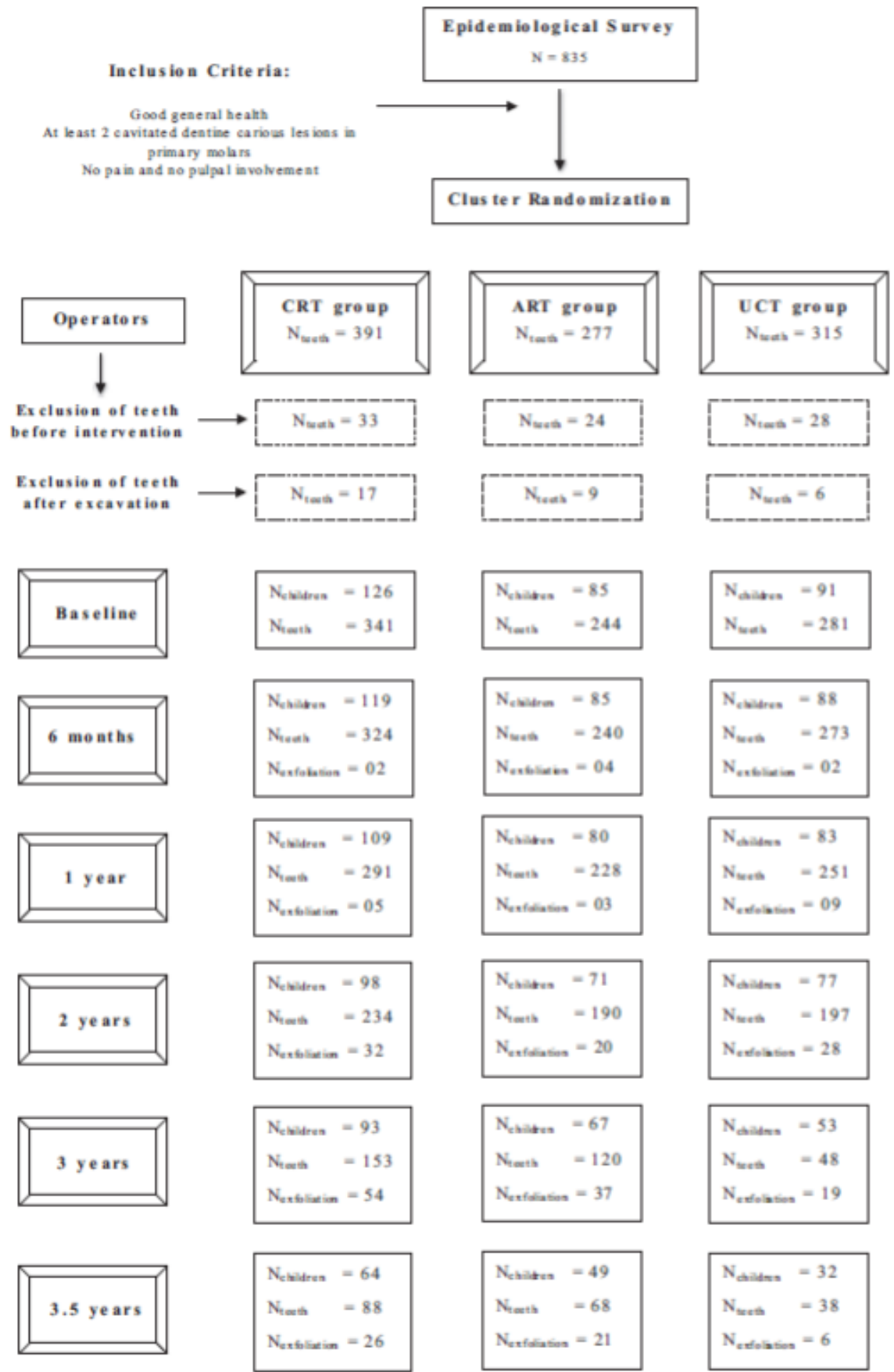

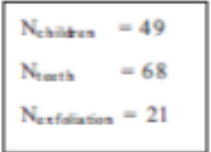

\begin{tabular}{|c|c|}
\hline $\mathrm{N}_{\text {dildes }}$ & $=32$ \\
\hline $\mathbf{N}_{\text {seet }}$ & $=38$ \\
\hline $\mathrm{N}_{\text {extolation }}$ & $=6$ \\
\hline
\end{tabular}

Fig. 1. Consort flow diagram of the controlled clinical trial. CRT, conservative restorative treatment, ART, atraumatic restora tive trea tment; UCT, ultraconservative treatment. 
Table 1. Background variables according to treatment protocol group

\begin{tabular}{lccc}
\hline & CRT & ART & UCT \\
\hline Mean age \pm SD & $6.7 \pm 0.4$ & $6.9 \pm 0.4$ & $6.9 \pm 0.4$ \\
Gender & & & \\
$N$ boys & 67 & 49 & 47 \\
$N$ girls & 59 & 36 & 44 \\
$\begin{array}{l}\text { Mean dmft } \\
\text { score } \pm \text { SD }\end{array}$ & $5.8 \pm 3.2$ & $5.8 \pm 2.7$ & $5.5 \pm 2.6$ \\
Type of surface & & & \\
$N$ single surface & 103 & 56 & 62 \\
$N$ multiple & 238 & 188 & 219 \\
surfaces & & & \\
\hline
\end{tabular}

CRT, conventional restorative trea tment; ART, atraumatic restorative treatment; UCT, ultraconservative treatment; $N$, number; SD, standard deviation.

tion and a nonrestored cavity cleaned with toothpaste/toothbrush. At baseline, there was no effect observed of gender $(P=0.71)$ and mean dmft score $(P=0.75)$. However, an effect was present of type of surface $(P=0.03)$ and of age $(P<0.0001)$ among children in the treatment protocol groups. Children from the CRT group were on average 02 years younger than those of the ART and UCT groups and there were proportionally fewer molars with a multiple-surfaces cavity in the CRT than in the ART and UCT protocol groups.

The overall 3.5-year lost-to-follow-up rate of children was $52.0 \%$. The lost-to-follow-up rates over the 3.5-year period of children who were really absent was $12.2 \%$ while the rate for children who were present but had all study teeth exfoliated and/or extracted was $39.7 \%$. The nonresponse analysis revealed no effect for age ( $P=0.28)$, gender $(P=0.29)$ and baseline mean dmft scores $(P=0.70)$.

Exfoliation pattern of primary molars by treatment group

Table 2 shows the exfoliation rates of all treated primary molars and their standard error by treat- ment protocol group and interval period. The Wald test showed no statistically significant difference in exfoliation rates for all treated primary molars among the three treatment protocol groups over the 3.5-year period ( $P=0.37$ ). After 3.5 years, $51.6 \%$ of all teeth had exfoliated in the CRT group, $49.6 \%$ in the ART group, and $48 \%$ in the UCT group. Despite there being no overall difference, differences in exfoliation rate between the treatment groups were noted at intervals. First primary molars: Those from UCT had exfoliated at a statistically significant higher rate than those of the CRT group at 1 year $(P=003)$ (Fig, 2a). Second primary molars: Those from UCT groups had exfoliated at a statistically significantly higher rate than those from the ART at 2 years $(P=0.009)$ and 3 years $(P=0.04)$, and from the CRT group ( $P=$ 0.04 ) at 3 years (Fig. 2b).

\section{Analyses of background variables}

Effects of age $(P<0.0001)$, gender $(P=0.02)$, type of molar $(P<0.0001)$, and type of surface $(P=0.03)$ on the exfoliation rates of all treated primary molars among the three treatment protocol groups over the 3.5-year period were observed. The age of CRT children with exfoliated teeth was on average 0.2 years younger compared to the children from both the UCT and ART group. First primary molars had exfoliated earlier than second primary molars. From all the primary molars that had exfoliated those teeth with multiplesurface treatments had exfoliated at a higher rate than those with singlesurface treatments. This finding leads to an additional analysis on the effect of type of surface on the exfoliation rates of the molars between the three treatment groups.

Figure 3 shows the exfoliation rates of all treated primary molars with multiple-surfaces cavities and their standard error by treatment protocol group and interval period. The Wald test showed

Table 2. Cumulative exfoliation rates of all primary molars (\%) and Jackknife standard error (SE) by trea tment protocol group and interval period (IP)

\begin{tabular}{|c|c|c|c|c|c|c|c|c|c|c|c|c|}
\hline \multirow[b]{2}{*}{ IP (years) } & \multicolumn{4}{|c|}{ CRT } & \multicolumn{4}{|c|}{ ART } & \multicolumn{4}{|c|}{ UCT } \\
\hline & $N$ & $\mathrm{Nx}$ & $\%$ & SE & $N$ & $N_{x}$ & $\%$ & SE & $N$ & $N_{x}$ & $\%$ & SE \\
\hline $0.0-0.5$ & 324 & 02 & 0.0 & 0.0 & 240 & 04 & 1.6 & 1.0 & 273 & 02 & 0.7 & 0.5 \\
\hline $0.5-1.0$ & 291 & 07 & 2.4 & 1.1 & 228 & 07 & 2.9 & 1.5 & 251 & 11 & 43 & 1.7 \\
\hline $1.0-2.0$ & 234 & 39 & 14.5 & 2.9 & 190 & 27 & 12.6 & 2.7 & 197 & 39 & 175 & 3.5 \\
\hline $2.0-3.0$ & 153 & 93 & 36.8 & 4.1 & 120 & 64 & 33.6 & 4.8 & 48 & 58 & 402 & 6.3 \\
\hline $3.0-3.5$ & 88 & 119 & $51.6^{\circ}$ & 4.1 & 68 & 85 & 49.6 & 6.0 & 38 & 64 & $480^{*}$ & 6.6 \\
\hline
\end{tabular}

$N$, number of teeth; $N_{\mathrm{X}}$, cumulative number of exfoliations; CRT, conventional restorative treatment, ART, atraumatic restora tive treatment; UCT, ultraconservative trea tment.

"CRT and UCT groups $(P=0.04)$. 
Mijan et al.
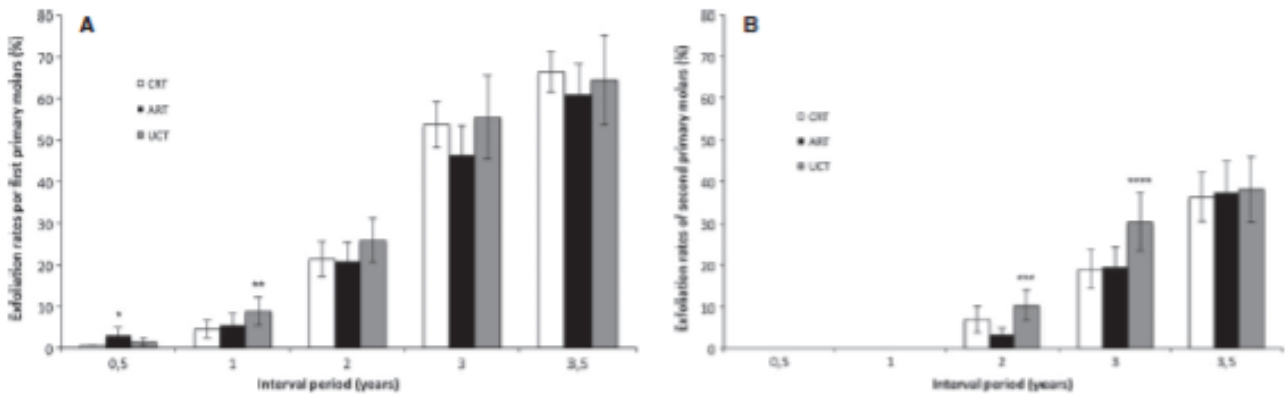

Fig. 2. Exfoliation rates (\%) and Jadkknife standand error of (a) first primary molars and (b) second primary molars, treated by protocol group after a period of 3.5 year of evaluation. * ART and CRT groups $(P=0.02)$. * UCT and CRT group $(P=0.03) * *$ ART and both UCT $(P=0.009)$ and CRT $(P=0.04)$ groups. *** UCT and both ART $(P=0.04)$ and CRT $(P=0.04)$ groups.

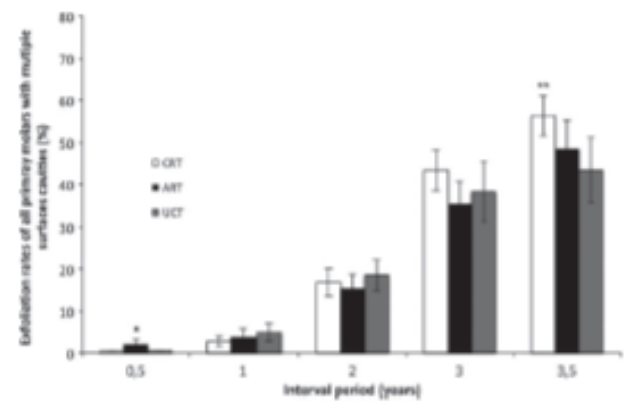

Fig. 3. Exfoliation rates $(\%)$ and Jackknife standard error of primary molars with multiplesurfaces cavities, treated by protocol group after a period of 3.5 year of evaluation. * ART and CRT $(P=0.04)$. $*$ CRT and UCT group $(P=0.04)$.

no statistically significant difference in exfoliation rates for all treated primary molars among the three treatment protocol groups over the total 3.5year period ( $P=0.63)$. After 3.5 years, $56.3 \%$ of all teeth had exfoliated in the CRT group, $48.5 \%$ in the ART group, and $43.4 \%$ in the UCT group. Despite there being no overall difference, differences in rate of exfoliation between the treatment groups were noted at intervals. Those of the ART group had exfoliated at a statistically significantly higher rate than those of the CRT group $(P=0.04)$ at 05-year interval and those of the CRT group had exfoliated at a statistically significantly higher rate than those of the UCT group $(P=0.04)$ at the 3.5-year interval.

\section{Discussion}

\section{Research methodology}

This being a secondary analysis, it draws on the study design and randomization process that were used to investigate the effect of the UCT protocol on the tooth survival in comparison with the CRT and the ART treatment protocols. That study concluded that it was very unlikely that a selection bias had influenced the study outcome (12). Blinding of operators and evaluators could neither be obtained, as the dental materials used and open cavities were clearly distinguishable, nor that of the statistician, who had performed the primary analyses. Blinding of the patients was most probably obtained (12). Considering the nature of the study and that of the secondary analysis, the best level of blindness was achieved (19).

The 3.5-year lost-to-follow-up percentage of children was low, and missing values were accounted for though use of an imputation process that was applied straightforwardly. These two aspects provided the most accurate estimation of tooth exfoliation rates. The statistical analysis used took care of the dependency of data within a child. Because the cluster covered only two schools, a mixed effect 
model, which is usually used in cluster randomized study designs, was not considered appropriate. Therefore, the proportional hazard model with frailty corrections for children was used.

Considering the nature of the present study, it is doubtful that any systematic error existed and had influenced the study outcomes. Consequently, the internal validity of this controlled clinical trial is considered high.

\section{Main findings}

The hypothesis was accepted. Considering the overall period of 3.5 years, there was no significant difference in exfoliation rates of primary molars treated according to the UCT protocol compared to those treated according to the CRT and ART protocols. However, when looking for the exfoliation pattem of the primary teeth at each interval period, it was noticed that teeth from the UCT group had exfoliated in a higher rate compared to those from both the CRT and ART groups. The difference between the CRT group for first primary molars at 1 year and for second primary molars at 3 years may have occurred as a consequence of children's age as those in the CRT group were 0.2 years younger than those in the UCT group. This reason may not be applicable for the difference observed between the exfoliation rates from UCT and ART groups. This difference was observed for second primary molars only and occurred at the 2- and 3year evaluation period. It might well be possible that the difference is related to the natural exfoliation pattem of those teeth, considering the age ( 9 and 10 years old) of the children. This assumption is supported by the absence of an exfoliation effect for the treatment groups at the 3.5 years. At that time, most primary teeth had exfoliated, which is in line with the time for the eruption of the corre sponding permanent teeth (20-22). Whether this relative early exfoliation pattem of UCT teeth has an effect on the eruption pattem of the corresponding permanent teeth is under investigation.

Additionally, the present study showed that teeth treated for multiple-surface cavities had exfoliated in a higher proportion compared to those treated having a single-surface cavity. This was applicable for all treatment groups. Within the group of teeth with multiplesurface cavities, a difference in exfoliation rate between such teeth in the UCT and CRT at the 3.5 years interval period was observed. This is, most probably, due to CRT children being younger than the UCT children, as mentioned above. Therefore, there was no significant difference in the clinical behavior of exfoliation of primary molars between the restored teeth from CRT and ART groups compared to the nonrestored dentin cavitated, but cleaned, teeth from UCT.

Only few studies have reported about the exfoliation and eruption pattems of restored and nonrestored primary and permanent teeth. Restored primary teeth survived significantly longer than nonrestored cavitated primary teeth $(4,23)$, suggesting that the presence of open cavities in primary dentition accelerates the exfoliation rates of teeth. Moreover, an analysis of permanent teeth enuption patterns indicated that the caries experience, independently of primary teeth had been restored or not, accelerated the eruption process of the successors (24). The early loss of primary teeth due to dental caries, especially primary molars, would cause space problems, and restoring those teeth would minimize possible functional and alignment effects in permanent dentition compared to extracting such teeth (25). These leads to the following question: Would the cleaning protocol applied in the UCT teeth bring differences in biological effects that has been related to the early loss of primary teeth due to dental caries?

Considering the results obtained in the present study and those reported above, it is possible to postulate the following hypothesis: Not restoring dentin cavitated carious lesions in primary molars but allowing them to be plaque free as applied in the UCT treatment protocol should bring similar biological effects as restorative treatments regarding the process that is triggered until a physiological and symptomless exfoliation of those teeth and, would not induce early loss of primary teeth and functional prejudice in permanent dentition as consequences. Despite this assumption, there is no evidence of such event in the present research and further analysis regarding the differences in patterns of exfoliation and eruption of primary and permanent teeth adding untreated dentin cavitated teeth as well as sound primary teeth as controls should be conduced.

The UCT protocol could become an appropriate altemative to restoring cavitated primary teeth as it allows symptomless exfoliation of teeth at similar rates than the restorative treatments. However, the external validity of the present study is not very high.

In conclusion, there was no difference in the 3.5 year exfoliation rates of primary molars treated according to the CRT, ART, and UCT protocols. 
Mijan et al.

However, teeth with multiple-surface involvements exfoliated in a higher proportion than the single surfaces, especially second primary molars. The ultraconservative treatment protocol tested in the present study, in addition to the existing ART approach, should become an option for guiding cavitated teeth to symptomless exfoliation. Further research on the application of UCT is still required.

\section{Acknowledgements}

The authors wish to thank Danielle Matos de Menezes Abreu for performing the treatment; Gabriela Lopes and Luciana Oliveira for carrying out the evaluation; dental assistants for their kind assistance; FAP-DF and Radboud University Medical Centre for providing financial support; and ABCD-DF for their valuable logistic support. We also owe adknowled gements to the Educational Department of the local government, as well as to directors, teachers, employees, and students of the public schools in Paranoá.

\section{Declaration of interests}

None of the authors have any financial or personal conflict of interests to declare.

\section{References}

1. Baelum V, van Palenstein Helderman WH, Hugoson A, Yee R, Fejerskov O. A global perspective on changes in the burden of caries and periodontitis: implications for dentistry. J Oral Rehabil 2007,34872-906.

2. Tickle M, Milsom K, King D, Kearney-Mitchell P, Blinkhorn A. The fate of the carious primary teeth of children who regularly attend the general dental service. Br Dent J 2002;192:219-23.

3. Levine RS, Pitts NB, Nugent Z. The fate of 1,587 unrestored carious deciduous teeth: a retrospective general dental practice based study from northern England. Br Dent J 2002:193:99-103.

4. Hu X, Chen X, Fan M, Mulder J, Frendken JE. What happens to cavitated primary teeth over time? A 35 year prospective cohort study in China. Int Dent J 2013 63:183-8.

5. Kidd EAM. Should deciduous teeth be restored? Reflections of a cariologist Dent Update 2012;39.15966.

6. Frencken JE, Pilot T, Songpaisan $Y$, Phantumvanit $P$. A traumatic restorative treatment (ART): rationale, technique, and development. J Public Health Dent 1996:56:135-40.

7. Frencken JE, Leal SC, Navarro MF. Twenty-five-year atraumatic restorative treatment (ART) approach: a comprehensive overview. Clin Oral Investig 2012;16: $1337-46$.
8. Mickenautsch S, Yengopal V. Failure rate of high-viscosity GIC based ART compared with that of conventional amalgam restorations-evidence from an update of a systematic review. SADI 2012;67:329-31.

9. Raggio DP, Hesse D, Lenzi TL, A B Guglielmi C, Braga MM. Is Atraumatic restcrative treatment an option for restoring occlusoprcximal caries lesions in primary teeth? A systematic review and meta-analysis Int J Paediatr Dent 2013,23:435-43.

10. Innes NP, Evans DJ, Stirrups DR. Sealing caries in primary molars randomized control trial, 5-year results. I Dent Res 2011 90:1405-10.

11. Gruythuysen RJ. Non-restorative cavity treatment. Managing rather than masking caries activity. Ned Tijdschr Tandheelld 2010;117:173-80.

12. Mijan M, de A morim RG, LealSC, Mulder J, Oliveira L. Creugers NH et al. The 3.5-year survival rates of primary molars treated according to three treatment protocols a controlled clinical trial. Clin Oral Investig 2014:18:1061-9.

13. de Amorim RG, Figueiredo MJ, Leal SC, Mulder J, Frencken JE Caries experience in a child population in a deprived area of Brazil, using ICDAS II. Clin Oral Investig 2012;16:513-20.

14. Topaloglu-Ak A, Eden E, Frencken JE, Oncag O. Two years survival rate of dass II composite resin restorations prepared by ART with and without a chemomechanical caries removal gel in primary molars. Clin Oral Investig 2009;13:325-32.

15. Figueiredo MJ, de Amorim RG, Leal SC, Mulder J, Frencken JE. Prevalence and severity of clinical consequences of untreated dentine carious lesions in children from a deprived area of Brazil. Caries Res 201 1;45:435-42.

16. Cox DR. Regression models and life tables (with discussion). J R Stat Soc B 1972:34:187-220.

17. Hougaand P. Frailty models for survival data. Lifetime Data Anal 1995;1:255-73.

18. Efron B. The jackknife, the bootstrap, and other resampling plans. Philadelphia: SLAM-NSF; 1982.

19. Schulz KF, Grimes DA. Blinding in randomized trials: hiding who got what. Lancet 2002:359:696-700.

20. Wedl JS, Danias S, Schmelzle R, Friedrich RE. Eruption times of permanent teeth in children and young adolescents in Athens (Greece). Clin Oral Investig $2005,9: 131-4$.

21. Bayrak S, Sen Tunc E, Tuloglu N, Acikgoz A. Timing of permanent teeth eruption in Turkish children. IClin Pediatr Dent 2012:37:200-11.

22. Pamer ET, Heidmann IM, Vaeth M, Poulsen S. A longitudinal study of time trends in the eruption of permanent teeth in Danish children. Arch Oral Biol 2001;460425-31.

23. Stephenson J, Chadwick BL, Playe RA, Treasure ET. A competing risk survival analysis model to assess the efficacy of filling carious primary teeth. Caries Res 2010;44285-93.

24. Leroy R, Bogaerts K, Lesaffre E, Declerck D. Impact of caries experience in the deciduous molars on the emergence of the successors. Eur J Oral Sci 2003;111:106-10

25. Northway WM, Wainright RL, Demirian A. Effects of premature loss of deciduous molars. Angle Orthod 1984,54295-329. 